El presente trabajo de tesis para optar al grado de Doctor en Ciencias Bioquímicas fue realizado en el Centro de Investigación $y$ Desarrollo en Fermentaciones Industriales (CINDEFI), Facultad de Ciencias Exactas de la Universidad Nacional de la Plata, bajo la dirección del Doctor Antonio P. Balatti.

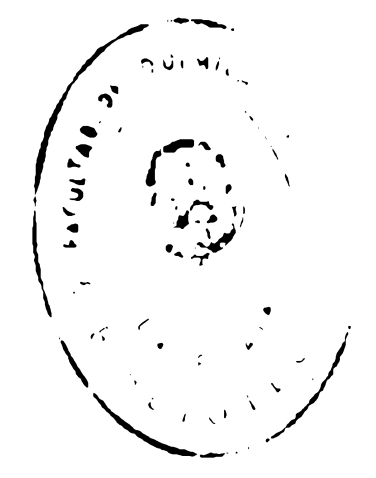

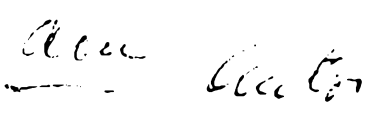

$2 \div+85$

$\div 2327$ 
A mi esposa e hijos

A mis padres y hermano 
Mi reconocimiento

Al Dr. Antonio P. Balatti por haberme brindado la oportunidad de realizar el presente trabajo en las instalaciones del Centro de Investigación y Desarrollo en Fermentaciones Industriales.

A la Facultad de Ciencias Exactas de la Universidad Nacional de La Plata, por permitirme el empleo de sus equipos e instalaciones.
Al Consejo Nacional de Investigaciones Cientificas
y Técnicas por el otorgamiento de sucesivas becas que permitieron la realización de estos estudios. 


\section{Mi agradecimiento}

Al Dr. Antonio P. Balatti por su guía y estímulo permanentes.

Al Lic. Luis Bruno Blanch por la preparación del reactivo clorhidrato de o-dianisidina.

A mi madre y a la Sra. Diana Venturini por su inestimable trabajo dactilográfico.

Al Sr. Julio C. Figari por su inapreciable asistencia técnica y al resto del personal del CINDEFI. 
1.1. La reacción catalitica

1.2. Fuentes de glucosa oxidasa

1.3. Estructura y propiedades de la glucosa oxidasa

1.4. Aplicaciones de la glucosa oxidasa

1.5. Valoración de la actividad enzimática 10

1.6. Obtención de glucosa oxidasa 13

1.7. Desarrollo del trabajo

2. MATERIALES Y METODOS

2.1. Microorganismo

2.1.1. Cepa empleada en los estudios 17

2.1.2. Conservación de la cepa

2.2. Medios de cultivo

2.2.1. Medio de producción de esporos 17

2.2.2. Medio base de fermentación 18

2.3. Determinaciones analiticas

2.3.1. Recuento de esporos 18

2.3.2. Peso seco

2.3.3. Medida de $\mathrm{pH}$

2.3.4. Medida de oxígeno disuelto

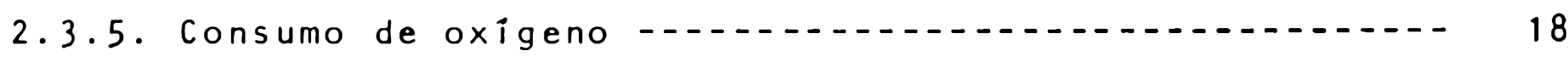

2.3.6. Medida del consumo de sacarosa 19

2.3.7. Medida del consumo de nitrato

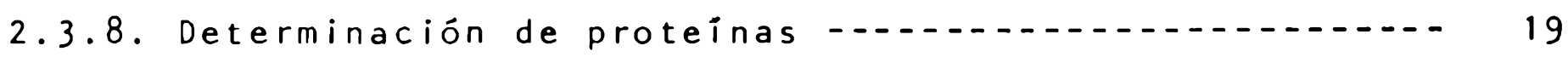

2.3.9. Medida de la velocidad de absorción de oxigeno (VAO) - 19

2.3.10. Cromatografía en papel de ácidos orgánicos -.-...- 20

2.3.11. Determinación de glucosa oxidasa

2.4. Condiciones de operación

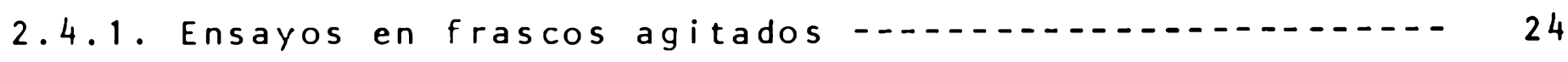

2.4.2. Ensayos en fermentadores con agitación mecánica---- 24

2.4.3. Esterilización -......... 25

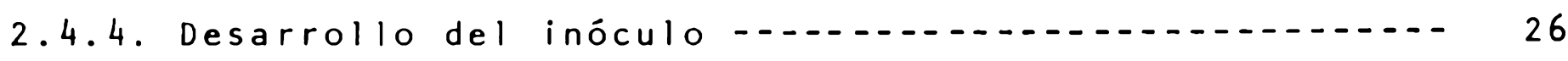

2.4.5. Procesamiento de las muestras del cultivo

2.4.6. Extracción de glucosa oxidasa 26 
3.1. Determinación colorimétrica de glucosa oxidasa - .

3.2. Comparación de diferentes tratamientos del micelio en la extracción de glucosa oxidasa

3.3. Influencia de la composición del medio de cultivo en la producción enzimática

3.3.1. Producción en el medio base - 43

3.3.2. Influencia de la fuente de nitrógeno

3.3.3. Influencia de la fuente de carbono

3.3.4. Influencia de productos que aportan factores de crecimiento

3.3.5. Concentración de nitrato de calcio - 50

3.3.6. Producción enzimática en el medio modificado -......- 50

3.3.7. Discusión de los resultados en frascos.

3.4. Estudio con la Prensa-X

3.5. Estudios en tanques agitados

3.5.1. Inóculo - 63

3.5.2. Influencia del pH

3.5.3. Influencia de la aeración

3.5.4. Influencia de la concentración de la fuente

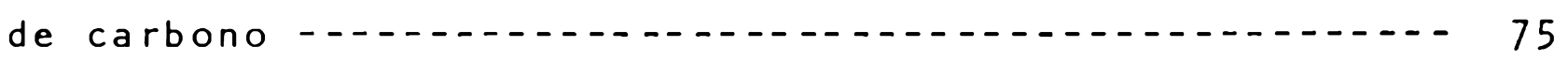

3.5.5. Discusión de los resultados en tanque

4. CONCLUSIONES

BIBLIOGRAFIA 
Los microorganismos sintetizan numerosas enzimas que cumplen sus funciones en los procesos de crecimiento, metabolismo y autolisis de la célula. Un variado número de ellas, tanto de naturaleza intracelular como extracelular ha encontrado un importante campo de aplicación en diversos procesos industriales, en la medicina, en la analitica quimica y en la investigación bioquímica $(5,32,33,42,89,90,94)$. Dentro de este grupo heterogéneo se encuentra la enzima cuya producción es objeto de estudio en el presente trabajo y que comúnmente se denomina glucosa oxidasa (GOD). El interés por la misma surge fundamentalmente de sus múltiples aplicaciones en la tecnología de alimentos, como asi también a su difundido empleo como reactivo específico para la determinación de gluco sa, aspecto este de relevancia en el diagnóstico clínico (7, $25,80,84,85,97,104)$.

El método de producción de la glucosa oxidasa lo constitu ye la clásica fermentación en cultivo sumergido y es llevado a cabo con el empleo de hongos filamentosos $(7,85)$. Como todo proceso de interés comercial su tecnología de obtención se encuentra patentada o bien es un secreto de las firmas pro ductoras $(34,35,50,62,75)$. Esto motiva que la información bibliográfica accesible, si bien orientativa, solo permite disponer de un conocimiento parcial sobre la elaboración del preparado enzimático. Teniendo en cuenta este contexto y la falta de antecedentes sobre el tema en nuestro pais, se consideró de interés la realización del presente trabajo cuya finalidad es contribuir al conocimiento del proceso fermentativo como un aporte para el desarrollo de una tecnología nacional de producción de la enzima.

\subsection{La reacción catalitica}

La glucosa oxidasa pertenece a la clase de enzlmas clasificadas como óxidoreductasas (E.C. 1.1.3.4) y su nombre sís 
temático es $\beta$-D-glucosa-l-oxigeno-oxidoreductasa (22). La enzima cataliza la oxidación de la $\beta$-D-glucopiranosa a $D-g l \underline{u}$ cono- $\delta$-lactona formando en presencia de oxígeno una cantidad equivalente de peróxidode hidrógeno $(8,18,30)$. Esto lo diferencia de otras deshidrogenasas que actúan sobre la glucosa pero que no pueden utilizar el oxígeno como aceptor de hi drógeno $(8,60)$. Como coenzima utiliza flavin adenin dinucleó tido (FAD) transcurriendo la reacción en dos etapas. La primera de ellas consiste en la remoción de dos átomos de hidró geno de la molécula de glucosa con la consiguiente reducción del FAD y la formación de la lactona. En la segunda etapa los átomos de hidrógeno son transferidos al oxígeno molecular, produciendo peróxido de hidrógeno y la simultánea oxidación de la coenzima. Un esquema de esta secuencia de reacciones se representan en la figura l'

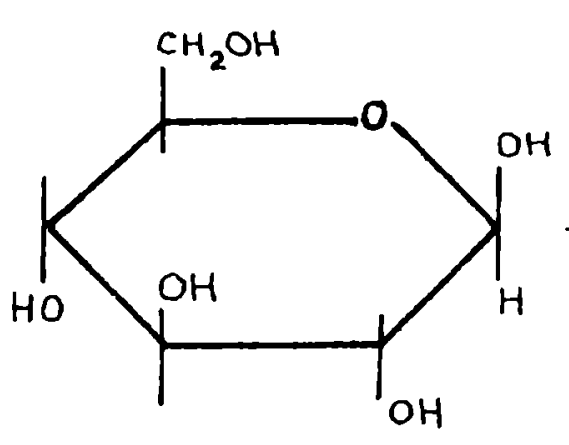

$\beta$ - D. glucopiranosa

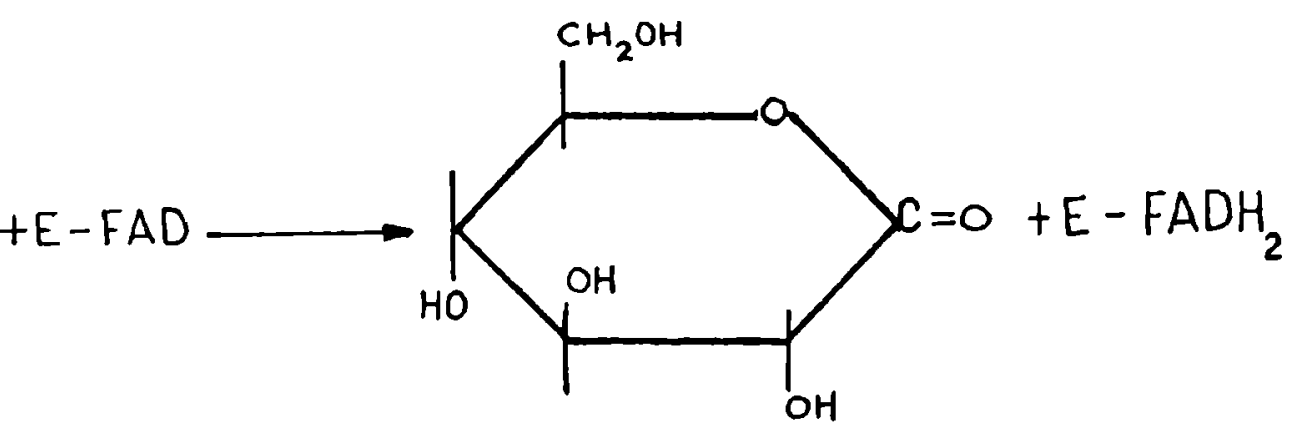

D- glucono-d- Lactona

$E-\mathrm{FADH}_{2}+\mathrm{O}_{2}$

$\mathrm{E}-\mathrm{FAD}+\mathrm{H}_{2} \mathrm{O}_{2}$

Figura 1: Oxidación de la $\beta$-D-glucosa en presencia de glucosa oxidasa

E-FAD y E-FADH 2 : glucosa oxidasa en estado oxidado $y$ reducido respectivamente. 
En una etapa posterior la gluconolactona se hidroliza a ácido glucónico dando como resultado el siguiente balance:

$$
\begin{array}{ll}
\mathrm{C}_{6} \mathrm{H}_{12}{ }^{\mathrm{O}} 6+\mathrm{O}_{2}+\mathrm{H}_{2} \mathrm{O} \longrightarrow \mathrm{GOD} & \mathrm{C}_{6} \mathrm{H}_{12}{ }^{\mathrm{O}} 7+\mathrm{H}_{2}{ }^{\mathrm{O}} 2 \\
\mathrm{C}_{6}{ }^{\mathrm{H}} 12^{\mathrm{O}}{ }_{6}: \beta-\mathrm{D}-\mathrm{glucosa} & \mathrm{C}_{6} \mathrm{H}_{12}{ }^{\mathrm{O}} 7 \text { : ácido glucónico }
\end{array}
$$

Normalmente la actividad de la glucosa oxidasa es complementada por la acción de la catalasa:(E.C.1.11.1.6) que descompone el peróxido de hidrógeno en oxígeno y agua $(13,52)$.

$$
2 \mathrm{H}_{2} \mathrm{O}_{2} \stackrel{\text { catalasa }}{\longrightarrow} 2 \mathrm{H}_{2} \mathrm{O}+\mathrm{O}_{2}
$$

Si consideramos entonces un sistema combinado de glucosa oxidasa-catalasa y la hidrólisis de la gluconolactona tenemos finalmente la siguiente estequiometria:

$$
\mathrm{C}_{6} \mathrm{H}_{12}{ }^{0} 6+1 / 2 \mathrm{O}_{2} \frac{\mathrm{GOD}}{\mathrm{catalasa}} \mathrm{C}_{6} \mathrm{H}_{12}{ }^{\mathrm{O}} 7
$$

De acuerdo a estas reacciones la oxidación de un micromol de glucosa por la acción enzimática implica la formación de una cantidad equivalente de ácido glucónico o peróxido de hidrógeno y un consumo de $22.4 \mu l$ de $0_{2}$ (CNTP). En presencia de catalasa la mitad del oxigeno es reciclado de manera que la oxidación de un micromol de glucosa corresponde en este caso a un consumo de $11.2 \mathrm{\mu l}_{2} \mathrm{O}_{2}$ (CNTP). Estas consideraciones son de suma importancia en particular cuando la actividad enzimática es determinada mediante métodos basados en medidas de consumo de oxígeno $(74,110)$.

\subsection{Fuentes de glucosa oxidasa}

La enzima se encuentra presente en diferentes microorganismos principalmente hongos filamentosos del género Aspergillus y Penicillum que son la fuente de su producción industrial (85). Se ha detectado también su presencia en Sporotrichum pulverulentum donde integra un complejo sistema enzimático responsable de la degradación de material lignocelulósico (23) y en Caldariomyces fumago donde participa de mecanismos de cloración biológica vinculados a la sintesis de caldariomicina (79). Es producida además por algunas bacterias 
acéticas como Acetobacter suboxydans (sinónimo: Gluconobacter suboxydans) y salvo unas pocas excepciones no fué encontrada en células de vegetales o animales superiores $(7,12)$.

Su descubrimiento puede ser atribuido a Maximov, quien en 1904 obtuvo por precipitación con acetona un preparado celular de Aspergillus niger en el cual la capacidad de consumo de oxígeno resultaba más perdurable que la correspondiente producción de $\mathrm{CO}_{2}$. Pudo observar además que la adición de glucosa estimulaba el consumo de $\mathrm{O}_{2}$ y que dicho efecto no era promovido por otras sustancias como el glicerol. Concluyó de esta manera que dicho preparado contenía una "oxidasa" que actuaba en forma independiente del metabolismo respiratorio (actividad zimásica) y que la misma era activada por glucosa (24). Transcurrieron sin embargo más de 20 años, hasta 1926, para que Muller realizara la misma observación en extractos celulares de Aspergillus niger y Penicillum glaucum y aislara la enzima responsable de dicha propiedad a la cual denominó glucosa oxidasa (God). Pudo constatar además que uno de los productos de la reacción enzimática era el ácido glucónico estableciendo de esta manera las bases bioquimicas de la fermentación glucónica descubierta en 1922 por el microbiólogofrancés Molliard (24). En estudios posteriores realizados por diversos investigadores la enzima proveniente de Aspergillus niger fué estudiada en detalle, elucidándose su estructura, propiedades físicoquimicas y los mecanismos de la reacción catalítica $(2,18,30,52,72,73,95,101)$ En la década del 40 y en relación con el descubrimiento y la investigación sobre la penicilina se aislaron de los cultivos de Penicillum notatum sustancias que en presencia de oxigeno y glucosa eran muy bacteriostáticas y se describieron con el nombre de Notatina, Penicilina $B$ y Penatina $(8,24,102)$. Su forma de preparación fué incluso patentada por diversas firmas comerciales $(15,93)$. Posteriormente se demostró que todos estos compuestos eran idénticos a la glucosa oxidasa, y que el peróxido de hidrógeno formado enzimáticamente era el responsable de la acción bactericida. Resulta evidente que la cepa utilizada o bien las condiciones del cultivo promovian la formación de la enzima con una minima o nula presencia de catalasa, permitiendo de esta manera la acumulación del $\mathrm{H}_{2} \mathrm{O}_{2}$. Al igual que la enzima proveniente de Aspergillus niger, se realizaron intensas investigaciones para establecer el comportamiento y pro- 
piedades de los preparados obtenidos del Penicillum notatum 8, 12, 45). La enzima ha sido también aislada en forma cristalina de los medios de cultivo de Penicillum amagasakiense (49). El primer preparado enzimático ofrecido comercialmente data de 1952 (102), persistiendo en la actualidad su producción industrial la cual es realizada preferentemente con cepas de Aspergillus niger $(34,35,50)$, Penicillum amagasakiense y Penicillum vitale $(75,85)$. Otras especies de Penicillum (ej.purpurogenum) han sido también aisladas evidenciando altos rendimientos en glucosa oxidasa (65).

\subsection{Estructura y propiedades de la glucosa oxidasa.}

Detallados estudios comparativos realizados con la enzima obtenida de Aspergillus niger, Penicillum notatum y Penicillum amagasakiense, muestran que además de la reacción catalítica, existe una gran semejanza en muchas de sus propiedades (85). Teniendo en cuenta este aspecto y el hecho de emplear en nuestros estudios una cepa de Aspergillus niger, la siguiente descripción estará referida a la enzima proveniente de dicho microorganismo.

La enzima es una glicoproteina de peso molecular 160.000 constituida por dos subunidades idénticas (PM 79,000) unidas covalentemente por puentes disulfuro (101). El análisis de su composición revela un $74 \%$ de proteina, $26.4 \%$ de azúcares neutros, $2.4 \%$ de aminoazúcares y dos moles de FAD ( flavin, adenin, dinucleótido) por mol de enzima (73, 101). En su cadena polipeptídica existe un marcado predominio de ácido aspártico y ácido glutámico como asi también de glicina, alanina y leacina que comprenden en conjunto el $44 \%$ del total de aminoácidos presentes en la molécula. Los carbohidratos están constituidos principalmente por manosa y en mucha menor proporción galactosa y galactosamina. La unión de estos azúcares a la cadena polipeptídica se haria probablemente por enlaces aminoglicosidicos entre el carbohidrato y el grupo amido de la asparagina (73). Se ha podido observar que la remoción de un $40 \%$ de los carbohidratos por tratamiento con periodato no altera significativamente las propiedades cataliticas de la enzima pero si afecta sus resistencia térmica, sugiriendo de esta manera que los mismos no participan en la conformación del centro activo pero le confieren estabilidad a la estructura molecular (63). 
La glucosa oxidasa manifiesta una alta especificidad por su sustrato. En el Cuadro 1 se puede observar las velocidades de reacción relativas a la $\beta$ - $D$-glucosa para diferentes compuestos.

\begin{tabular}{lllllll}
$C$ & $U$ & $A$ & $D$ & $R$ & 0 & 1 \\
\hline
\end{tabular}

Especificidad de sustrato para la glucosa oxidasa

\begin{tabular}{|c|c|c|c|}
\hline $\begin{array}{l}\text { Posición } \\
\text { modificada } \\
n^{\circ} \text { de carbono }\end{array}$ & Compues to & $\begin{array}{l}\text { Cambios con respecto } \\
\text { a la } \beta-D-g l u c o s a\end{array}$ & $\begin{array}{l}\text { Velocidad } \\
\text { relativa }\end{array}$ \\
\hline- & $\beta$-D-glucosa & - & 100 \\
\hline \multirow[t]{2}{*}{1} & $d-D-g l u c o s a$ & Configuración del $\mathrm{OH}$ & 0.64 \\
\hline & $\begin{array}{l}1.5 \text { anhidro-D- } \\
\text { glucitol }\end{array}$ & Reemplazo del $\mathrm{OH}$ por $\mathrm{H}$ & 0 \\
\hline \multirow[t]{3}{*}{2} & $\begin{array}{c}\text { 2-Deoxy-D- } \\
\text { glucosa }\end{array}$ & Reemplazo del $\mathrm{OH}$ por $\mathrm{H}$ & 3.3 \\
\hline & D-manosa & Configuración del $\mathrm{OH}^{-}$ & 0.98 \\
\hline & $\begin{array}{l}\text { 2-o-met il-D- } \\
\text { glucosa }\end{array}$ & $\begin{array}{l}\text { Sustitución del } \mathrm{H} \text { en el } \mathrm{OH} \\
\text { por metilo }\end{array}$ & 0 \\
\hline 3 & $\begin{array}{l}\text { 3-Deoxy-D- } \\
\text { glucosa }\end{array}$ & Reemplazo del $\mathrm{OH}$ por $H$ & 1 \\
\hline \multirow[t]{2}{*}{4} & D-galactosa & Configuración del $\mathrm{OH}$ & 0.5 \\
\hline & $\begin{array}{l}\text { 4-Deoxy-D- } \\
\text { glucosa }\end{array}$ & Reemplazo del $\mathrm{OH}$ por $\mathrm{H}$ & 2 \\
\hline \multirow[t]{2}{*}{5} & $\begin{array}{l}\text { 5-Deoxy-D- } \\
\text { glucosa }\end{array}$ & $\begin{array}{l}\text { Reemplazo del } \mathrm{OH} \text { por } \mathrm{H} \\
\text { (no se forma anillo piranósico }\end{array}$ & 0.05 \\
\hline & L-glucosa & Configuración del $\mathrm{OH}$ & 0 \\
\hline \multirow[t]{2}{*}{6} & $\begin{array}{l}\text { 6-Deoxy-D- } \\
\text { glucosa }\end{array}$ & Reemplazo del $\mathrm{OH}$ por $\mathrm{H}$ & 10 \\
\hline & xylosa & Reemplazo del $\mathrm{C}_{6}$ por $\mathrm{H}$ & 0.98 \\
\hline
\end{tabular}


observamos que la oxidación de la $\beta-D-g l u c o s a$ es 160 veces más rápida que la de su anómero $\alpha$ (alfa), aunque este aspecto es de poca importancia en sus aplicaciones industriales, ya que los preparados comerciales contienen en general mutarotasa. En condiciones anaeróbicas puede utilizar como aceptores de hidrógeno a ciertos colorantes como azul de metileno, tionina, etc., pero la reacción transcurre mucho más lenta en comparación con el oxígeno. Esta propiedad ha motivado que la enzima sea caracterizada como una deshidrogenasa más que como una oxidasa sugiriéndose que su nombre más correcto sea el de glucosa aerodeshi drogenasa. Sin embargo por su difusión el término glucosa oxida sa sigue vigente en la actualidad. Alternativamente el FAD redu cido puede ser regenerado electroquimicamente mediante un poten cial de $+200 \mathrm{mV}$ (59).

La enzima es activa en un amplio rango de pH. La velocidad de reacción es máxima entre 4 y 6.5 con un ligero pico en 5.5 . A pH alcalino es inestable perdiendo por ejemplo un $90 \%$ de act vidad si se la mantiene durante 10 minutos a pH 8.1 (85, 102). En relación a la temperatura debemos considerar que los cambios en este parámetro implica también variaciones en la concentración de uno de los reactivos, el oxígeno. La solubilidad del mismo disminuye con el aumento de la temperatura y compensa de esta manera los beneficios que desde el punto de vista termodinamico implica un incremento de la temperatura. La velocidad de reacción es prácticamente constante en el rango de $30^{\circ}$ a $60^{\circ} \mathrm{C}$ $(33,85)$. La estabilidad térmica es una propiedad importante a considerar sobre todo en la tecnología de alimentos donde radica su principal aplicación industrial, ya que los productos ali menticios son habitualmente sometidos a diferentes tratamientos térmicos como pasteurización, etc. En este sentido debemos mencionar que la enzima es estable durante 6 horas a $40^{\circ} \mathrm{C}$ en un rango de $\mathrm{pH}$ de 4.5 a 6.0 , mientras que a $50^{\circ} \mathrm{C}$ la actividad di $\underline{s}$ minuye en el mismo lapso en un $10 \%$. A temperaturas de $60^{\circ} \mathrm{C} y$ superiores la inactivación ocurre con mayor velocidad dependiendo del pH. En el cuadro 2 se presentan algunos datos sobre la estabilidad de la glucosa oxidasa a diferentes valores de pH y a temperaturas superiores a $60^{\circ} \mathrm{C}$. La presencia de glucosa, su sustrato, ejerce un cierto efecto protector aumentando su estabilidad en medios alcalinos y la resistencia térmica (33). Estas propiedades que se refieren al comportamiento de la enzima 
len solución pueden ser modificadas favorablemente si la misma

se inmoviliza en soportes adecuados $(4,99,103)$. De esta for ma se ha podido ampliar el rango de pH en el cual la enzima

es activa, aumentar su termoestabilidad y favorecer la cinéti ca de la reacción catalitica $(6,11,44,82,103)$.

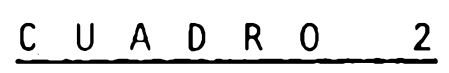

Tiempo (en minutos) requerido para inactivar el $90 \%$ de

la actividad enzimática bajo diferentes condiciones de

pH y temperatura

\begin{tabular}{|c|c|c|c|c|c|c|c|c|}
\hline \multirow{2}{*}{$\mathrm{pH}$} & $\mathrm{T}$ & e m & $p$ & $r$ & a & $t$ & $\mathrm{u}$ & $a$ \\
\hline & \multicolumn{2}{|l|}{$65^{\circ}$} & \multicolumn{2}{|l|}{$70^{\circ}$} & & \multicolumn{2}{|l|}{$75^{\circ}$} & $80^{\circ}$ \\
\hline 4.5 & - & & 11 & & & 3 & & 1.1 \\
\hline 5.0 & 106 & & 23 & & & 7 & & 1.5 \\
\hline 5.5 & 90 & & 16 & & & 6 & & 2.0 \\
\hline 6.0 & - & & 12 & & & 4 & & 1.3 \\
\hline
\end{tabular}

En relación a la cinética de la reacción enzimática la cons tante de Michaelis (Km) para glucosa se ha determinado en 0.11$0.12 \mathrm{M}$. Para el oxígeno el $\mathrm{km}$ es función de la temperatura con valores comprendidos entre $0.21 \mathrm{mM}\left(0^{\circ} \mathrm{C}\right)$ y $0.83 \mathrm{mM}\left(38^{\circ} \mathrm{C}\right)(30,64$.

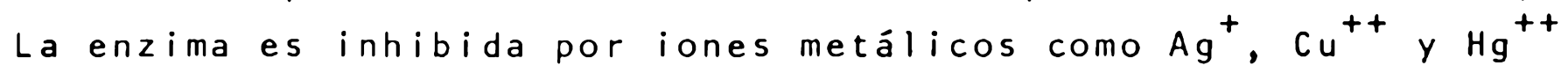
y en forma competitiva por arabinosa y 2-deoxy-glucosa. Los productos de reacción gluconolactona y $\mathrm{H}_{2} \mathrm{O}_{2}$ muestran también un efecto inhibitorio sobre la actividad de la enzima $(30,33)$. 
La glucosa oxidasa de Aspergillus niger no ha sido aún cristalizada pero si procesada hasta un alto grado de pureza mediante precipitación con sulfato de amonio, cromatografía de intercambio iónico (DEAE-celulosa) (punto isoeléctrico: 4.21) y cromatografía por tamiz molecular (Sephadex G-200). La actividad especifica del preparado purificado determinado a $30^{\circ} \mathrm{C}$ y pH 5.6 en presencia de un exceso de catalasa resultó de 172 umoles $0_{2}$ consumidos/min/mg de proteina (101).

\subsection{Aplicaciones de la glucosa oxidasa}

Las variadas aplicaciones que la enzima ha encontrado fundamentalmente en la industria alimentaria han sido ampliamente descriptas y analizadas por Scott (84) y Schmidt (86). En la actualidad nuevas elaboraciones tecnológicas continúan en desarrollo reflejándose este aspecto en la aparición de nuevas patentes. Básicamente la reacción enzimática es utilizada con los siguientes propósitos: remover glucosa en presencia de un exceso de oxígeno, remover oxígeno en presencia de un exceso de glucosa, producir ácido glucónico y formar peróxido de hidrógeno. Con relación a la remoción de glucosa, su principal aplicación está dirigida a prevenir la reacción de Maillard durante la elaboración de productos desecados como huevos, papas y carne, y a la preparación de bebidas dietéticas como jugos de fruta, vinos y cerveza. Por su parte, la eliminación de oxígeno para preservar productos sensibles ha dado lugar al mayor número de patentes y publicaciones sobre el empleo de la enzima (en conjunto con catalasa) en la tecnología de alimentos. Entre las más importantes debemos mencionar la prevención de rancidez en mantecas, aceites y mayonesa; estabilización de bebidas citricas, vinos y cerveza;, en la prevención del empardeamiento de productos congelados como cerezas, duraznos y mariscos y en la coestabilización de ácido ascórbico y cianocobalamina. Con relación a la producción de ácido glucónico, la enzima se ha inmovilizado en una gran variedad de soportes con el fin de producir soluciones de este ácido o sus sales con un alto grado de pureza $(1,44,48,97)$. Se ha mencionado también la posibilidad de desarrollar nuevos productos lácteos actuando en combinación con la $\boldsymbol{\beta}$-galactosidasa (77). Dentro del campo analítico la cinética de formación de glucónico ha servido como base para calcular la velocidad de 
transferencia de oxígeno en sistemas gas-liquido (100). Finalmente, y con relación a la última aplicación mencionada, debemos decir que la capacidad de la reacción enzimática de formar $\mathrm{H}_{2}{ }_{2}$ ha sido utilizada como base para el desarrollo de una gran variedad de técnicas destinadas a la determinación cuantitativa de glucosa. Las más difundidas consisten en determinar el $\mathrm{H}_{2} \mathrm{O}_{2}$ producido con un sistema enzimático indicador que contiene peroxidasa (E.C.1.11.1.7) y sustancias oxidables cromogénicas o fluorescentes $(25,57,80,76,88)$. Alternativamente el $\mathrm{H}_{2} \mathrm{O}_{2}$ puede ser valorado amperométricamente (105). Una variedad interesante de esta aplicación es el desarrollo de electrodos o sensores especficos para glucosa que contienen a la enzima (31). La aplicación de este método enzimático en el diagnóstlco clinico y para la determinación de glucosa en una gran variedad de fluidos biológicos, es en la actualidad de amplia difusión. otras aplicaciones propuestas son la producción de oxigeno en presencia de catalasa para satisfacer los requerimientos de enzimas inmovilizadas que consuman $0_{2}(51)$ y como agente bacterióstatico en pastas dentifricas (86).

\subsection{Valoración de la actividad enzimática}

Un aspecto de fundamental importancia en el estudio enzimológico es contar con métodos analiticos adecuados para determinar la actividad de las enzimas. En el caso particular de la glucosa oxidasa la medida de actividad puede ser efectuada por diversos métodos, los cuales incluyen medidas de consumo de oxigeno, de producción de ácido glucónico y de formación de peróxido de hidrógeno. A continuación se realiza un breve análisis de las distintas posibilidades propuestas.

- Medidas de consumo de oxígeno.

La velocidad de consumo de $0_{2}$ puede ser determinada empleando técnicas manométricas con respirómetros convencionales $(9,74$, 85) o bien con el uso de electrodos de oxigeno $(52,101)$. En la realización de este tipo de medidas es fundamental conocer el destino final de $\mathrm{H}_{2}{ }_{2}$ producido ya que el mismo determinará en última instancia el consumo neto de oxigeno de la reacción enzimática. Teniendo en cuenta que aún bajo las condiciones más favorables parte del $\mathrm{H}_{2}{ }_{2}{ }_{2}$ generado se descompone y que además 
los preparados de glucosa oxidasa contienen normalmente catalasa, es recomendable que las medidas se efectúen en presencia de un exceso de esta enzima para asegurarnos la total y rápida descomposición del $\mathrm{H}_{2} \mathrm{O}_{2}$ a medida que se produce. Bajo estas condiciones y para el cálculo de la actividad es necesario considerar que la catalasa recicla la mitad del $0_{2}$ consumido en la reacción por lo cual la oxidación de un micromol de glucosa implica el consumo de 0,5 micromoles de $0_{2}$ o sea $11,2 \mu 1$ de $0_{2}$ en CNTP.

Por otra parte es conocido que la catalasa en presencia de $\mathrm{H}_{2} \mathrm{O}_{2}$ y sustancias oxidables como ciertos alcoholes puede actuar como una peroxidasa oxidando el alcohol a aldehido (43). Esta reacción puede representarse de la siguiente manera:

$$
\mathrm{R}-\mathrm{CH}_{2} \mathrm{OH}+\mathrm{H}_{2} \mathrm{O}_{2} \text { Catalasa }-\mathrm{R}-\mathrm{CHO}+2 \mathrm{H}_{2} \mathrm{O}
$$

La determinación de glucosa oxidasa puede también ser realizada en presencia de catalasa y alcohol (generalmente etanol) pero en este caso la oxidación de un micromol de glucosa da lugar a un consumo de $22.4 \mu 1$ de $0_{2}$ (CNTP) debido al empleo del $\mathrm{H}_{2} \mathrm{O}_{2}$ en esta reacción acoplada de oxidación $(9,43,85)$

En el siguiente esquema de reacciones se resumen las tres situaciones posibles bajo las cuales pueden realizarse las determinaciones:

oxidación de la glucosa en presencia de glucosa oxidasa:

$$
\mathrm{C}_{6} \mathrm{H}_{12}{ }_{6}{ }_{6}+\mathrm{H}_{2} \mathrm{O}+\mathrm{O}_{2} \longrightarrow \mathrm{C}_{6} \mathrm{H}_{12}{ }{ }_{7}+\mathrm{H}_{2}{ }^{\mathrm{O}} 2
$$

oxidación de la glucosa en presencia de glucosa oxidasa y catalas a:

$$
\mathrm{C}_{6}{ }^{\mathrm{H}} 12{ }^{\mathrm{O}} 6+1 / 2 \mathrm{O}_{2} \longrightarrow \mathrm{C}_{6}{ }^{\mathrm{H}} 12{ }^{\mathrm{O}} 7
$$

oxidación de la glucosa en presencia de glucosa oxidasa, catalasa y etanol:

$$
\begin{aligned}
& \mathrm{C}_{6} \mathrm{H}_{12} \mathrm{O}_{6}+\mathrm{O}_{2}+\mathrm{CH}_{3} \mathrm{CH}_{2} \mathrm{OH}-\mathrm{C}_{6} \mathrm{H}_{12} \mathrm{O}_{7}+\mathrm{CH}_{3} \mathrm{CHO}+\mathrm{H}_{2} \mathrm{O} \\
& \frac{\mathrm{C}_{6} \mathrm{H}_{12} \mathrm{O}_{6}}{\mathrm{CH}_{3} \mathrm{CH}_{2} \mathrm{OH}} \text { : etanol, } \underline{\mathrm{CH}}{ }_{3} \mathrm{CHO} \text { : acetaldehido }
\end{aligned}
$$


De acuerdo a lo mencionado surge la necesidad de establecer con exactitud bajo qué condiciones se realiza la medida, a fin de asegurarnos que los valores de consumo $0_{2}$ sean estequiométricos con la cantidad de sustrato (glucosa) transformado.

Las medidas de consumo de $0_{2}$ son precisas y de gran sens $\underline{i}$ bilidad $(0,02$ a 0,5 U. $1 . *)$ pero son desventajosas en el sentí do de que insumen tiempo y son tediosas cuando es necesario procesar un gran número de muestras.

- Medida de la producción de ácido glucónico.

El método propuesto por Underkofler (102) se basa simplemente en titular el ácido glucónico producido luego de un determinado tiempo de reacción. El procedimiento es simple y práctico pero poco sensible $(5$ a $25 \mathrm{U} .1 . *)$ y a diferencia del método manométrico no es necesario considerar la presencia de catalasa. Se ha mencionado como una posible fuente de error en la determinación, la cinética de hidrólisis de la gluconolactona.

- Medida de la formación de peróxido de hidrógeno.

Las distintas alternativas propuestas para medir la velocidad de formación de $\mathrm{H}_{2}{ }_{2}$ son las siguientes:

1. Determinación amperométrica del $1_{2}$ formado por la acción del $\mathrm{H}_{2}{ }_{2}{ }_{2}$ sobre el ioduro (70).

2. Determinación potenciométrica de la disminución de $\mathrm{SO}_{2}$ producido por la acción del $\mathrm{H}_{2} \mathrm{O}_{2}$ sobre el $\mathrm{SO}_{3} \mathrm{H}^{-}$(3).

3. Determinación fluorimétrica en presencia de peroxidasa y sustancias oxidables fluonescentes $(76 ; 81)$.

4. Determinación colorimétrica en presencia de peroxidasa y sustancias oxidables cromogénicas $(54,60,98)$.

La sensibilidad de estas técnicas es comparable a las medidas de consumo de $0_{2}$ pero presentan la ventaja de una mayor rapidez en a determinación.

* UI: Unidades Internacionales 


\section{6 obtención de glucosa oxidasa}

El método de producción de glucosa oxidasa lo constituye la clásica fermentación en cultivo sumergido. De acuerdo a la bibliografía el sistema de cultivo empleado casi con exclusividad es el "batch" y a excepción del trabajo de Novak (66) su produción en sistema continuo no ha sido mencionada. En Aspergillus $y$ en Penicillum la enzima es de carácter inducible y su formación por el hongo es marcadamente dependiente de la composición del medio de cultivo siendo de particular importancia la influencia de las fuentes de carbono y nitrógeno $(26,27,28,29)$. Al igual que en otros procesos fermentativos la composición del medio de cultivo y las condiciones de operación óptimas para su producción dependen de los requerimientos particulares de cada cepa $(27,28,65,69)$. La enzima es de naturaleza intracelular pero un aspecto importante distingue la fermentación con ambos géneros de hongos. En Aspergillus la misma es extraida del micelio generalmente con el empleo de métodos físicos o mecánicos de ruptura celular entre los que se destaca por su eficiencia la agitación con abrasivos $(55,107,109)$. En cambio con Penicillum la progresiva autolisis que sufre el microorganismo en el transcurso del proceso hace que su recuperación sea finalmente efectuada a partir del medio de cultivo, asemejándose en este aspecto a la producción de enzimas extracelulares (85). Estas diferencias tienen su incidencia en los tiempos de proceso que necesitan estas cepas para alcanzar sus máximos rendimientos. Las fermentaciones con Aspergillus oscilan entre 16 y 24 horas, en cambio con Penicillum los períodos son más prolongados, alrededor de 60 hs. $(55,65,108)$.

Los mecanismos bioquimicos que regulan la sintesis de glucosa oxidasa en estos hongos filamentosos no han sido elucidados en su totalidad. Algunas apreciaciones han sido realizadas a partir del comportamiento observado en la fermentación glucó nica particularmente con Aspergillus Niger. Se considera que la producción de ácido glucónico es la expresión fenotípica de lo que se ha denominado metabolismo por sobreflujo (overflow metabolism) de los carbohidratos $(17,24)$. El concepto suyacen te en esta definición es el siguiente: bajo determinadas condi ciones de cultivo el hongo recibe un aporte de carbohidrato que 
supera su capacidad de utilizarlo como fuente de energía y biomasa, derivando de esta manera una fracción del mismo hacia la formación de glucónico el cual es segregado al exterior y acumulado en el medio de cultivo. La imposición de este sobreflujo puede ser logrado mediante el manejo conveniente de numerosos factores como la concentración de la fuente de carbono, el pH, etc. A modo de ejemplo podemos mencionar que cuando el hongo se cultiva en un medio con adecuado balance de minerales y fuente de nitrógeno,en presencia de bajas concentraciones de fuente de carbono como pueden ser $0,5 \%$ ó $1 \%$, el mismo crecerá sintetizan do material celular con una nula o ínfima formación de ácido or gánico. Pero al incrementar la concentración de azúcar al $5 \%$ ó $10 \%$, una importante fracción de la misma aparecerá como ácido orgánico en el medio de cultivo. De igual manera si en el primero de los casos el crecimiento es impedido o seriamente limitado por ausencia o deficit de algún componente del medio, la fuente de carbono será convertida en ácido orgánico en una alta proporción. Un comportamiento similar es observado en relación a la formación de otros ácidos orgánicos como son cítrico, oxálico, fumárico, etc. $(24,96)$. De esta manera y con un correcto manejo del medio de cultivo y de las condiciones de operación se han alcanzado conversiones de hasta un $90 \%$ y $100 \%$ a partir de soluciones conteniendo entre $15 \%$ y $30 \%$ de carbohidrato $(16,42,96)$. Cabe mencionar que en general la producción de un ácido orgánico por estas cepas de Aspergillus Niger no es excluyente de la formación de otro. Dependiendo de las condiciones de cultivo y de la especificidad de la cepa, es común observar la acumulación de glucónico, cítrico u oxálico (24). Este comportamiento demuestra la versatiilidad del metabolismo de los hongos y la necesidad de establecer con limites precisos las condiciones óptimas de proceso según sea el producto de nuestro interés. El ácido glucónico lina vez presente en el medio de cultivo pue de ser utilizado por el microorganișmo como fuente de carbono lo cual generalmente ocurre cuando la fuente original se ha consumido en su mayor parte (53). Algunos estudios bioquímicos han demostrado que la degradación del gluconato puede ser realizada por diversos caminos metábolicos que conducen a interme diarios de la vía glicolttica $(21,40)$. Podemos decir entonces que la capacidad genética de sintetizar glucosa oxidasa por 
estos hongos es un recurso del cual disponen cuando por diversas causas se encuentran en un medio desbalanceado que no les permite aprovechar con total eficiencia la fuente de carbono, obligándose a derivar la misma hacia la formación de glucónico. Por lo tanto se puede establecer en principio ciertas analogías entre la fermentación glucónica y el proceso de obtención de glucosa oxidasa ya que evidentemente la primera de ellas requiere la presencia activa de la enzima en las células del hongo. Sin embargo cabe hacer la siguiente consideración; en la producción de glucónico el objetivo es obtener la mayor conversión posible de la fuente de carbono en ácido orgánico lo cual conduce necesariamente a una reducida formación de bio masa. En cambio cuardo elproceso es enfocado hacia la producción de enzima considerando esta como un producto intracelular como en el caso de la fermentación con Aspergillus Niger, es necesario tener-en cuenta que los rendimientos serán función no sólo del contenido de glucosa oxidasa de la biomasa sino también de la concentración de dicha biomasa en el medio de cultivo. En esta situación se debe buscar un compromiso entre ambos parámetros para que el proceso no sea antieconómico y es por ello que las condiciones que resulten más favorables para la producción de la enzima no deben ser necesariamente las mis mas que las establecidas para una óptima fermentación glucónica.

\subsection{Desarrollo del trabajo}

Para realizar el presente trabajo se empléo la cepa de Aspergillus niger NRRL3 productora de ácido glucónico y por lo tanto fuente potencial de glucosa oxidasa (16). En la primera parte se estudió un mézodo colorimétrico para la determinación de la actividad enzimática el cual por su fácil realización y simplicidad resultó sumamente adecuado como técnica de rutina. Las experiencias del proceso fermentativo se iniciaron con la selección de un método dé extracción de la enzima y con los en sayos en frascos agitados donde se investigó la influencia de la composición del medio de cultivo sobre la producción enzimática. Finalizadis estos ensayis se estudió la operación de extracción a efectos de establecer las condiciones óptimas de 
procesamiento de las células del hong.o. Por último se utllizaron fermentadores con agitación mecánica en una escala de cuatro litros donde se analizó la influencia de diversas variables de operación en los rendimientos de la fermentación. 


\subsection{Microorganismo}

2.1.1. Cepa empleada en los estudios

Se emplé como microorganismo productor de enzima la cepa de Aspergillus niger NRRL 3 provista por el Northern Regional Research Center (U.S.Department of Agriculture).

\subsubsection{Conservación de la cepa}

La cepa se recibió como esporos liofilizados, los cuales se resuspendieron en solución fisiológica y se sembraron en el medio 1. Luego de incubar a $30^{\circ} \mathrm{C}$ durante 6 días la nueva generación de esporos se recolectó de los desarrollos con solución fisiológica conteniendo $0.01 \%$ de Tween 80 . Una fracción de la suspensión obtenida se la liofilizó en suero de conejo o suero de equino para el mantenimiento de los esporos por períodos pro longados de tiempo $(36,68)$. Otra fracción se la llevó a una concentración de glicerol del $15 \%$ v/v y se la congeló en pequeñas ampollas a la temperatura de $-20^{\circ} \mathrm{C}$ empleándose estos esporos para la preparación de los cultivos de trabajo por un tiem po máximo de 6 meses. Transcurrido dicho período se tomó un lio filizado y se repitió el procedimiento, es decir, se obtuvieron nuevos esporos sembrando el medio l con los cuales se preparó una nueva serie en gi icerol. Este procedimiento permitió un correcto manejo de la cepa preservando de esta manera su capacidad fermentativa.

\subsection{Medios de cultivo}

2.2.1. Medio de producción de esporos (medio $\mathrm{N}^{\circ} 1$ )

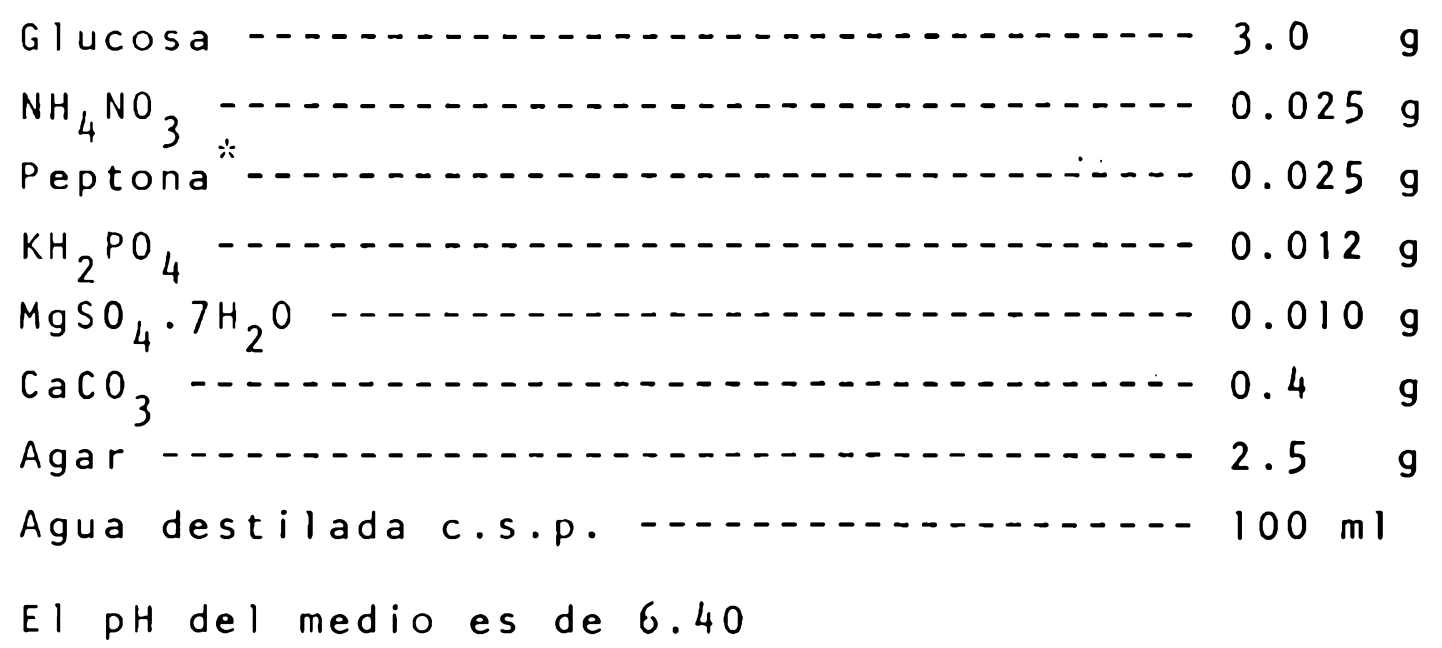

* hidrolizado pepsínico de hígado de cerdo 


\subsubsection{Medio base de fermentación (medio $N^{\circ} 2$ )}

Como medio base para el desarrollo del proceso fermentativo se empleó una modificación del medio de Muller (27) cuya composición es la siguiente:

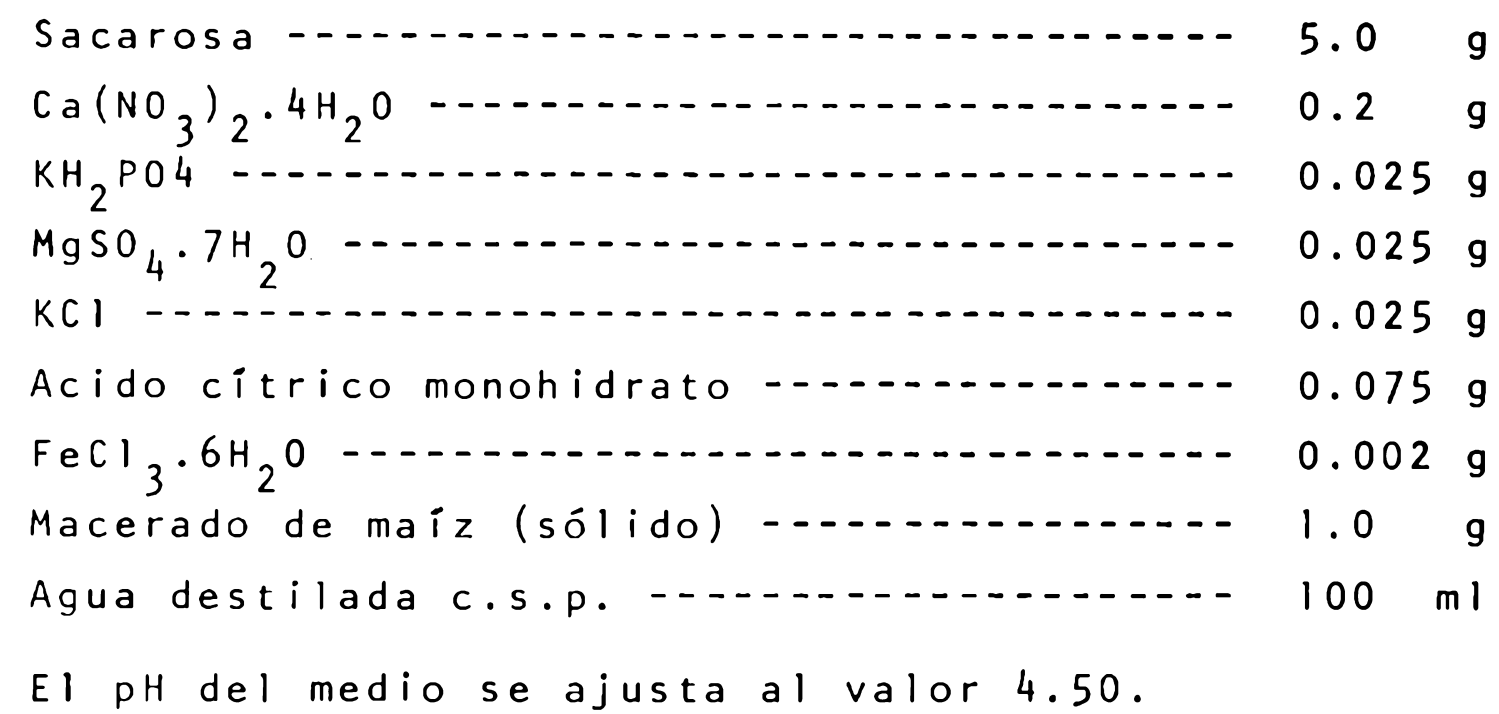

\section{3 Determinaciones analiticas}

\subsubsection{Recuento de esporos}

Se realizó en una cámara de recuento celular del tipo Neubauer

\subsubsection{Peso seco}

El contenido de materia seca del micelio o de un volumen determinado de la suspensión de células desintegradas se determinó en estufa a $105^{\circ} \mathrm{C}$ hasta pesada constante.

\subsubsection{Medida de $\mathrm{pH}$}

La misma fué efectuada utilizando un peachimetro Metrohm E 396

\subsubsection{Medida del oxigeno disuel to}

Se realizó por medio de un electrodo galvánico marca Biotec. Se expresa en forma relativa como porcentaje del valor inicial presente en el cultivo que se toma como $100 \%$ de saturación.

\subsubsection{Consumo de oxigeno en el fermentador}

Se estimó por un balance de materia considerando el porcentaje de $0_{2}$ en los gases de entrada y salida del fermentador. Se empleó la siguiente fórmula.

$$
V C O=\frac{F}{V}\left(0_{e}-0_{s}\right) \times 600
$$


VCo: Velocidad de consumo de $0_{2}\left(\frac{m l 0_{2}}{1 \times h}\right)$

F : Caudal de aire suministrado al cultivo ( $\left.\frac{1 \text { aire }}{\text { minuto }}\right)$

$V$ : Volumen de cultivo (1)

$0_{\text {e }} \mathrm{y}_{\mathrm{s}}$ : Porcentaje de $0_{2}$ en los gases que entran y salen del fermentador respectivamente

Los porcentajes de $\mathrm{O}_{2}$ se midieron en un analizador Beckman modelo OM- 14

\subsubsection{Medida del consumo de sacarosa}

Se efectuó en el filtrado del cultivo empleando el método de Hyvarinen y Nikkila (39) previa hidrólisis en HCL 1,25\% (concentración final) en baño maría durante 15 minutos.

\subsubsection{Medida del consumo de nitrato}

Se efectuó en el filtrado del cultivo empleando el método colorimétrico de Lees y Quastel (66).

\subsubsection{Determinación de proteinas}

La concentración de proteína soluble en los extractos celu lares se determinó por el micrométodo de Biuret en el ultravio leta según ltzhaki R. (41). Cuando la determinación se realizó sobre la suspensión celular, la misma fué previamente diluída a una concentración aproximada de $1 \mathrm{mg} / \mathrm{ml}$ de materia seca y tratada con $\mathrm{NaOH}, \mathrm{N}$ (concentración final) a $100^{\circ} \mathrm{C}$ durante 5 minu tos para su digestión (37). Luego se procedió a centrifugar y determinar en el sobrenadante la concentración de proteína por el método mencionado.

\subsubsection{Medida de la velocidad de absorción de oxígeno (VAo)}

El valor de VAO en los fermentadores con agitación mecánica y del sistema de frascos agitados se calculó en base al método de Cooper. (14). 
Se llevó a cabo por la técnica descendente con papel Whatman $N^{\circ} 3$ y empleando como solvente de desarrollo n-Butanol, ácido fórmico y agua en relación 10:7:10 (53). Como revelador se utilizó una solución de etanol $(50 \%)$ conteniendo $5 \%$ de xilosa y $5 \%$ de anilina (92). La cromatografia de las muestras del cultivo fueron realizadas en el filtrado, el cual previamente se acidificó con HCl para desolver los cristales formados durante la fermentación y centrifugó para eliminar todo resto de sedimento. Del sobrenadante se sembraron directamente $5 \mu l$ sobre el papel y se realizó la corrida durante 3 a 4 horas a temperatura ambiente. En forma paralela se corrieron los ácidos patrones $(100 \mu g)$ como ser glucónico, citrico y oxálico. La localización de los ácidos se realizó impregnando el papel con la solución reveladora y calentando brevemente a $105^{\circ} \mathrm{C}(92)$.

\subsubsection{Determinación de glucosa oxidasa}

Luego de analizar las distintas alternativas propuestas para valorar la actividad enzimática (item 1:5) se consideró interesante utilizar el método colorimétrico que consiste en medir la velocidad de formación de $\mathrm{H}_{2}{ }_{2}{ }_{2}$ con peroxidasa y una sustancia oxidable cromogénica. En su elección se tomó en cuenta que la bibliografia menciona su aplicación a la determinación de la enzima en extractos celulares de Aspergilus niger $(60,98)$ como a la conveniencia de no requerir equipos especiales para su realización y a la sensibilidad y sencillez de procedimiento que implica este tipo de método. Sin embargo y debido a que los autores emplean esta determinación bajo condiciones de ensayo muy diferentes y se limitan a dar una descripción parcial del desarrollo de la técnica, resultó necesario estudiar con mayor detalle el método colorimétrico a fin de establecer una metodología confiable y precisa para su utilización. Las experiencias que se realizaron con tal fin se incluyen en resultados experimentales (item 3.1) describiéndose en la presente sección el fundamento del método y las condiciones finales establecidas para la realización de la medida.

Fundamento de la determinación.

Se mencionó anteriormente que el $\mathrm{H}_{2}{ }^{0} 2$ formado por la acción de la glucosa oxidasa es determinado colorimétricamente mediante 
el empleo de un sistema enzimático acoplado que contiene perox! dasa y una sustancia oxidable cromogénica. Por lo tanto el princi pio en que se fundamenta la medida es el mismo que el empleado para la determinación cuantitativa de glucosa con reactivos similares $(25,47,57)$. La diferencia reside en que las condiciones del ensayo se adaptan para que la velocidad de la reacción colorimétrica sea función de la actividad de glucosa oxidasa. La secuencia de reacciones es la siguiente:

Reacción principal (glucosa oxidasa)

$$
\mathrm{C}_{6} \mathrm{H}_{12}{ }^{\mathrm{O}} 6+\mathrm{O}_{2}+\mathrm{H}_{2} \mathrm{O} \longrightarrow \mathrm{C}_{6} \mathrm{H}_{12}{ }^{\mathrm{O}} 7+\mathrm{H}_{2}{ }^{\mathrm{O}} 2
$$

Reacción indicadora (peroxidasa, donor):

$$
\begin{aligned}
& E+\mathrm{H}_{2} \mathrm{O}_{2} \longrightarrow E S_{1} \\
& E S_{1}+\mathrm{AH}_{2} \longrightarrow \mathrm{E}+\mathrm{A}+2 \mathrm{H}_{2} \mathrm{O}
\end{aligned}
$$

E: peroxidasa ES, complejo enzima-sustrato

$\mathrm{AH}_{2}$ y A: Donor de hidrógeno reducido $y$ oxidado respectivamente.

De acuerdo al esquema podemos decir que en presencia de un exceso de glucosa y oxígeno y un sistema enzimático indicador que utilice el $\mathrm{H}_{2}{ }_{2}{ }_{2}$ con una velocidad mucho mayor que la de su formación, el incremento en la concentración de A (donor oxidado) será proporcional a la actividad de glucosa oxidasa. La especifi cidad de peroxidasa por su sustrato es alta y sólo el $\mathrm{H}_{2} \mathrm{O}_{2}$ y algunos alquil peróxidos monosustituidos pueden actuar como tal $(13,56)$. En cambio una gran variedad de sustancias pueden ser utilizadas como donores de hidrógeno algunas de las cuales al oxidarse dan lugar a un producto coloreado. De esta manera la o-dianisidina (3,3'-dimetoxibenzidina) y el ABTS (sal diamónica del ácido 2,2'-azinobis (3-etilbenzotiazolina) sulfónico) han sido empleados para determinar el incremento de absorbancia debido a la reacción enzimática, la cual puede seguirse espectrofotométricamente a 410 y $440 \mathrm{~nm}$, o bien como en el caso de la o-dianisidina la reacción puede detenerse con la adición de ácido dando lugar a un color rojo estable con un máximo de absorción de alrededor de $530 \mathrm{~nm}(54,60)$. Esta última alternativa presenta mayor practicidad ya que permite adaptar el ensayo para medir varias muestras simultáneamente. La actividad de la glucosa oxidasa se calcula entonces conociendo mediante una curva de calibración 
la relación entre la concentración de $\mathrm{H}_{2} \mathrm{O}_{2}$ y la absorbancla de la solución.

Reactivos:

1. Peroxidasa (E.C.1.11.1.7); se empleó siempre un preparado liofilizado obtenido de Boehringer, de grado I con un indice de pureza (PN) de 3.0. Para estandarizar este reactivo se determinó su actividad por el método del guayacol a $25^{\circ} \mathrm{C}$ en las condiciones de ensayo para la constante cinética $k_{4}$ (13). La unidad se definió como la cantidad de enzima que produce un incremento de 0.05 unidades de absorbancia por segundo. El preparado comercial presentó una actividad de $107 \pm 5.0 \mathrm{U} / \mathrm{mg}$.

11. Clorhidrato de o-dianisildina:Se preparó haciendo burbujear cloruro de hidrógeno en una solución de 0-dianidisina ( FLUKA) en benceno anhidro durante 20 minutos. Una vez filtrado y secado se lo recristalizó en metanol. Se conservó a $-16^{\circ} \mathrm{C}$ en recipiente hermético y protegido de la acción de la luz.

111. Solución comercial $\mathrm{H}_{2}{ }^{0} 2$ al $30.4 \%$ (Atanor S.A.). Acido sulfúrico $96 \%$ d: 1.84 (Merck), Glicerol de grado analitico (Laboratorio Cicarrelli). Glucosa anhidra (BDH). Se empleó siempre en la preparación de los reactivos agua destilada.

Para realizar la determinación enzimática se preparan las siguientes soluciones:

A. Solución de peroxidasa $(70 \mathrm{ug} / \mathrm{ml})$ y clorhidrato de o-dianisidina $(300 \mathrm{ug} / \mathrm{ml})$ en glicerol al $40 \% \mathrm{v} / \mathrm{v}$. Se conserva $-20^{\circ} \mathrm{C}$ durante 30 dias.

B. Regulador de fosfato de sodio $0.1 \mathrm{M}, \mathrm{pH} 7.0$.

C. Solución de D-glucosa 0.66 M en agua destilada.

D. Acido sulfúrico al $50 \%$ ( 1 volumen de $\mathrm{H}_{2} \mathrm{SO}_{4} 96 \%$, $: 1.84+1$ volumen de agua destilada)

E. Reactivo indicador: Se prepara en el momento previo a la determinación mezclando volúmenes iguales de las soluciones $A$ y $B$. Se mantiene refrigerado en hielo.

F. Solución patrón de $\mathrm{H}_{2} \mathrm{O}_{2}$ : Se prepara mediante una dilución 
1:1000 de la solución comercial. Contiene aproximadamente 8.9 umoles de $\mathrm{H}_{2} \mathrm{O}_{2} / \mathrm{ml}$. Puede conservarse a $4^{\circ} \mathrm{C}$ (en reclpiente oscuro) durante 2 a 3 meses. Antes de realizar la curva de callibración su concentración exacta se determina iodométricamente con $\mathrm{S}_{2} \mathrm{O}_{3} \mathrm{Na}_{2} \cdot 5 \mathrm{H}_{2} \mathrm{O}$ normalizado frente a una solución patrón de $\mathrm{Cr}_{2}{ }^{\mathrm{O}} \mathrm{K}_{2}$.

Procedimiento:

La medida se realiza $37^{\circ} \mathrm{C}$ utilizando un baño termostático $\left( \pm 0.1^{\circ} \mathrm{C}\right)$ con agitación mecánica. En el mismo se coloca un tubo de ensayo de $1.5 \times 7.5 \mathrm{~cm}$ al cual se adicionan sucesivamente $1 \mathrm{ml}$ de reactivo indicador más $0.4 \mathrm{ml}$ de solución de $0.66 \mathrm{M}$ de glucosa. Una vez alcanzada la temperatura de trabajo se agregan $0.2 \mathrm{ml}$ de solución enzimática (conteniendo como máximo $0.45 \mathrm{U} / \mathrm{ml}$ ) y el sistema se agita intensamente para proveer un adecuado grado de aeración. Al cabo de 1 minuto o un mayor tiempo si es necesario la reacción se detiene con $\mathrm{l} \mathrm{ml}_{\mathrm{de}} \mathrm{H}_{2} \mathrm{SO}_{4}$ al $50 \%$ que produce al mismo tiempo un color rojo estable. El blanco se realiza con $0.2 \mathrm{ml}$ de agua destilada en reemplazo de la solución enzimática y la curva de calibración con $0.2 \mathrm{ml}$ de soluciones de $\mathrm{H}_{2} \mathrm{O}_{2}$ de concentración conocida obtenidas por diluciones apropiadas de la solución patrón. La absorbancia del color se determina a $530 \mathrm{~nm}$.

Definición de la actividad enzimática.

Una unidad de glucosa oxidasa corresponde a la cantidad de enzima que produce la formación de un micromol de $\mathrm{H}_{2}{ }_{2}{ }_{2}$ por minuto en las condiciones del ensayo. Esto es equivalente a la oxidación de un micromol de glucosa por minuto.

Expresión de resultados.

El contenido en glucosa oxidasa del hongo se expresó en unidades por gramo de micelio seco. Las mismas se calculan realizando al cociente entre la actividad del extracto celular y la concentración de células (en base seca) presentes en el mismo.

La producción volumétrica se expresó en unidades por litro de medio. 
Método manométrico.

Durante el estudio del método colorimétrico se reallzaron ensayos comparativos con determinaciones manométricas del consumo de oxigeno. Las mismas fueron efectuadas en un equipo Warburg a $37^{\circ} \mathrm{C}$ colocando los reactivos de la siguiente manera:

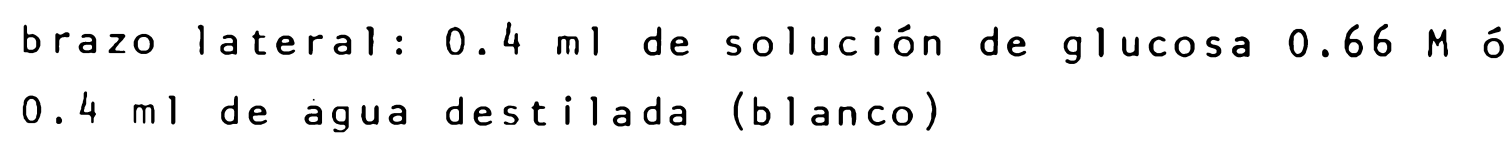

La solución de catalasa empleada en la medida contiene 120 unidades Baker /ml determinadas según scott y Hammer (83). En las condiciones en que se realiza el ensayo manométrico la oxidación de un micromol de glucosa o la equivalente formación de un micromol de $\mathrm{H}_{2} \mathrm{O}_{2}$ corresponden a un consumo de 22.4 ul de $\mathrm{O}_{2}$.

\subsection{Condiciones de operación}

\subsubsection{Ensayos en frascosagitados}

En esta escala de trabajo se realizaron las experiencias donde se estudió la influencia de la composición del medio de cultivo sobre la producción de enzima. Se trabajó por el sistema de lotes empleándose frascos del tipo erlenmeyer de $1000 \mathrm{ml}$ de capacidad conteniendo $100 \mathrm{ml}$ de medio. La incubación se realizó en cuarto estufa a $30^{\circ} \mathrm{C}$ y la agitación fué provista por un agitador rotatorio de $2.5 \mathrm{~cm}$ de excentricidad que se operó a $250 \mathrm{rpm}$. La velocidad de absorción de oxigeno (V.A.O.) para el sistema emṕleado es de $21 \mathrm{~m}$ moles de $0_{2} \times 1^{-1} \times \mathrm{h}^{-1}$.

\subsubsection{Ensayo en fermentadores con agitación mecánica}

En esta escala de trabajo se estudió el efecto sobre los rendimientos enzimáticos de las siguientes variables del proceso: 
1. Inóculo

2. $\mathrm{pH}$ del cultivo

3. Suministro de oxigeno

4. Concentración de la fuente de carbono.

Las experiencias se realizaron en un equipo marca LKB 1601 Ultroferm con volumen de trabajo de 2 a 4 litros de cultivo y provisto de controles para agitación, temperatura, caudal de aire, pH, espuma y monitores continuos para oxígeno disuelto, volumen de agente neutralizante o antiespuma adicionado, etc. Todos los ensayos se efectuaron a $30^{\circ} \mathrm{C}$ empleando 4 (cuatro) 1 i tros de cultivo al cual se le suministró un caudal constante de aire a razón de l litrox litro de medio $x$ minuto. El aire que se introduce al fermentador por un aerador anular de 18 orificios de $0.5 \mathrm{~mm}$ de diámetro se esterilizó haciéndolo pasar a través de un filtro papel de fibra de vidrio de $47 \mathrm{~mm}$ de diá metro sostenido en el interior de un soporte de polipropileno.

El conjunto filtro-soporte se autoclava previamente con el res to de la unidad de fermentación.

El control de pH se realizó automáticamente utilizando como agente neutralizante solución de $\mathrm{NaOH}$ al 20 ó $30 \%$ que no se esterilizó. Como sensor de pH se empleó un electrodo INGOLD que fué sumergido 30 minutos en alcohol de $70 \%$ previo a su introduc ción en el fermentador.

Las diferentes condiciones de aeración del cultivo se obtuvieron modificando la velocidad de agitación. El agitador, una turbina plana de 6 paletas, se operó a 550, 700 y 850 rpm correspondiendo valores de velocidad de absorción de oxígeno de $71,3,136$ y $200 \mathrm{~m}$ moles $0.2 \times 1^{-1} \times \mathrm{h}^{-1}$ respectivamente. El nivel de espuma se controló en forma automática empleando anties umante a base de siliconas tipo SAG 471 (Darmex) el cual se pre paró bajo la forma de una emulsión acuosa al $10 \%$.

\subsubsection{Esterilización}

Todos los materiales y medios de cultivo empleados en escala de frascos agitados se esterilizaron en autoclave tipo Chamberlain con vapor saturado de $121^{\circ} \mathrm{C}$ durante 20 minutos. Para el medio base $\left(N^{\circ} 2\right)$ se procedió a esterilizar por separado los fosfatos, lasacarosa junto al nitrato de calcio y el macerado 
de maiz con el resto de los componentes. Cuando se Introdujeron modificaciones en la composición del medio los nuevos componentes se esterilizaron siguiendo un esquema similar. La planta de fermentación junto al filtro de aire y el antiespumante fueron en cambio esterilizados en un autoclave automático reduciéndose en este caso a 15 minutos el tiempo de retención a $121^{\circ} \mathrm{C}$.

\subsubsection{Desarrollo del inóculo}

Para la obtención del inóculo se parte del material conservado en la solución de glicerol (item 2.1.2.) el cual se descongela (generalmente una ampolla) y se siembra en el medio 1. Luego de incubar durante 6 días a $30^{\circ} \mathrm{C}$ los esporos se resuspenden en solución fisiológica conteniendo $0.01 \%$ de Tween 80 y se transfieren al medio base $\left(N^{\circ} 2\right)$ en una concentración de $10^{4} / \mathrm{ml}$. El material sembrado se cultiva durante 20 horas y el desarro110 vegetativo se emplea para inocular al $10 \%$ el mismo medio o alguna de sus modificaciones. El inóculo presenta generalmente un $\mathrm{pH}$ de 4.2-4.3 y una concentración celular comprendida entre 3.5 y $4.0 \mathrm{~g} / 1$ de micelio seco. Esta condición de inóculo se utilizó durante los ensayos efectuados en escala de frascos agitados y se modificó posteriormente para las experiencias en fermentadores según se discute en el punto 3.5.1.

\subsubsection{Procesamiento de las muestras del cultivo}

Para los ensayos en frascos agitados y a una hora prefijada del proceso se retiró un frasco del agitados y luego de medir el $\mathrm{pH}$ y el volumen exacto del cultivo, el contenido total del mismo se filtró a través de papel Whatman $N^{\circ} 4$ empleando un filtro de tipo Butchner con ayuda de vacio. La torta de micelio se lavó repetidas veces con agua destilada, se escurrió entre papeles de filtroy se la congeló en cajas de Petri a $-20^{\circ} \mathrm{C}$ hasta el momento de proceder a la extracción de la enzima. En ensayos previos se determinó que las muestras de micelio pueden conservarse congeladas durante 30 días sin pérdida apreciable de actividad. La extracción se realizó desintegrando el micelio con una 
prensa $X$ (Biox-Sweden) de $25 \mathrm{ml}$ de capacidad, reallzando un solo pasaje de la muestra a $-28^{\circ} \mathrm{C}$. (la descripclón y operación del equipo se detallan en el punto 2.4.6). Luego del tratamiento la suspensión acuosa de células desintegradas se llevó a un volumen conocido tomándose de la misma una alicuota para determinar su contenido de materia seca y evaluar de esta manera la concentración celular del cultivo. A continuación la suspensión se centrifugó a $4^{\circ} \mathrm{C}(15000 \mathrm{~g} \times 10 \mathrm{minutos})$ y en el sobrenadante se determinó la actividad de glucosa oxidasa. Generalmente se empleó en el proceso de extracción entre 1 y 2.5 g de micelio húmedo. Cuando se obtuvieron del cultivo cantidades superiores en peso húmedo de células se adoptó el siguiente procedimiento; se fraccionó el micelio en dos porciones de peso húmedoconocido, una de las cuales se congeló y la otra se colocó inmediatamente en un tubo o pesa filtro previamente tarado para determinar el peso seco de células contenido en dicha fracción. Con la muestra congelada se procedió de manera similar a lo descripto anteriormente. La concentración celular del cultivo se obtuvo en estos casos de los valores de peso seco de ambas fracciones.

Para las experiencias en tanques agitados se procesaron entre 30 y $50 \mathrm{ml}$ de caldo separando las céliulas del medio en la forma descripta anteriormente y congelando la totalidad del micelio contenido en dicho volumen. Las condiciones de extracción fueron en cambio modificadas realizando en este caso tres pasajes de la suspensión por la Prensa-x a $-28^{\circ} \mathrm{C}$ y determinando la actividad de glucosa oxidasa en el homogenizado sin centrifugar.

\subsubsection{Extracción de glucosa oxidasa}

Comparación de diferentes tratamientos del micelio en la eficiencia de extracción: En esta experiencia se ensayaron diversas técnicas convencionales de extracción de enzimas con el objeto de evaluar su eficiencia en la extracción de glucosa oxidasa del micelio. Los métodos empleados fueron:
a. Homogeneización
b. Secado con acetona
c. Tratamiento ultrasónico 
d. Desintegración con abrasivos (arena)

e. Extrusión sólida (Prensa-X)

Para realizar el estudio se empleó un cultivo de 12 horas de desarrollo en el medio base $\left(N^{\circ} 2\right)$. Las células fueron separadas del medio en la forma descripta en 2.4.5. y congeladas en porciones de $l g$. Cuando fué requerido se descongeló una cantidad determinada de micelio y se lo sometió a uno de los métodos mencionados. Luego de cada tratamiento las suspensiones se centrifugaron a $4^{\circ} \mathrm{C}(15000 \mathrm{G} \times 10 \mathrm{minutos})$ determinándose en el sobrenadante la actividad de glucosa oxidasa. Cada tratamiento se realizó por cuadruplicado. Los resultados se expresan en unidades enzimáticas extraídas por gramo de micelio húmedo tratado.

\section{Descripción de los tratamientos}

a. Homogeneización: 2 g de micelio se homogeneizaron con 40 $\mathrm{ml}$ de $\mathrm{H}_{2} \mathrm{O}$ en un $0 \mathrm{mni}-\mathrm{Mixer}$ (Sorvall) durante 30 minutos manteniendo el sistema refrigerado en un baño de hielo.

b. Secado con acetona: 2 g de micelio se trataron con $15 \mathrm{ml}$ - de acetona a $-25^{\circ} \mathrm{C}$ durante 2 minutoscon agitación. Las células se filtraron y la operación se volvió a repetir (2 veces) renovando la acetona en cada tratamiento. Finalmente el resto de solvente se eliminó en un desecador con vacio y el micelio se extrajo con $40 \mathrm{ml}$ de agua.

c. Tratamiento ultrasónico: $2 \mathrm{~g}$ de micelio se resuspendieron en $40 \mathrm{ml}$ de agua y se sonicaron durante 30 minutos con una potencia(nominal) de $300 \mathrm{w}$. Se empleó un equipo Megason (ultrasonic Instruments International) con transductor de tipo piezoeléctrico y una punta de 0.5 pulgadas de diámetro terminal. Como recipiente para la suspensión celular se utilizó un tubo de centrifuga de $9.76 \mathrm{~cm}$ de altura por $3.83 \mathrm{~cm}$ de diámetro interno con un espesor de pared de $0.39 \mathrm{~cm}$ que se mantuvo inmerso en baño de hielo durante el tratamiento.

d. Desintegración con abrasivos: 2 g de micelio se disgregaron en un mortero refrigerado durante 20 minutos con $15 \mathrm{~g}$ de arena y $15 \mathrm{ml}$ de agua. La suspensión se volvó a un erlenmeyer y el mortero se lavó con $25 \mathrm{ml}$ de agua. Luego de agitar intensa- 
'mente durante 10 minutos se filtró a tiravés de una gasa y se centrifugó en la forma anteriormente indicada. La calidad de arena adecuada se obtuvo tratando arena común con HCL al $10 \%$ durante I semana a baño maría renovando 3 a 4 veces el ácido y lavando posteriormente con agua común y luego destilada has ta reacción de $\mathrm{Cl}^{-}$negativa. En una etapa final se seca en es tufa.

e. Extrusión sólida (Prensa-X) 2 g de micelio se resuspen dieron en $25 \mathrm{ml}$ de agua y se sometieron a un solo pasaje a $-28^{\circ} \mathrm{C}$.

\section{Descripción y operación de la prensa-X}

El equipo fué desarrollado por Edebo (19) y resulta sumamente eficiente para desintegrar células mecánicamente resis tentes como son ciertas bacterias y el micelio de determinados hongos filamentosos $(20,38)$. Permite además realizar la opera ción de extracción a baja temperatura, lo cual es ventajoso cuando se trata de obtener un producto termolábil como es en es te caso la glucosa oxidasa (109). El efecto desintegrativo se obtiene forzando el pasaje de una suspensión congelada de célú las a través de un pequeño orificio por medio de presión (extrusión sólida). Para tener una buena eficiencia debe trabajar se a temperaturas comprendidas entre $-25^{\circ} \mathrm{C}$ y $-60^{\circ} \mathrm{C}$. La presión que debe aplicarse para forzar el pasaje de la muestra es función de diversos factores como la temperatura, la concentración del material a extrusar y el diseño del equipo. Generalmente os cila entre 1600 y $2500 \mathrm{~kg} / \mathrm{cm}^{2}$. El equipo consiste de dos cámaras cilindricas (A) separadas por un disco (B) que contiene en su parte central un orificio de $2.5 \mathrm{~mm}$ de diámetro. Estos compo nentes son de acero inoxidable y se sellan herméticamente con aros de goma. Las cámaras y el disco son mantenidos en posición correcta por medio de dos piezas de titanio (C) que se enroscan entre si. Como accesorios el equipo contiene dos pequeños pisto nes (D) y un pistón mayor (E) que transmite el movimiento a la muestra y sobre el cual se ejerce la presión. Para realizar la extrusión se arma primeramente el equipo y se coloca en una de las cámaras uno de los pequeños pistones. Luego se cierran los extremos de los cilindros con dos tapones de goma y la prensa se sumerge en un baño (alcohol de 60?) durante 30 a 45 minutos. 
Luego se procede a introducir en la otra cámara la suspensión de células a desintegrar y sobre la misma el otro pistón que previamente se enfrió a la misma temperatura. El equipo se en fría nuevamente durante 30 minutos, luego de lo cual se retira del baño y se coloca en una prensa hidráulica realizando el extrusado de la suspensión con ayuda del pistón mayor. Para realizar varios pasajes por el orificio basta simplemente con invertir el equipo y repetir el prensado. Una vez culmina do el procesamiento se desarma el equipo y la muestra se retira del cilindro procediendo luego a descongelarla o bien manteniéndola en dicho estado hasta el momento de su análisis.

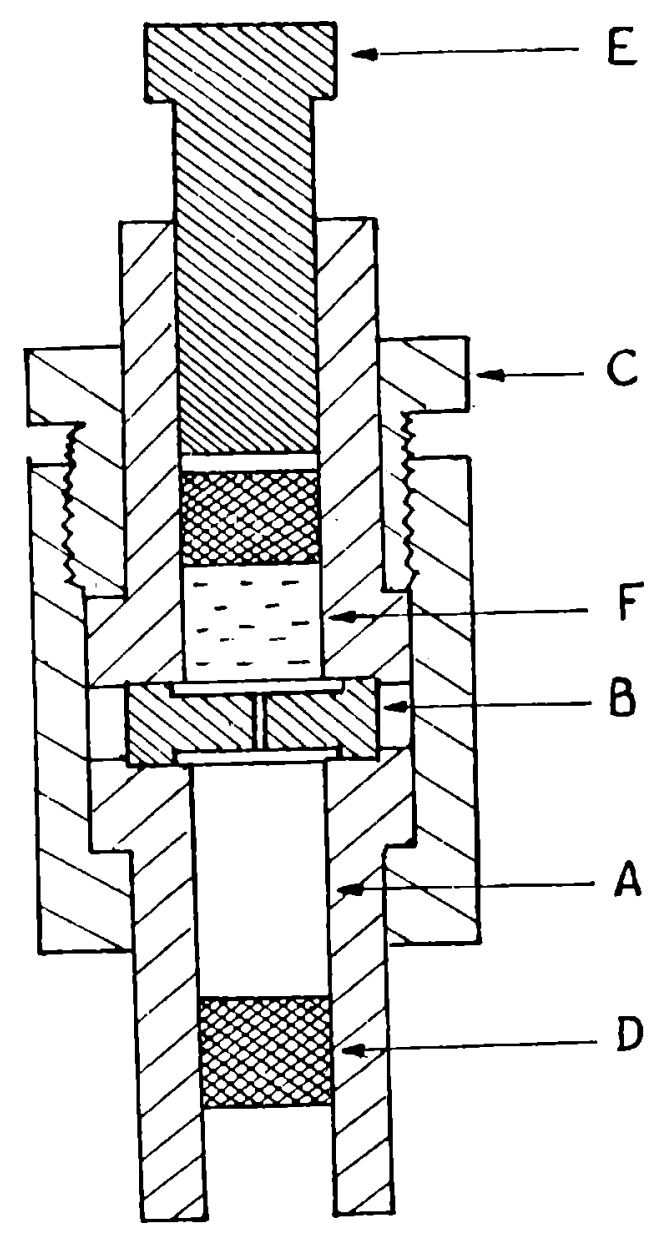

Figura 2. Esquema de la Prensa-X: Cámara cilindrica (A). disco (B), sostén de titanio (C), pistán menor $\left(D_{1}\right)$, pistón mayor (E), muestra congélada (F). 


\section{RESULTADOS EXPERIMENTALES Y DISCUSION}

\subsection{Determinación colorimétrica de glucosa oxidasa}

Las experiencias realizadas tuvieron por finalidad determinar los siguientes aspectos del método:

- Correlación entre ta concentración de peróxido de hidrógeno y absorbancia de la solución.

- Rango de actividad de glucosa oxidasa que es posible medir luego de establecer una concentración apropiada del sistema enzimát ico indicador.

- Correlación de los valores de actividad con los obtenidos mediante determinaciones de consumo de oxigeno.

Para el estudio se tomó como referencia el trabajo de Tholey (98) modificando el procedimiento de acuerdo a lo descripto en materiales y métodos (item 2.3.11. i. Se estableció una concentración de glucosa del $3 \%(166 \mathrm{mM})$ a fin de corresponderse con valores empleados en otras determinaciones $(74,102$ ) (este valor como los que se indican para otros reactivos en el texto y las figuras indica la concentración final en la mezcla de reacción cuyo volumen fue en todos los casos de $1.6 \mathrm{ml}$ ). Teniendo en cuenta que el oxígeno es sustrato de la glucosa oxidasa y para no limitar la velocidad de reacción con el mismo, el sistema se agitó intensamente durante las medidas empleándose para ello un agitador rotatorio $(250 \mathrm{rpm}$ y $2.5 \mathrm{~cm}$ de excentricidad) que cumple a su vez la función de baño termostático. Las medidas de absorbancia se realizaron en todos los casos en un espectrofotómetro Beckman 25 con celda de $1 \mathrm{~cm}$ de espesor.

\section{Curva de calibración}

En la figura 3 se representa una curva de calibración típica. La misma se realizó empleando soluciones de $\mathrm{H}_{2} \mathrm{O}_{2}$ de concentración conocida en reemplazo de la glucosa oxidasa. El rango ensayado fue desde $12 \times 10^{-3}$ a $90 \times 10^{-3}$ umoles de $\mathrm{H}_{2}{ }^{0}{ }_{2} / \mathrm{ml}$. Se observa que la relación es lineal hasta una concentración de $75 \times 10^{-3}$ umoles/ml con la intercepción de la abcisa en cero. La sensibilidad es de aproximadamente 0.1 unidad de absorbancia por 
$8 \times 10^{-3}$ umoles/ml de $\mathrm{H}_{2} \mathrm{O}_{2}$. La reproducibliidad de la curva es excelente pudiendo constatarse diferenclas no mayores del $5 \%$ en el factor de correlación para un mismo lote de reactivos.

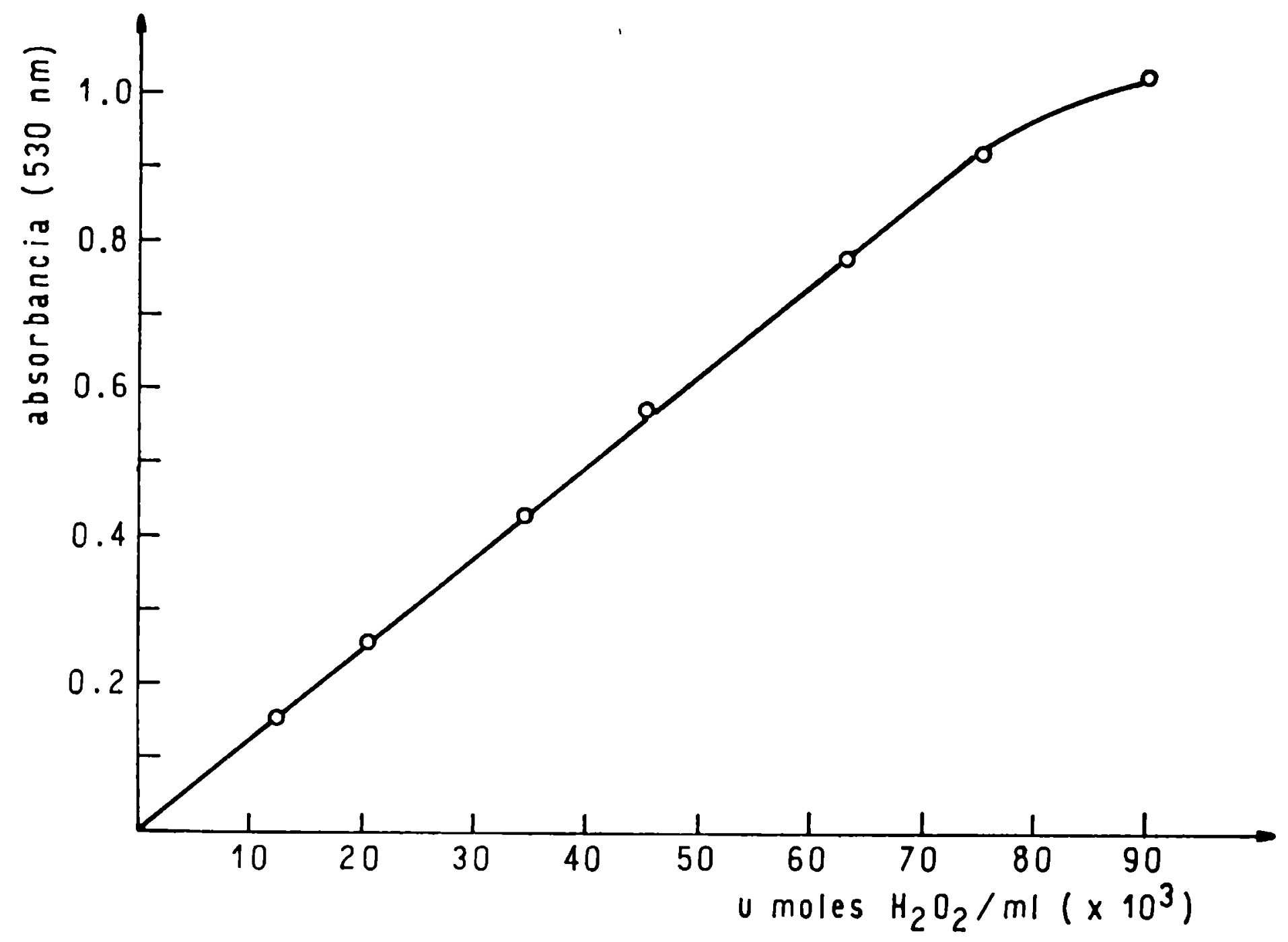

Figura 3 Curva de calibración para la determinación colorimétrica de glucosa oxidasa

\section{Concentración de reactivos del sistema indicador}

Para establecer qué actividad del sistema enzimático indicador resultaba adecuada para determinar un cierto rango de glucosa oxidasa se efectuó un primer ensayo midiendo el valor de absorbancia de la solución para un minuto de reacción en función de la concentración de peroxidasa y manteniendo constante la concentración del donor (o-dianisidina). El ensayo se realizó con dos concentraciones de un preparado comercial de glucosa oxidasa ( 1 iofilizada de 


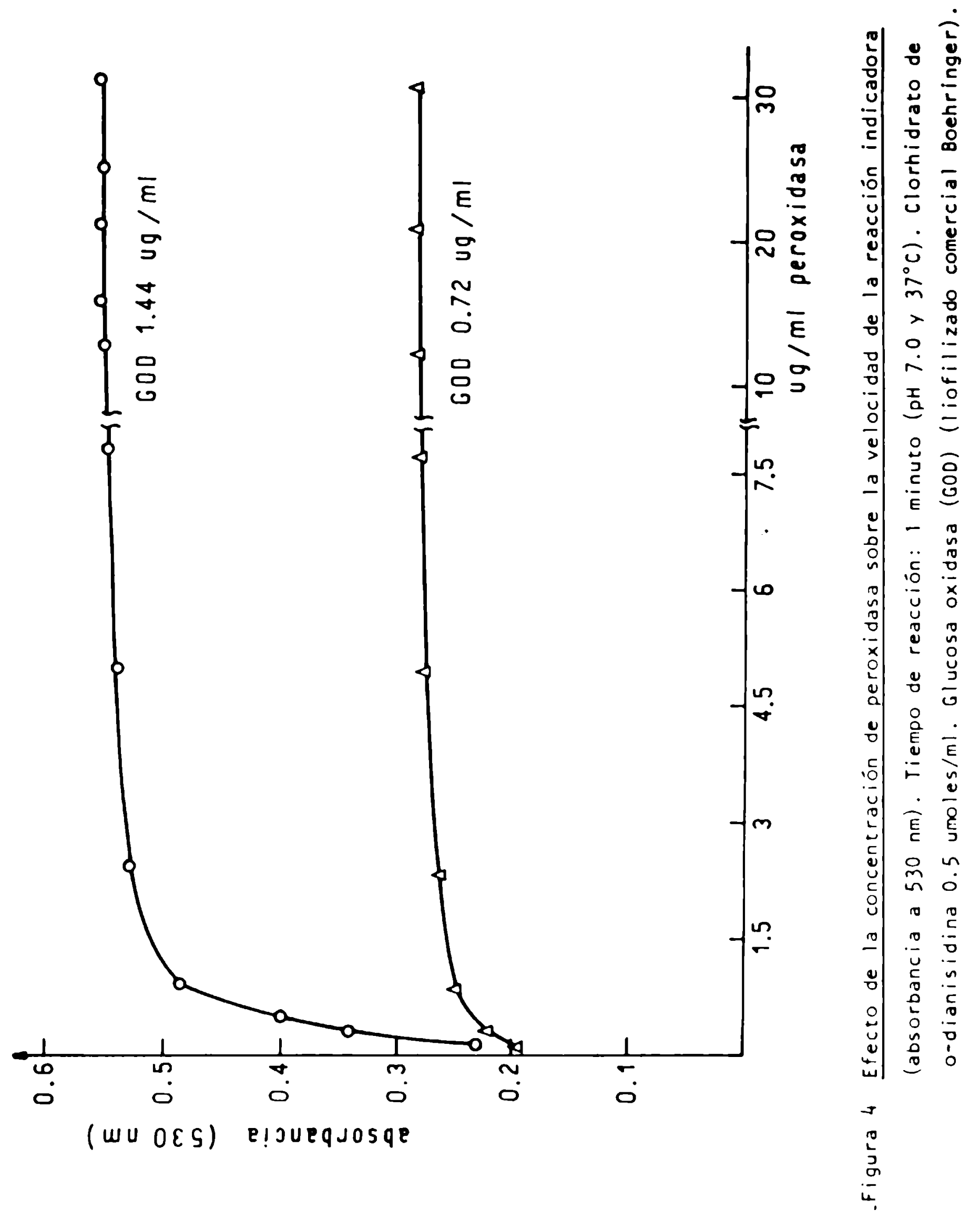


Boehringer) variando la peroxidasa desde 0.15 hasta $31 \mathrm{ug} / \mathrm{ml} y$ manteniendo la cantidad de donor en $156 \mathrm{ug} / \mathrm{ml}$ que corresponde a 0.79 umoles/ml de clorhidrato de o-dianisidina. Los resultados - se muestran en la figura 4 donde se observa que la absorbancla de la solución aumenta rápidamente hasta una concentración de $2.5 \mathrm{ug} / \mathrm{ml}$ de peroxidasa siendo el efecto más pronunciado con la mayor actividad de glucosa oxidasa ensayada. Luego de un ligero incremento la absorbancia se hace independiente por encima de $10 \mathrm{ug} / \mathrm{ml}$ de peroxidasa resultando finalmente proporcional a la cantidad de glucosa oxidasa adicionada. De esta manera y con el objeto de tener un exceso de enzima indicadora se decidió emplear una concentración de $22 \mathrm{ug} / \mathrm{ml}$ de peroxidasa equivalente a $35 \mathrm{ug}$ de la enzima en la mezcla de reacción.

Para seleccionar una cantidad apropiada de donor se efectuó un ensayo similar al anterior pero variando la concentración de clorhidrato de o-dianisidina en el rango de 31 a $156 \mathrm{ug} / \mathrm{ml}$ que equivalen a 0.1 y 0.5 umoles $/ \mathrm{ml}$ del donor respectivamente. Se utilizó $22 \mathrm{ug} / \mathrm{ml}$ de peroxidasa y $1.4 \mathrm{ug} / \mathrm{ml}$ de glucosa oxidasa con un tiempo de reacción de 1 minuto. Los valores representados en el Cuadro 3 muestran que a partir de 0.2 umoles/ml la absorbancia se mantiene constante. De acuerdo a ello se estableció una concentración de 0.3 umoles/ml de donor a fin de asegurarnos un exceso de dicho reactivo.

\section{\begin{tabular}{lllllll}
$C$ & $U$ & $A$ & $D$ & $R$ & 0 & 3 \\
\hline
\end{tabular}}

Absorbancia de la solución en función de la concentración de clorhidrato de o-dianisidina.

Clorhidrato de o-dianisidina umoles/m l
0.10
0.15
0.20
0.30
0.40
0.50

Absorbancia $(530 \mathrm{~nm}$ )
0.47
0.51
0.53
0.53
0.52
0.53

Peroxidasa $22 \mathrm{ug} / \mathrm{ml}, \mathrm{glucosa}$ oxidasa $1.37 \mathrm{ug} / \mathrm{ml}$. Tiempo de reacción 1 minuto $\left(\mathrm{pH} 7.0\right.$ y $\left.37^{\circ} \mathrm{C}\right)$. 
Seleccionada la actividad del sistema enzimático indicador con la concentración de peroxidasa y donor, se midió el incremento de absorbancia en función del tiempo de reacción para di ferentes concentraciones de glucosa oxidasa. Los resultados mos traron una excelente linealidad y la velocidad de reacción resultó proporcional a la concentración de glucosa oxidasa adicio nada (figura 5).

Para simplificar la realización de la medida se optó por elegir un tiempo fijo de reacción de 1 minuto y el rango de acti vidad medible en estas condiciones se estableció realizando nuevas determinaciones con el preparado comercial y graficando jun to a los valores anteriores las unidades enzimáticas en función de la concentración de glucosa oxidasa agregada. Los mismos se calcularon multiplicando el valor de la absorbancia por el factor de correlación obtenido de la curva de calibración. La curva de actividad se representa en la figura 6 observándose que la proporcionalidad se mantiene hasta $0.056 \mathrm{U} / \mathrm{ml}$ de glucosa oxidasa en la mezcla de reacción (aproximadamente 0.7 unidades de absorbancia). De acuerdo a la sensibilidad de la medida podemos considerar un limite inferior de $8 \times 10^{-3} \mathrm{U} / \mathrm{ml}(0.1$ unidad de absor bancia). Por lo tanto este rango representa valores comprendidos entre 0.06 y $0.45 \mathrm{U} / \mathrm{ml}$ de la solución enzimática original. Es evidente que con muestras más diluídas el tiempo de reacción puede incrementarse convenientemente. Por otra parte la actividad promedio para 16 determinaciones del preparado comercial dió una actividad promedio de $31.98 \mathrm{U} / \mathrm{mg}$ con una desviación standard de 0.815 lo cual muestra la reproducibilidad del método. La precisión de las medidas individuales oscila en $\pm 1.5 \%$.

\section{Comparación con el método manométrico}

Con el propósito de evaluar el método colorimétrico se hicieron experiencias de valoración de glucosa oxidasa empleando la medición manométrica y se comparó la actividad obtenida según ambos métodos. En el ensayo se empleó el preparado enzimático comercial y distintos extractos celulares obtenidos del proceso fermentativo.

Los datos de estas determinaciones se consignan en el Cuadro 4 donde se puede apreciar que la concordancia de ambos 


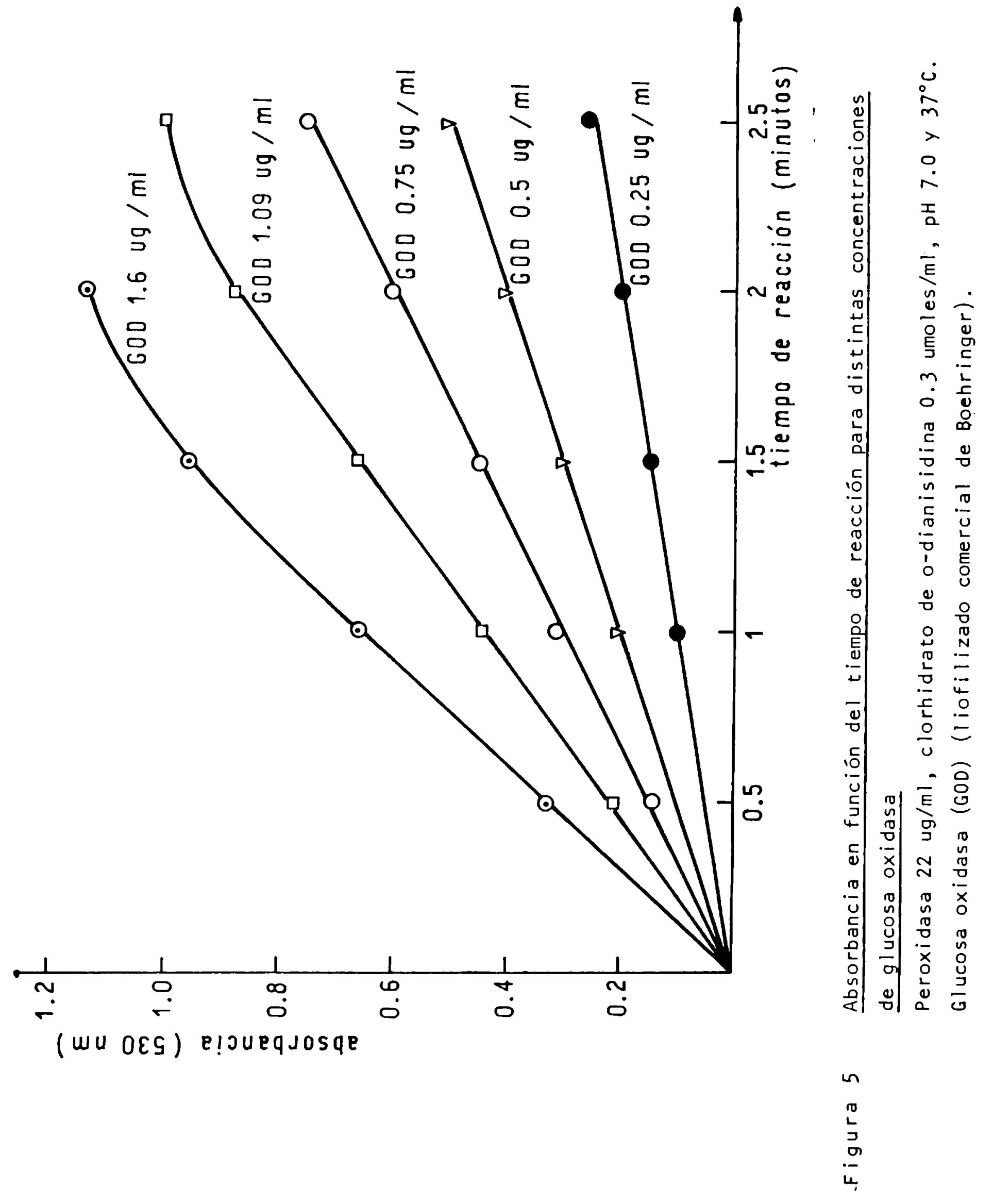




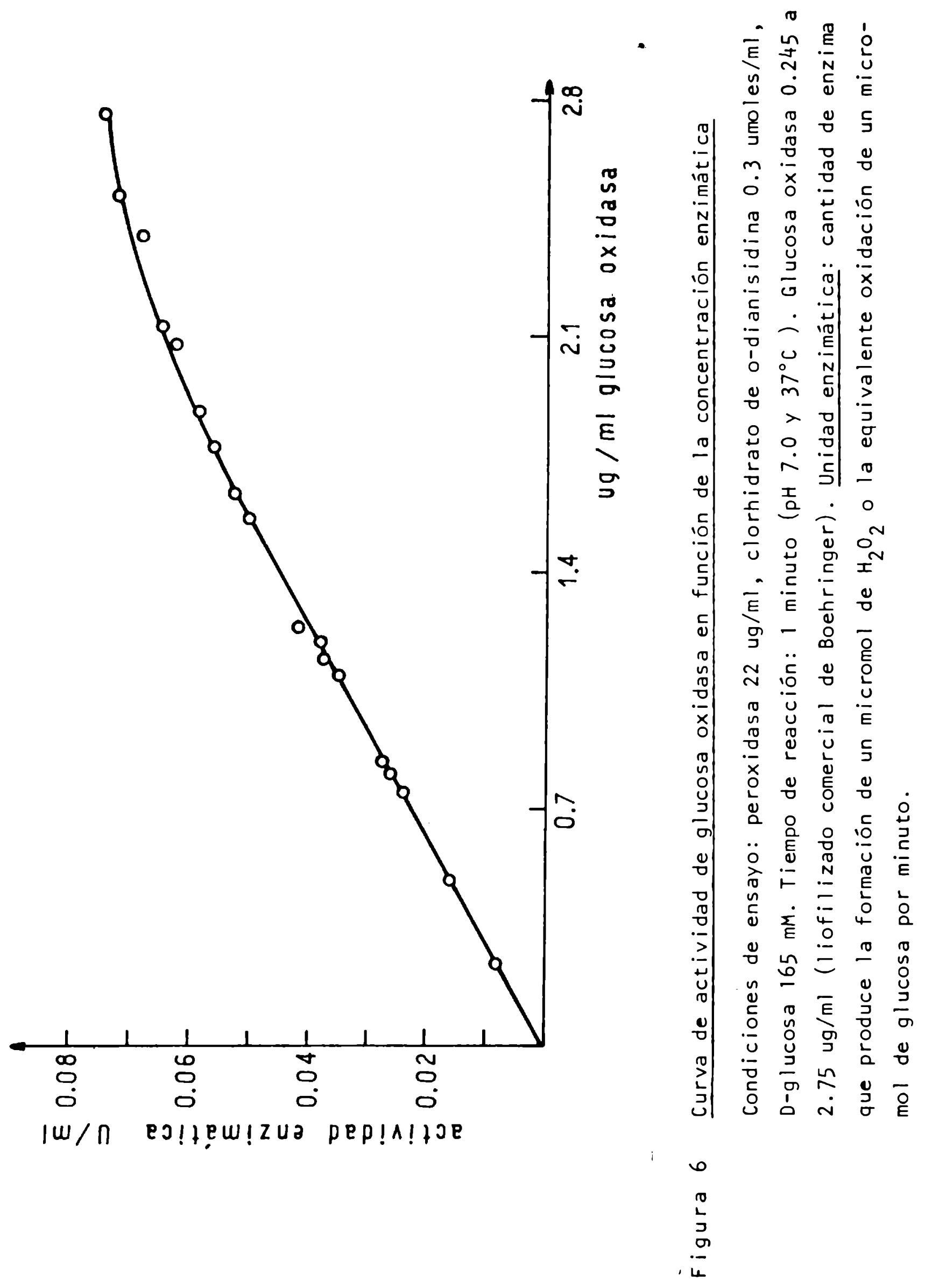




\section{$C U A D A R \quad 0 \quad 4$}

Comparación entre la determinación colorimétrica y manométrica de glucosa oxidasa

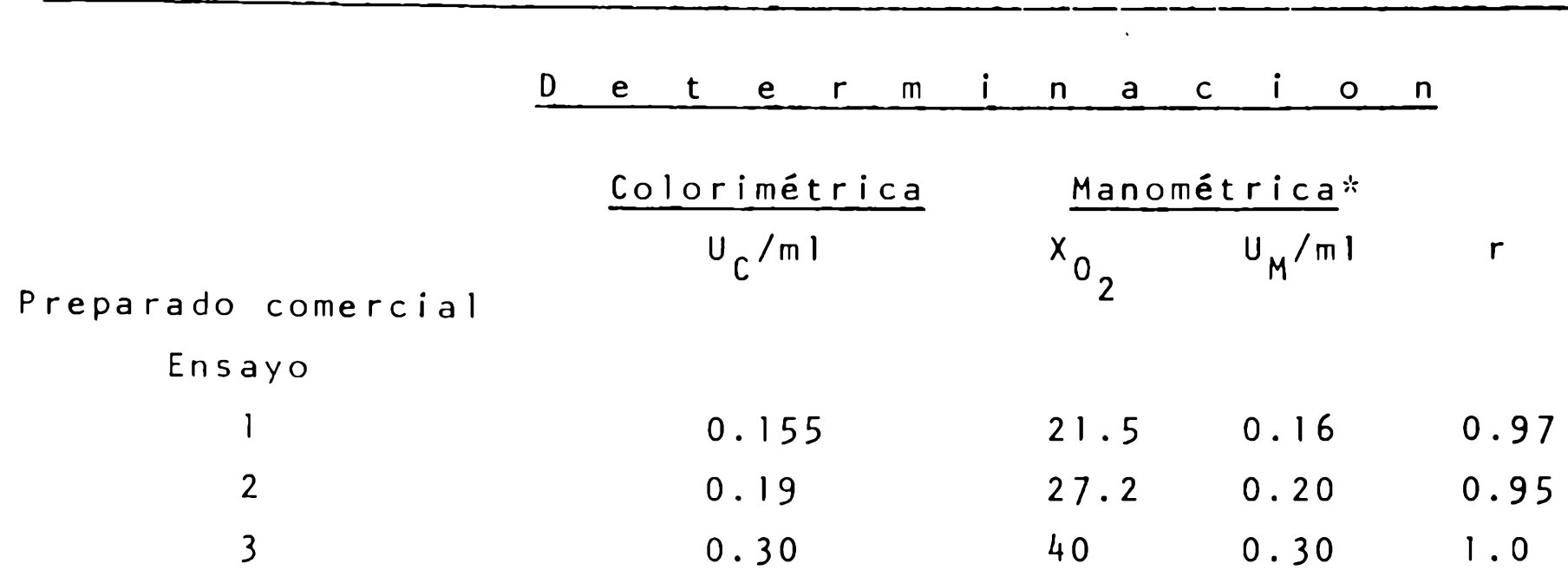

Extractos celulares

Muestra

$\begin{array}{lllll}A & 0.16 & 22.2 & 0.165 & 0.97 \\ \text { B } & 0.18 & 27.3 & 0.20 & 0.90 \\ \text { C } & 0.22 & 31.4 & 0.23 & 0.96 \\ \text { D } & 0.225 & 32.6 & 0.24 & 0.94 \\ \text { E } & 0.395 & 55.1 & 0.41 & 0.96\end{array}$

$U_{C} / m l$ y $U_{M} / m l:$ Actividad de la solución de enzima comercial o del extracto celular calculada por el método colorimétrico y el manométrico respectivamente.

$\mathrm{x}_{\mathrm{O}_{2}}$ : Consumo de oxígeno observado en 30 minutos de medida

$r$ : Relación entre las unidades colorimétricas y las manométricas

Las determinaciones manométricas se realizaron en un equipo Warburg en las condiciones descriptas en Materiales y Métodos (Item 2. 3..11). Como la medida se efectuó en presencia de un exceso de catalasa y etanol debemos considerar que la unidad enzimática representa el consumo de 22.4 ul de $0_{2}$ /minuto. 
métodos es satisfactoria. Para el preparado comerclal las diferen cias en promedio son de $12.6 \%$. Con las muestras de extractos celu lares los valores de actividad tienden a ser ligeramente inferiores para la determinación colorimétrica. El promedio de las diferencias oscila en estos casos en $5.4 \%$. Es interesante mencionar que muestras de los extractos celulares que no mostraban actividad en las condiciones de la medida colorimétrica tampoco acusaban consumo de $\mathrm{O}_{2}$ en la medida manométrica. Este control negativo es un indice de especificidad de la determinación.

\section{Consideraciones finales:}

Los estudios realizados nos permitieron establecer condiciones de ensayo definidas para realizar la determinación colorimétrica. El rango de actividad enzimática que permite evaluar el método, es comparable con otras técnicas de determinación de $\mathrm{H}_{2} \mathrm{O}_{2}$ $(70,81)$. La preparación de los reactivos no ofrece ninguna dificultad a excepción del clorhidrato de o-dianisidina, el cual una vez obtenido debe conservarse protegido de la luz y la humedad pa ra evitar su paulatina oxidación. Por su parte el reactivo peroxi dasa-donor muestra gran estabilidad cuando se lo conserva en glice rol al $40 \% \mathrm{v} / \mathrm{v}$ y a bajas temperaturas, lo cual hace innecesaria su preparación permanente. Con relación a la peroxidasa debemos mencionar que existen preparados con distintos grados de pureza y actividad. La pureza (purity number:PN) se define como el cociente entre la absorbancia del grupo hemo (banda soret a $403 \mathrm{~nm}$ ) y la absorbancia de la proteina $(275 \mathrm{~nm})$. Para un preparado cristalino el PN es de 3.04 . Los preparados comerciales comprenden un ran go que va desde 0.3 a 3.0. En la realización del estudio y durante el desarrollo del trabajo se empleó siempre una peroxidasa con PN 3.0. Cuando hacemos referencia a la concentración de peroxidasa debemos considerar en realidad la actividad de la enzima ya que esta propiedad es la que determina el comportamiento del sistema enzimático indicador. Como la pureza no da información sobre la actividad, la misma fué evaluada por el método del guayacol (item 2.3.11). De esta manera se obtuvo la información necesaria para caracterizar el preparado enzimático empleado en la determinación. Si se emplea preparado de menor actividad será necesario - ajustar la concentración del reactivo de manera de mantener la 
misma actividad peroxidásica.

Como conclusión final debemos mencionar que el método colorimétrico por su sencillez de procedimientos, rapidez y sensibilidad, es sumamente ventajoso frente a las clásicas determinaciones manométricas de consumo de oxígeno o medidas de valoración del ácido glucónico. 
Habiamos mencionado en la introducción de este trabajo que el procedimiento más difundido para extraer la enzima del micelio de Aspergillus Niger es el tratamiento de las células con abrasivos. Esta operación es generalmente realizada con el empleo de equipos mecánicos que permiten agitar la suspensión de células y abrasivo (bolillas de diversos diámetros) en condiciones controladas de proceso. En este sentido nuestra única posibilidad para el procesamiento de las muestras a escala de laboratorio era el empleo de arena y la realización de la operación en forma manual, lo cual por sus caracteristicas hace dificultosa la estandarización. Resultó por lo tanto conveniente ensayar otros tratamientos a fin de observar su eficiencia en la extracción y seleccionar el más apropiado. En la elección de los métodos se tomó en cuenta el trabajo de Zetelaki (109) realizado con otra cepa de Aspergillus Niger y a la disponibilidad de algunos de los equipos en el laboratorio.

Los resultados obtenidos en la experiencia se detallan en el cuadro 5, donde resulta evidente que el tratamiento con arena y la extrusión con la PRENSA-X son muy superiores en eficiencia a los restantes métodos. Con ultrasonido los rendimientos son inferiores en un $60 \%$ con respecto a la PRENSA-X, mientras que la simple agitación del micelio en un homogeinizador a cuchilla - la extracción acuosa de las células previamiente secadas con acetona resultaron totalmente inadecuadas. Considerando estos resultados se decidió utilizar como método de rutina la PRENSA-X ya que con respecto al tratamiento manual con arena, permite realizar la extracción bajo condiciones más controladas de operación.

Es importante señalar que no existen estudios sobre las condiciones óptimas de ruptura de hongos filamentosos con la PRENSA-X. En el caso particular del trabajo de Zetelaki, el autor se limita a evaluar la eficiencia del equipo con la simple observación microscópica de las células, luego del tratamiento. Ante la falta de información adecuada se optó en este ensayo comparativo y para los estudios de medio realizados en frascos, operar la prensa en su forma más simple, es decir realizando un solo prensado o pasaje de la suspensión celular y evaluando la actividad enzimática luego de separar los restos celulares por centrifugación. 


\section{Extracción de glucosa oxidasa del micelio de Aspergillus Niger por diferentes tratamientos}

\begin{tabular}{lcc}
\hline Tratamiento & $\begin{array}{c}\text { Actividad de) } \\
\text { extracto (1) } \\
(\text { valormedio) }\end{array}$ & $\begin{array}{c}\text { coeficiente de } \\
\text { variación (2) } \\
(\%)\end{array}$ \\
\hline Prensa-x & 14.1 & 7.1 \\
Abrasión con arena & 11 & 11.8 \\
Ultrasonido & 5.8 & 11.4 \\
Secado con acetona & 0.7 & 10.8 \\
Homogeinización & 0.27 & \\
\hline
\end{tabular}

(1) Unidades enzimáticas extraídas por gramo de micelio húmedo tratado.

(2) Coeficiente de variación (\%): $\frac{\text { desviación standard }}{\text { valor medio }} \times 100$ ( 4 determinaciones en todos los tratamientos). 


\subsection{Influencia de la composición del medio de cultivo en la}

producción enzimática.

\subsubsection{Producción en el medio base}

Como punto de partida para el estudio del proceso fermentativo se utilizó un medio de cultivo de composición similar al clásico medio de Muller (27) con la diferencia de que al mismo se lo suplementó con $1 \%$ de macerado de maíz (sólido) para estimular la germinación de los esporos y el crecimiento del micelio en la etapa correspondiente al desarrollo del inóculo vegetativo. Con dicho inóculo iniciamos la segunda etapa del proceso en la cual se llevaron a cabo los estudios tendientes a seleccionar las condiciones de medio y operación más favorables para la sintesis de la enzima y que podemos considerarla como "etapa de producción". Antes de comenzar con el estudio de los componentes del medio de cultivo se realizó una primera fermentación con este medio que denominamos base a efectos de observar la relación existente entre la producción de glucosa oxidasa y el crecimiento del hongo. La evolución del pH, peso seco, actividad enzimática del micelio y producción volumétrica obtenidas en esta experiencia inicial se representan en la figura 7. La fermentación muestra un curso caracteristico, el contenido en glucosa oxidasa del micelio es máximo en horas tempranas del cultivo y disminuye progresivamente a medida que se produce el crecimiento de la biomasa. La producción volumétrica de enzima alcanza su valor máximo a la hora 12 donde se obtiene un rendimiento de $470 \mathrm{u} / 1$. Se observa además durante el desarrollo de la fermentación una disminución continua del pH del medio que refleja la acumulación en el mismo de ácidos orgánicos como el glucónico que es el producto resultante de la actividad enzimática.

\subsubsection{Influencia de la fuente de Nitrógeno}

Luego del primer ensayo en el medio base se realizaron una serie de experiencias en las cuales se estudió la influencia de la fuente de nitrógeno sobre la producción de glucosa oxidasa. Con tal fin se ensayaron conjuntamente con el medio base diversos medios conteniendo $\mathrm{Ca}\left(\mathrm{HO}_{3}\right)_{2} \cdot 4 \mathrm{H}_{2} \mathrm{O}$, 

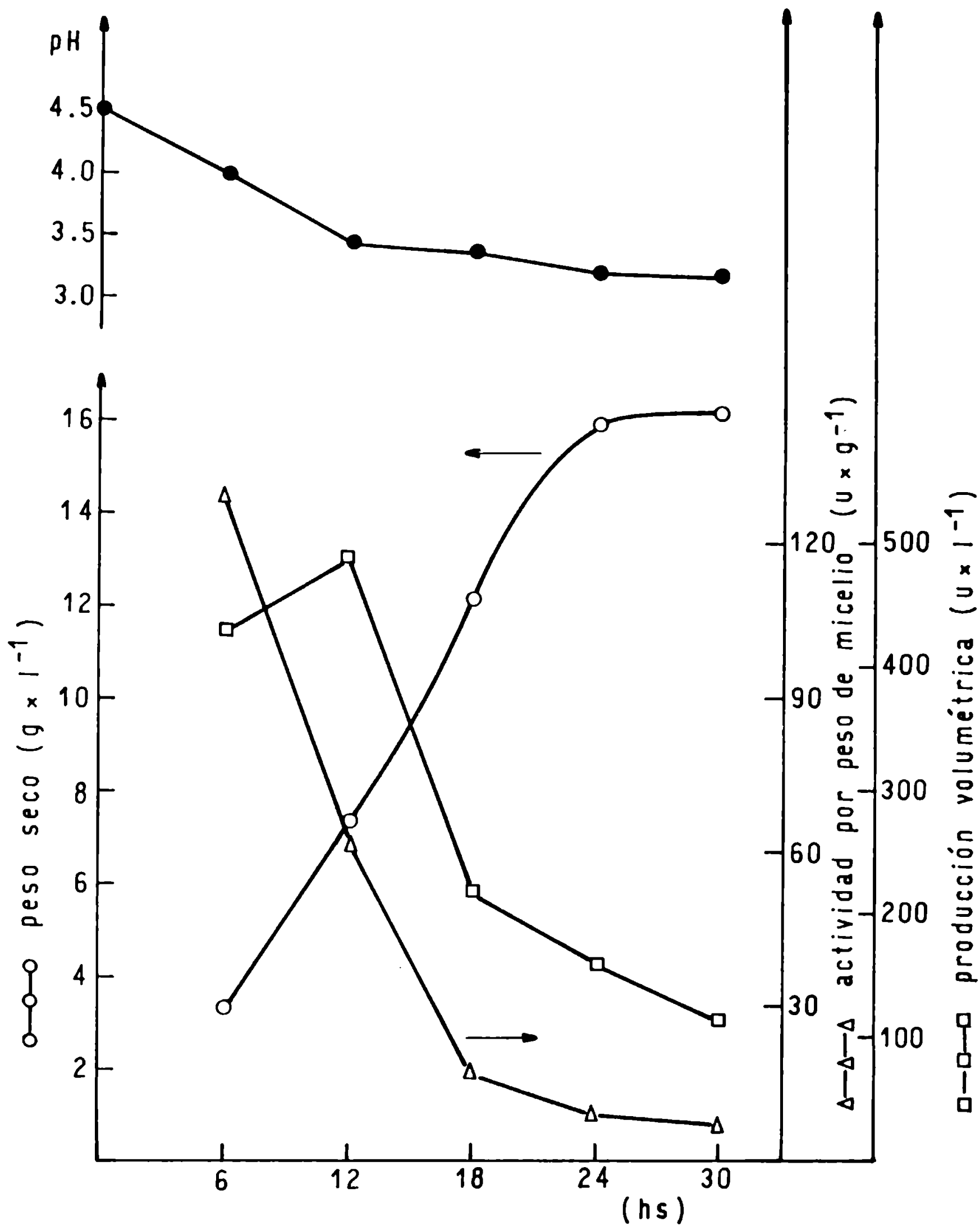

-Figura 7 Producción de glucosa oxidasa por Aspergillus Niger NRRL 3 en el medio base

Composición del medio en 9\%: Sacarosa (Merck) 5.0, macerado de maiz sólido $1.0, \mathrm{Ca}\left(\mathrm{NO}_{3}\right)_{2} \cdot 4 \mathrm{H}_{2} \mathrm{O} 0.20$, ácido citrico monohidrato 0.075 , y sales $\mathrm{KH}_{2} \mathrm{PO}_{4} 0.025$, $\mathrm{MgSO}_{4} \cdot 7 \mathrm{H}_{2} \mathrm{O} 0.025, \mathrm{KCl} 0.025, \mathrm{FeCl}_{3} \cdot 6 \mathrm{H}_{2} \mathrm{O} 0.001$. Condiciones de operación: Frascos de $1000 \mathrm{ml}$ con 100 $\mathrm{ml}$ de medio (V.A.0: 21 mmoles $\left.0_{2} / 1 / \mathrm{h}\right)$. pH inicial 4.50 Temperatura $30^{\circ} \mathrm{C}$. 
Influencia de la fuente de $\mathrm{N}$ en la producción de glucosa oxidasa por Aspergillus Niger NRRL 3

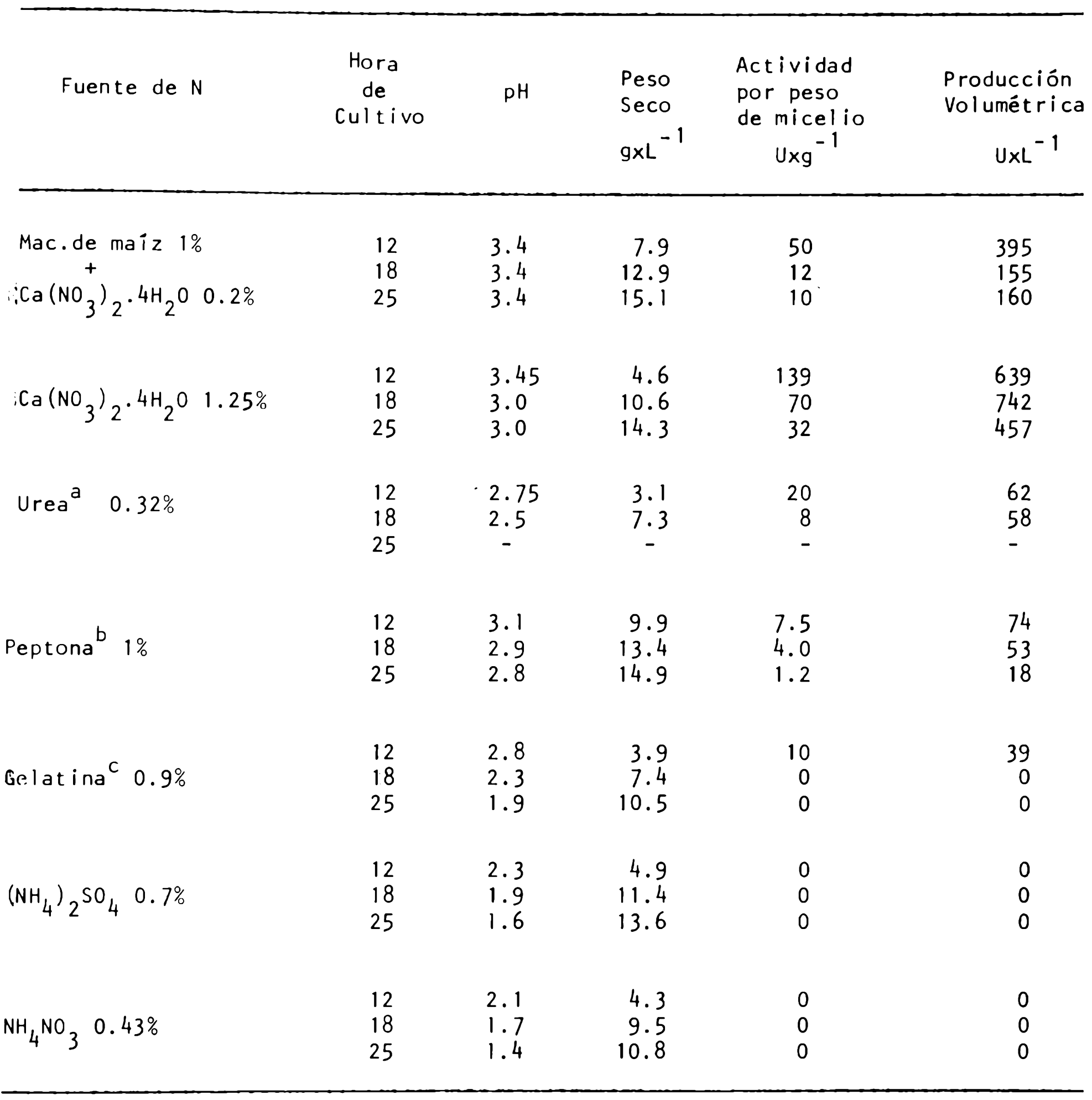

a. Urea $(B D H)$. b. Hidrolizado pancreático de caseina tipo MC7 (INORP)

c. Gelatina (USP).

Las fuentes inorgánicas son de grado analítico.

Además de la fuente de $\mathrm{N}$ los medios contienen en $\mathrm{g}(\%)$ : Sacarosa (Merck) 5.0, Acido citrico monohidrato 0.075 , y Sales: $\mathrm{KH}_{2} \mathrm{PO}_{4} 0.025, \mathrm{MgSO}_{4} \cdot 7 \mathrm{H}_{2} \mathrm{O} 0.025, \mathrm{KCL} 0.025$, $\mathrm{FeCl}_{3} \cdot 6 \mathrm{H}_{2} \mathrm{O} 0.001 . \mathrm{pH}$ inicial $\overline{4.50}$. 
$\mathrm{NH}_{4} \mathrm{NO}_{3}$, $\left(\mathrm{NH}_{4}\right)_{2} \mathrm{SO}_{4}$, urea, gelatina y peptona (hidrolizado pancreático de caseína). Estas fuentes se adicionaron individualmente en una concentración equivalente a $0.15 \%$ de N. Teniendo en cuenta la experiencia previa con el medio base se decldió procesar por cada fuente tres muestras correspondientes a un tiempo de cultivo de 12,18 y 25 horas. Los resultados obtenidos se detallan en el cuadro 6 donde se puede observar que la formación de glucosa oxidasa por el hongo es marcadamente afectada por la naturaleza de la fuente nitrogenada. Resulta claro que el empleo de nitrato de calcio como único componente nitrogenado permite inducir los mayores niveles de enzima en la biomasa obteniéndose una actividad entre 3 y 6 veces superior a la presente en el micelio del medio base que contiene este componente en mucho menor proporción combinado con una fuente compleja como es el macerado de maiz. Si bien el crecimiento celular es inferior, la mayor formación de enzima permite aumentar la producción total de enzima en forma significativa obteniéndose un rendimiento de $742 \mathrm{U/1}$ (hora 18) que representa un incremento del $87 \%$ en relación al medio base. En las restantes fuentes podemos apreciar en cambio una reducida actividad enzimática, inferior incluso a la del medio base, destacándose en particular el comportamiento de las sales de amonio cuya presencia inhibió totalmente la formación de glucosa oxidasa y que presentan además como caracteristica una disminución muy pronunciada en el pH del cultivo.

Por otra parte es interesante destacar de los resultados obtenidos que los valores de actividad enzimática no guardan una directa relación con el crecimiento del hongo. Tal como se deduce de los datos expuestos en el cuadro la concentración de enzima en el micelio puede variar entre amplios límites sin que este efecto tenga, su correspondencia con los valores de peso seco obtenidos en los distintos medios. El ejemplo más claro en este sentido son los resultados obtenidos con las sales de amonio y el nitrato de calcio que a pesar del efecto totalmente contrapuesto en relación a la producción de enzima muestran un crecimiento celular semejante.

\subsubsection{Influencia de la fuente de carbono}

A continuación del estudio efectuado con los componentes nitrogenados y utilizando un medio con $1,25 \%$ de $\mathrm{Ca}\left(\mathrm{NO}_{3}\right)_{2} \cdot 4 \mathrm{H}_{2} \mathrm{O}$ 
Influencia de la fuente de carbono en la producción de glucosa oxidasa por Aspergillus Niger NRRL 3

\begin{tabular}{|c|c|c|c|c|c|}
\hline Fuente de Carbono & $\begin{array}{l}\text { Hora } \\
\text { de } \\
\text { Cultivo }\end{array}$ & $\mathrm{pH}$ & $\begin{array}{l}\text { Peso } \\
\text { Seco } \\
\mathrm{gxL}^{-1}\end{array}$ & $\begin{array}{l}\text { Actividad } \\
\text { por peso } \\
\text { de micelio } \\
\text { Uxg }^{-1}\end{array}$ & $\begin{array}{l}\text { Producc ión } \\
\text { Vol umét rica } \\
\qquad U \times L^{-1}\end{array}$ \\
\hline Sacarosa & $\begin{array}{l}12 \\
18 \\
24\end{array}$ & $\begin{array}{l}3.5 \\
3.1 \\
2.9\end{array}$ & $\begin{array}{r}4.2 \\
9.7 \\
13.6\end{array}$ & $\begin{array}{r}122 \\
81 \\
40\end{array}$ & $\begin{array}{l}512 \\
786 \\
544\end{array}$ \\
\hline Glucosa & $\begin{array}{l}12 \\
18 \\
24\end{array}$ & $\begin{array}{l}3.45 \\
3.40 \\
2.80\end{array}$ & $\begin{array}{r}4.3 \\
8.6 \\
11.6\end{array}$ & $\begin{array}{l}87 \\
86 \\
44\end{array}$ & $\begin{array}{l}374 \\
740 \\
510\end{array}$ \\
\hline Mal tosa & $\begin{array}{l}12 \\
18 \\
24\end{array}$ & $\begin{array}{l}3.60 \\
3.60 \\
2.90\end{array}$ & $\begin{array}{r}3.5 \\
7.1 \\
11.0\end{array}$ & $\begin{array}{l}10 \\
12 \\
11.5\end{array}$ & $\begin{array}{r}35 \\
86 \\
126\end{array}$ \\
\hline Lactosa & $\begin{array}{l}12 \\
18 \\
24\end{array}$ & $\begin{array}{l}3.30 \\
2.90 \\
2.20\end{array}$ & $\begin{array}{l}3.4 \\
5.7 \\
8.0\end{array}$ & $\begin{array}{l}6 \\
8.5 \\
9\end{array}$ & $\begin{array}{l}21 \\
48 \\
72\end{array}$ \\
\hline Almi dón & $\begin{array}{l}12 \\
18 \\
24\end{array}$ & $\begin{array}{l}3.0 \\
2.4 \\
2.3\end{array}$ & $\begin{array}{r}3.5 \\
10.1 \\
13.4\end{array}$ & $\begin{array}{r}0 \\
15 \\
-\end{array}$ & $\begin{array}{r}0 \\
150 \\
-\end{array}$ \\
\hline
\end{tabular}

Sacarosa, Maltosa y Almidón soluble (Merck), Glucosa anhidra (Ciccarelli). Lactosa USP (BDH).

Composición de los medios en $\mathrm{g}(\%)$ : fuente de carbono $5.0, \mathrm{Ca}\left(\mathrm{NO}_{3}\right)_{2} \cdot 4 \mathrm{H}_{2} \mathrm{O} 1.25$, ácido citrico monohidrato 0.075 y Sales: $\mathrm{KH}_{2} \mathrm{PO}_{4} 0.025, \mathrm{MgSO}_{4} \cdot 7 \mathrm{H}_{2} \mathrm{O} 0.025$, $\mathrm{KCl} 0.025 \mathrm{FeCl}_{3} .6 \mathrm{H}_{2} \mathrm{O}$ 0.001. $\mathrm{pH}$ in icial $4: 50$. 
como fuente de nitrógeno, se realizaron experienclas con diferentes fuentes de carbono. Se ensayanon además de la sacarosa (medio base), glucosa, lactosa, maltosa y almidón en una concentración del $5 \%$. Las muestras se tomaron en esta experiencia a las 12,18 y 24 horas de cultivo.

Los datos que se indican en el cuadro 7 muestran que las fuentes más adecuadas para la producción de glucosa oxidasa son sacarosa y glucosa. Ambos azúcares inducen una concentración muy superior de enzima en el micelio y promuevan simultáneamente un crecimiento celular semejante o mayor que los restantes carbohidratos. A su vez se puede apreciar que los rendimientos alcanzados con ambos sustratos es similar obteniéndose en la hora 18 valores de $786 \mathrm{U} / 1$ y $740 \mathrm{U} / \mathrm{l}$ para sacarosa y glucosa respectivamente.

\subsubsection{Influencia de productos que aportan factores de creci- miento.}

Empleando un medio de cultivo con $5 \%$ de sacarosa y $1,25 \%$ de $\mathrm{Ca}\left(\mathrm{NO}_{3}\right)_{2} \cdot 4 \mathrm{H}_{2} \mathrm{O}$ como fuentes de carbono y nitrógeno respectivamente se investigó el efecto sobre la producción de enzima del agregado al medio de factores de crecimiento. Como fuente de factores se empleó el extracto de carne, extracto de levadura, extracto de malta y un proteolizado de levadura obtenido por fermentación del suero de leche con kluyveromyces fragilis. Estos materiales se adicionaron en diversas concentraciones en un rango comprendido entre 0.1 y $0.5 \%$ la experiencia incluyó además un medio testigo sin agregado de estos productos aunque es necesario tener presente que este medio no se encuentra totalmente exento de factores ya que hay un pequeño aporte proveniente del macerado de maíz presente en el inóculo.

En el cuadro 8 se representan los valores obtenidos a la hora 18 de la fermentación donde se puede observar que el agregado de estos productos permitió obtener en todos los casos una mayor concentración de micelio en el medio de cultivo, pero un efecto estimulante sobre la formación de glucosa oxidasa sólo se observa en presencia de $0.1 \%$ de extracto de carne y en menor proporción con la misma concentración de extracto de levadura. De esta manera los rendimientos con respecto al medio testigo se ven incrementados en un $40 \%$ y $13 \%$ 
Influencia del agregado de productos que contienen factores de crecimiento en la producción de glucosa oxidasa por Aspergillus Niger NRRL 3

\begin{tabular}{|c|c|c|c|c|c|}
\hline Fuente de factores & $\%$ & $\mathrm{pH}$ & $\begin{array}{l}\text { Peso } \\
\text { Seco } \\
\mathrm{gxL}^{-1}\end{array}$ & $\begin{array}{l}\text { Actividad } \\
\text { por peso } \\
\text { de micelio } \\
\qquad U_{x g}^{-1}\end{array}$ & $\begin{array}{l}\text { Producción } \\
\text { Vol umétrica } \\
\qquad U_{x L^{-1}}\end{array}$ \\
\hline Sin agregado & - & 2.9 & 9.2 & 80 & 736 \\
\hline Extracto de carne ${ }^{a}$ & $\begin{array}{l}0.1 \\
0.2 \\
0.3 \\
0.5\end{array}$ & $\begin{array}{l}3.25 \\
3.2 \\
3.3 \\
3.3\end{array}$ & $\begin{array}{l}10.2 \\
11.9 \\
11.8 \\
12.4\end{array}$ & $\begin{array}{r}100 \\
61 \\
42 \\
32\end{array}$ & $\begin{array}{r}1020 \\
726 \\
495 \\
396\end{array}$ \\
\hline Extracto de levadurab & $\begin{array}{l}0.1 \\
0.2 \\
0.3 \\
0.5\end{array}$ & $\begin{array}{l}3.25 \\
3.3 \\
3.7 \\
3.9\end{array}$ & $\begin{array}{l}10.1 \\
12.3 \\
12.8 \\
13.0\end{array}$ & $\begin{array}{l}85 \\
45 \\
37 \\
25\end{array}$ & $\begin{array}{l}858 \\
551 \\
473 \\
325\end{array}$ \\
\hline Extracto de malta & $\begin{array}{l}0.1 \\
0.5\end{array}$ & $\begin{array}{l}3.1 \\
3.15\end{array}$ & $\begin{array}{l}10.2 \\
11.2\end{array}$ & $\begin{array}{l}35 \\
41\end{array}$ & $\begin{array}{l}357 \\
460\end{array}$ \\
\hline $\begin{array}{l}\text { Proteolizado de } \\
\text { levadurad }\end{array}$ & 0.1 & 2.80 & 12.8 & 17.5 & 223 \\
\hline
\end{tabular}

a. Extracto de carne en polvo (Britania). b. Extracto de levadura en polvo (Oxold) d. Producto obtenido por fermentación del suero de leche con Kluveromyces fragilis.

Además de la fuente de factores los medios contienen en $\mathrm{g}(\%)$ : Sacarosa (Merck) 5.0, Ca $\left(\mathrm{NO}_{3}\right)_{2} \cdot 4 \mathrm{H}_{2} \mathrm{O} 1.25$, ácido citrico monohidrato 0.075 y Sales: $\mathrm{KH}_{2} \mathrm{PO}_{4}$ $0.025, \mathrm{MgSO}_{4} \cdot 7 \mathrm{H}_{2} \mathrm{O} 0.025, \mathrm{KCl} 0.025, \mathrm{FeCl}_{3} \cdot 6 \mathrm{H}_{2} \mathrm{O} 0.001$. Ph inicial 4.50. Los valores tabulados corresponden a la hora 18 de proceso. 
para el extracto de carne y de levadura respectivamente. Con valores superiores a $0.1 \%$ la concentración de enzima en la biomasa del hongo disminuye siendo la tendencia más pronunciada cuando mayor es la concentración empleada. Como resultado de ello y a pesar del mayor crecimiento celular, la producción volumétrica resulta inferior incluso a la obtenida en el medio testigo. Con extracto de malta y proteolizado de levadura los resultados son también desfavorables obteniéndose en el micelio una reducida. actividad enzimática y por consiguiente los rendimientos son netamente inferiores a los del medio testigo. Cansiderando estos resultados se decidió suplementar el medio de cultivo con $0.1 \%$ de extracto de carne.

\subsubsection{Concentración de nitrato de calcio.}

En el cuadro 9 se consignan los datos obtenidos con diferentes concentraciones de nitrato de calcio en el rango de 0.4 a $1.7 \%$. Se puede apreciar que no existen diferencias significativas en el crecimiento celular con valores superiores a $0.4 \%$ pero la mayor concentración de enzima en el micelio y por lo tanto los mayores rendimientos corresponden a los niveles de $0.8 \%$ y $1.25 \%$. En base a ello la concentración de este componente del medio se ajustó al valor de $0.8 \%$.

\subsubsection{Producción enzimática en el medio modificado}

Los resultados que se fueron obteniendo en el transcurso de las sucesivas experiencias permitieron ir adecuando la composición del medio de cultivo a los efectos de obtener una mayor producción de enzima. Por último con el medio modificado se realizó un proceso final para observar la evolución de los distintos parámetros durante la fermentación decidiéndose además emplear como fuente de carbono sacarosa comercial en reemplazo de la sacarosa de grado analitico ya que la misma mostró en experiencias previas un comportamiento similar. En la figura 8 podemos apreciar la cinética del proceso la cual se asemeja a la descripta en el medio base. El contenido en glucosa oxidasa del micelio se incrementa rápidamente en las primeras horas del cultivo y luego de alcanzar una actividad de $330 \mathrm{U} / \mathrm{g}$ a la hora 6 comienza a disminuir en forma progresiva. La producción de enzima por el hongo continúa hasta la hora 18 donde se alcanza 
Influencia de la concentración de nitrato de calcio en la producción de glucosa oxidasa por Aspergillus Niger NRRL3

$\begin{array}{ccc}\text { \% } \mathrm{Ca}\left(\mathrm{NO}_{3}\right)_{2} \cdot 4 \mathrm{H}_{2} \mathrm{O} & \mathrm{pH} & \text { Pctividad } \\ & \text { Seco } & \begin{array}{l}\text { por peso } \\ \text { de micelio }\end{array} \\ & \mathrm{gxL}^{-1} & \mathrm{U}^{-1}\end{array}$

Producción Volumétrica $U \times L^{-1}$

$\begin{array}{lrrrr}0.4 & 3.25 & 9.1 & 86 & 782 \\ 0.6 & 3.25 & 9.9 & 100 & 990 \\ 0.8 & 3.10 & 10.5 & 128 & 1344 \\ 1.25 & 3.30 & 9.9 & 122 & 1207 \\ 1.70 & 3.35 & 10.5 & 102 & 1071\end{array}$

Además del nitrato de calcio los medios contienen en $\mathrm{g} \%$ : Sacarosa (Merck) 5.0; extracto de carne 0.1 ; ácido citrico monohidrato 0.075 , y Sales: $\mathrm{KH}_{2} \mathrm{PO}_{4} 0.025$, $\mathrm{MgSO}_{4} \cdot 7 \mathrm{H}_{2} \mathrm{O} 0.025, \mathrm{KCl} 0.025, \mathrm{FeCl}_{3} \cdot 6 \mathrm{H}_{2} \mathrm{O}^{\circ} 0.001 . \mathrm{pH}$ inicial 4.50.

Los valores tabulados corresponden a la hora 18 de proceso. 


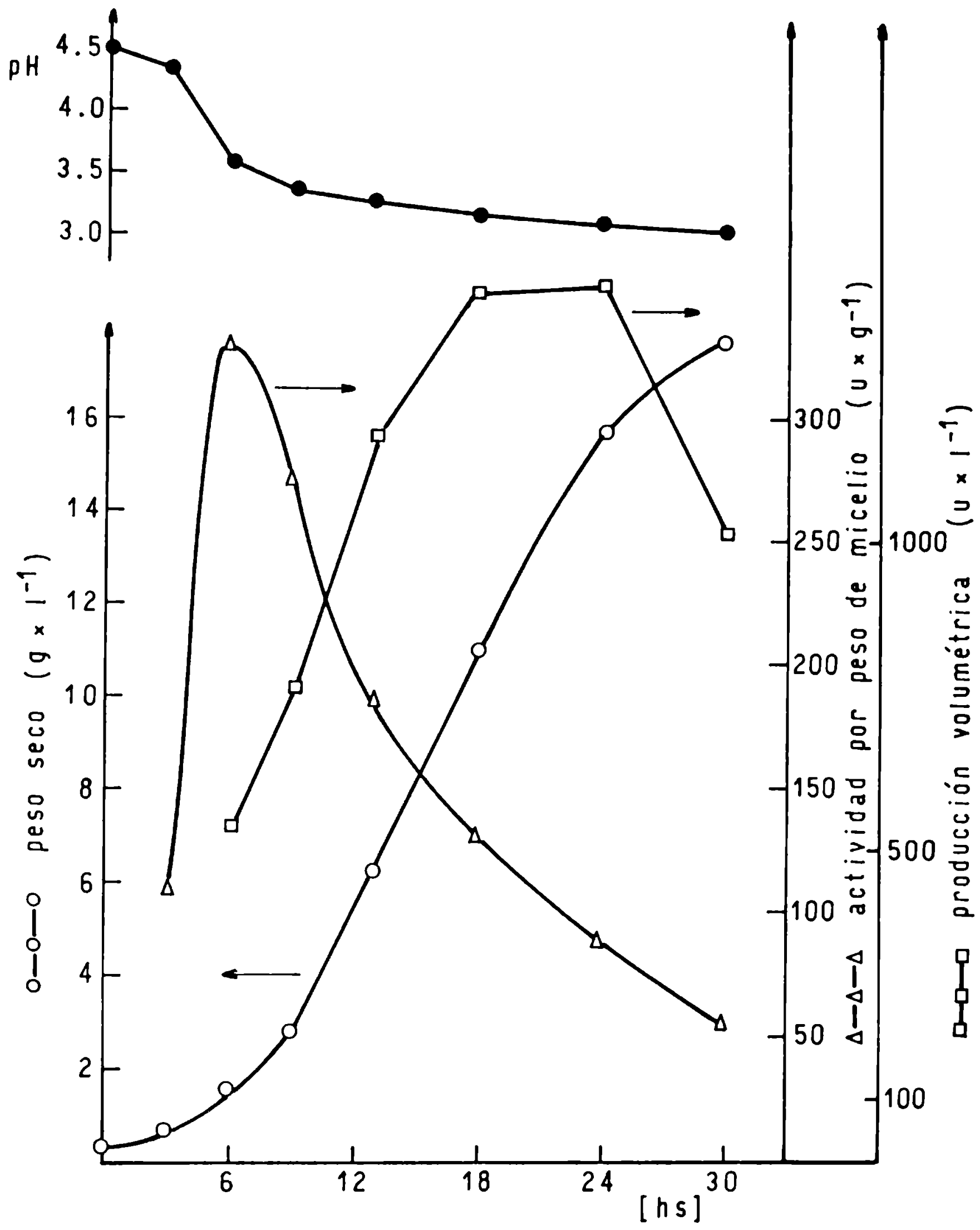

Figura 8 Producción de glucosa oxidasa por Aspergillus Niger NRRL 3 en el medio modificado

Composición del medio en $\mathrm{g} \%$ : Sacarosa comercial 5.0 ,

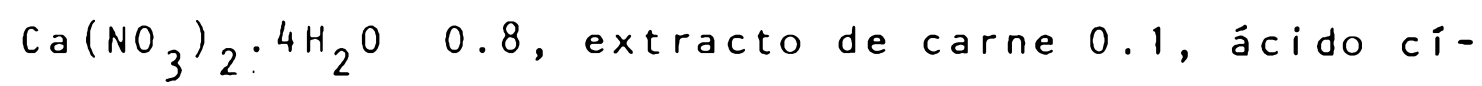
trico monohidrato 0.075 y sales: $\mathrm{KH}_{2} \mathrm{PO}_{4} 0.025$, $\mathrm{KCl} 0.025, \mathrm{MgSO}_{4} \cdot 7 \mathrm{H}_{2} \mathrm{O} 0.025, \mathrm{FeCl}_{3} \cdot 6 \mathrm{H}_{2} \mathrm{O} 0.001$. Condiciones de operación: Idem figura 7 


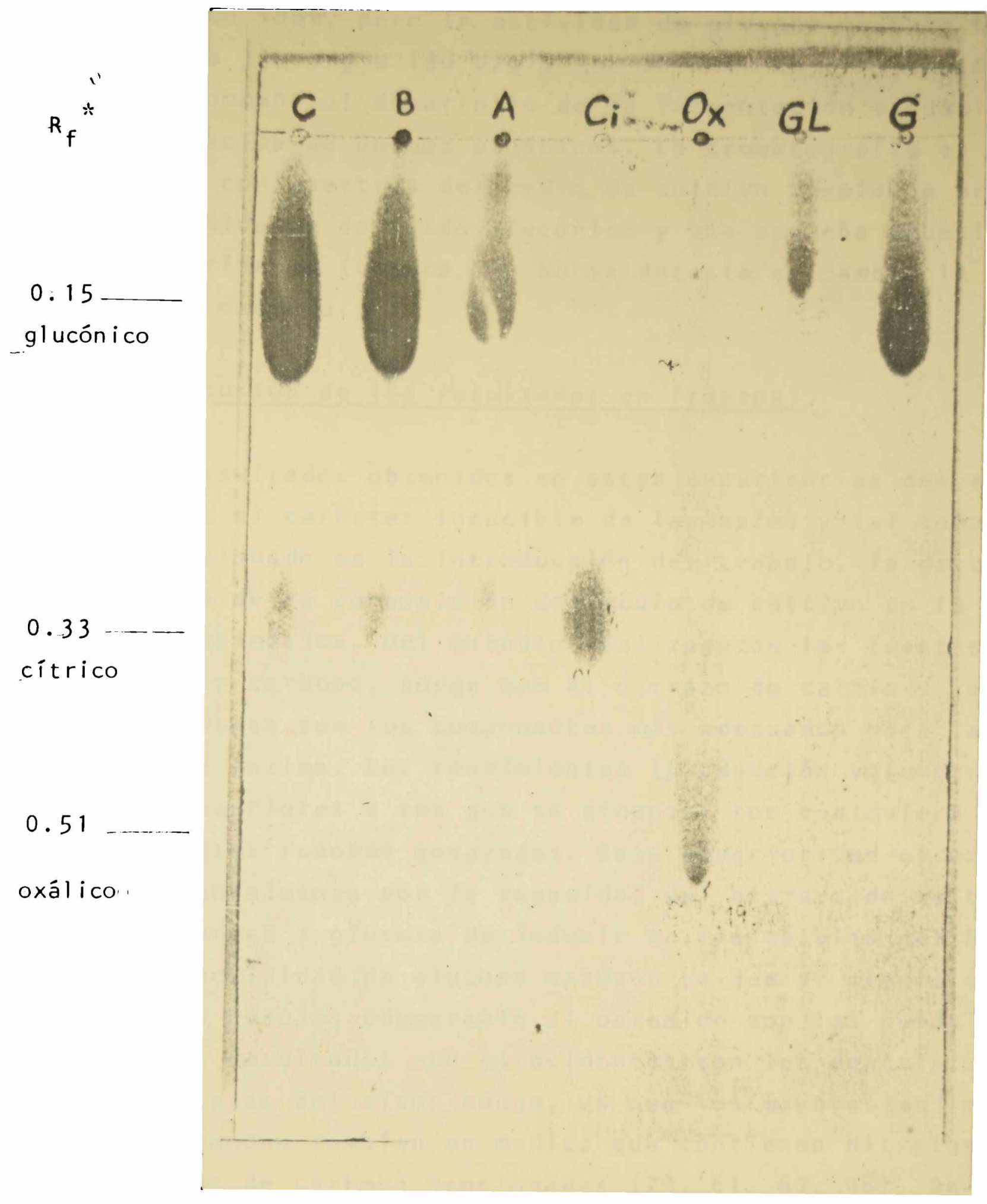

Figura 9: Cromatografía en papel de ácidos orgánicos en muestras del medio de cultivo modificado correspondientes a la hora 18 (A), 24 (B) y 30 (C) de la fermentación. Acidos patrones: glucónico (G), gluconolactona (GL), oxálico $(0 x)$, citrico (Ci). Siembra 100 ug.

* Rf: Relación entre la distancia del punto de siembra al centro de la mancha y la distancia del punto de siembra al frente del solvente. 
un rendimiento de $1400 \mathrm{U} / \mathrm{l}$. En dicho instante y con respecto a la hora 6 la biomasa se ha incrementado de $1.6 \mathrm{~g} / 1$ a $11 \mathrm{~g} / 1$, es decir un $580 \%$, pero la actividad de glucosa oxidasa ha dís minuido de $330 \mathrm{U} / \mathrm{g}$ a $130 \mathrm{U} / \mathrm{g}$ o sea un $60 \%$. La disminución de $\mathrm{pH}$ que acompaña al desarrollo de la fermentación es debido a la acumulación de ácidos orgánicos. La cromatografía en papel realizada con muestras del medio de cultivo revela la presencia predominante de ácido glucónico y una pequeña acumulación de ácido citrico (figura 9). No se detecta en cambio la presencia de oxálico.

\subsubsection{Discusión de los resultados en frascos:}

Los resultados obtenidos en estas experiencias demuestran claramente el carácter inducible de la enzima y tal como se había mencionado en la introducción del trabajo, la marcada influencia de la composición del medio de cultivo en la producción enzimática. Del estudio realizadocon las fuentes de nitrógeno y carbono, surge que el nitrato de calcio y la sacarosa o glucosa son los componentes más adecuados para la producción de enzima. Los rendimientos (producción volumétrica) son muy superiores a los que se alcanzan con cualquiera de las restantes fuentes ensayadas. Esta superioridad es motivada fundamentalmente por la capacidad del nitrato de calcio y de la sacarosa o glucosa de inducir en las células del hongo una alta actividad de glucosa oxidasa ya que el crecimiento microbiano resulta comparable al obtenido con las demás fuentes. Estos resultados son coincidentes con los descriptos para otras cepas del mismo hongo, ya que los mayores rendimientos se alcanzan tambien en medios que contienen nitratos y las fuentes de carbono mencionadas $(29,61,67,98)$. De acuer do a ciertos trabajos el calcio ejerce un efecto favorable en la producción de glucosa oxidasa $(28,61)$. Esto sugiere que en el comportamiento del nitrato de calcio debemos considerar ade más de la naturaleza de la fuente nitrogenada una posible acción estimulante promovida por la presencia del catión. Por otra parte habiamos destacado entre las fuentes de nitrógeno la acción represiva de las sales de amonio. Esta acción adver sa puede ser atribuida a un efecto sobre el pH del medio, ya que en la bibliografía se puede apreciar que la producción de enzima se reduce en forma pronunciada o se inhibe totalmente cuando la acidificación del cultivo es excesiva $(17,61)$. 
Además y tal como lo demuestran los trabajos de Franke (19) y de Drews (17), la enzima puede ser produclda en medios que contienen amonio si la acidez es neutralizada. Podemos decir entonces que la acción represiva del amonio es más bien un efecto de carácter general motivado por la influencia negati va que esta fuente tiene sobre el pH del medio. Es interesante mencionar que el mismo fenómeno ha sido observado en cepas de Penicillum (65).

En relación a las fuentes de carbono los rendimientos enzimáticos que obtuvimos fueron similares con sacarosa y glucosa. En la fermentación glucónica el carbohidrato utilizado es generalmente glucosa, la cual es directamente convertida en ácido glucónico por la acción enzimática. En cambio cuando el proceso es enfocado hacia la producción de glucosa oxidasa, la sacarosa ha mostrado en muchas oportunidades una acción inductora muy superior a la glucosa $(28,29)$. En nuestro caso particular el comportamiento de ambos carbohidratos fué semejante y tal como se menciona en el trabajo de Franke, estas diferencias dependen de la cepa empleada (29). Cabe mencionar que los resultados obtenidos con el empleo de sacarosa, ha motivado que tanto en Aspergillus como en penicilum, se estudie a la melaza como una fuente alternativa del carbohidrato (65, 69, 106). Otro aspecto a destacar de los resultados obtenidos con estos componentes del medio es que el crecimiento del hongo no implica necesariamente la formación de glucosa oxidasa. Este hecho es consistente con el carácter inducible de la enzima y con la función que aparentemente desempeña la fermenta ción glucónica en la fisiología del microorganismo. Como se sabe la producción del ácido orgánico no está integrada a rutas metabólicas indispensables para el desarrollo del micelio sino que representa un camino subsidiario del metabolismo de los glúcidos. En este sentido los ensayos realizados con productos que aportan factores de crecimiento ponen también en evidencia la compleja relación que existe entre el crecimiento del hongo y la producción de la enzima. El enriquecimiento del medio de cultivo con bajas concentraciones de extracto de carne y de levadura $(0.1 \%)$ permitió incrementar simultáneamente la concentración de micelio y la actividad enzimática consiguiendo de esta manera un aumento global de los rendimientos. En cambio con mayores concentraciones se observa un efecto contrapuesto,es decir una mayor formación de biomasa pero una 
progresiva disminución en la actividad del micelio lo cual indica que bajo estas condiciones se produce una acción represiva sobre la sintesis de glucosa oxidasa. Resultados semejantes fue ron obtenidos por Malanowska (55) quien observó que los medios de cultivo que promovian altos rendimientos de micelio, llevaban como contrapartida una reducida formación de glucosa oxidasa. Podrímos decir entonces que la concentración óptima de estos factores en el medio de cultivo representa un compromiso entre los requerimientos que estimulan por un lado el crecimiento del hongo y aquellos bajo los cuales se favorece la producción de enzima. En este sentido la concentración de estos factores debe seleccionarse cuidadosamente ya que los rendimientos dependen del balance que se pueda establecer entre ambos parámetros. Por otra parte los resultados obtenidos con diferentes concentraciones de la fuente de nitrógeno, serian consistentes con el efecto estimulante del calcio que se mencionara anteriormente ya que el contenido en glucosa oxidasa de la biomasa se incrementa con la concentración de la fuente hasta un nivel óptimo. Su efecto sobre el crecimiento es en cambio poco significativo.

La finalidad del estudio realizado fué obtener información sobre la influencia del medio de cultivo en la producción de glucosa oxidasa. Como se puede deducir de los resultados obtenidos la correcta selección de los componentes del medio permi te incrementar en forma significativa los rendimientos de la fermentación. Con el medio base que utilizamos en una experien cia inicial se obtenía en el momentode mayor producción volumétrica (hora 12), 7,4 g/l de micelio seco con una actividad de $64 \mathrm{U} / \mathrm{g}$ lo que significa un rendimiento de $472 \mathrm{U} / \mathrm{l}$. A partir de los cambios introducidos en la composición de dicho medio se pudo alcanzar una concentración de biomasa de $11 \mathrm{~g} / 1$ contenien do $130 \mathrm{U} / \mathrm{g}$ lo cual implica un rendimiento de $1400 \mathrm{U} / \mathrm{l}$ es decir un incremento de aproximadamente el $200 \%$. Si bien el tiempo de fermentación es mayor (18 hs) la productividad aumenta por la mayor producción en un $100 \%$. La cinética de la fermentación en este medio modificado muestra como principal caracteristica que la concentración de glucosa oxidasa en el micelio varía continuamente durante la etapa de producción. La máxima actividad se alcanza a la hora 6 cuando la concentración celular es aún escasa $(1,63 \mathrm{~g} / 1)$ y luego disminuye en forma progresiva. Cuando las células cesan de producir enzimar, es decir, 
cuando la producción volumétrica alcanza su máximo valor, la actividad con respecto a la hora 6 es un $60 \%$ inferior. Estos cambios pueden interpretarse considerando que la velocidad con que el micelio sintetiza la enzima en relación al crecimiento global de la bigmasa, varía continuanmente con la evolución del cultivo. Habíamos mencionado en la introducción que las cepas de Aspergillus Niger podian producir diversos ácidos orgánicos como glucónico, citrico u oxálico dependiendo entre otras factores de las condiciones de cultivo. La cromatografía realizada con muestras del medio modificado revela la presencia predominante de ácido glucónico lo cual pone de manifiesto que las condiciones de medio seleccionadas son adecuadas para el desarrollo de esta fermentación. 


\subsection{Estudios con la PRENSA-X.}

En una experiencia previa al estudio sobre la influencia del medio de cultivo en la producción enzimática, habiámos seleccionado a la PRENSA-X como método para desintegrar las célúlas del hongo y extraer de esta manera la enzima del micelio. Mencionamos también que ante la falta de información adecuada vinculada al empleo del equipo en la ruptura de hongos filamentosos, habiamos adoptado procesar las muestras realizando un simple pasaje o prensado de la suspensión celular. Al finalizar las experiencias en frascos que nos permitieron seleccionar un medio más adecuado para la producción de glucosa oxidasa, se consideró apropiado estudiar con mayor detalle el proceso de ruptura celular con la PRENSA-X a efectos de establecer condiciones óptimas para nuestro microorganismo y poder evaluar con mayor exactitud la cantidad de enzima producida. La variable investigada fué el número de pasajes, manteniendo constante otras condiciones como la temperatura $\left(-28^{\circ}\right)$ y la concentración celular.

Para la experiencia se realizó una fermentación con el medio modificado recolectando el micelio a las 18 horas de proceso que corresponde de acuerdo a los anteriores resultados al momento de mayor producción volumétrica de enzima. Se ensayaron (por duplicado) desde uno a cinco pasajes empleando en cada caso 1 gramo de micelio húmedo en $25 \mathrm{ml}$ de agua destilada. Cada muestra se sometió a un determinado número de pasajes luego de lo cual fué centrifugada para determinar en el sobrenadante la actividad de glucosa oxidasa y también de catalasa a fin de comparar los resultados con la enzima que complementa la actividad de glucosa oxidasa en la célula del hongo. El grado de ruptura celular obtenido se evaluó midiendo la concentración de proteina en el extracto y refiriendo este valor al contenido total de proteina del micelio, es decir el efecto desintegrativo, se cuantificó como porcentaje de proteina solubilizada.

Los resultados obtenidos se representan en la figura 10 , donde se observa claramente que el procentaje de proteina solubilizada y la actividad de glucosa oxidasa se incrementan siguiendo una tendencia similar.hasta alcanzar un máximo luego de tres pasajes. La proteina soluble representa en esa condición un $73 \%$ del total presente en el micelio y la máxima actividad de glucosa oxidasa en el extracto $(1.8 \mathrm{U} / \mathrm{ml})$ implica un 
incremento del $38 \%$ respecto al valor obtenido con un solo pasaje $(1.3 \mathrm{U} / \mathrm{ml})$. Correlacionando la actividad enzimática con la concentración de proteina soluble obtenemos valores de actividad especifica de $0.55,0.60,0.62$ y 0.59 (U/ma de oroteina) para las muestras procesadas de uno a cuatro pasajes respectivamente. Como vemos este parámetro se mantiene aproximadamente constante y sería consistente con la posible localización citoplasmática de la enzima $(53,78)$. Coincide además que los valores máximos se obtienen con el mismo número de pasajes, lo cual indica que el máximo efecto desintegrativo conduce también a la mayor actividad de glucosa oxidasa en el extracto. Estos resultados muestran una excelente correlación con el grado de ruptura celular que es posible apreciar mediante la observación microscópica. Como ejemplo podemos ver en la fotografía el efecto de ruptura provocado en el micelio luego de tres pasajes de la suspensión celular. Por su parte la catalasa muestra un perfil diferente aumentando la actividad en forma casi proporcional hasta cuatro pasajes. Estas diferencias podrían atribuirse a una diferente localización de la enzima en la estructura de la hifa.

Queda por establecer si la máxima actividad de glucosa oxidasa determinada en el extracto representa en realidad la actividad total presente en la suspensión de micelio o bien como suele suceder cuando se obtienen homogeneizados de células, una cierta fracción sedimenta durante la centrifugación. Para evaluar este aspecto se midió la enzima en la suspensión celular proveniente de las muestras que se procesaron mediante tres, cuatro y cinco pasajes. El valor medio de estas determinaciones resultó de $2.06 \mathrm{U} / \mathrm{ml}$ no encontrándose diferencias según el núme ro de pasajes, lo cual permite suponer que el repetido prensado no afecta la actividad de la enzima. De acuerdo a este valor el máximo porcentaje de glucosa oxidasa en el extracto, representa un $90 \%$ del total presente en la suspensión de micelio. Estos resultados indican entonces que una pequeña fracción de la enzima sedimenta durante la centrifugación adsorbida probablemente a componentes estructurales del micelio. Es interesante destacar que la actividad de glucosa oxidasa en el sobrenadante no es afectada por las condiciones de centrifugación, es decir, los mismos valores se obtienen si la muestra es sucesivamente centrifugada desde condiciones moderadas $(1700 \mathrm{~g} \times 10$ minutos) hasta $100.000 \mathrm{~g}$ durante 2 horas, Esto significa que la enzima 
presenta en este aspecto un comportamiento similar a las enzlmas que se localizan en la fracción soluble del citoplasma.

Finalmente debemos considerar los rendimientos del proceso fermentativo en función de los resultados obtenidos en el presente estudio. Es evidente que en las condiciones óptimas de extracción con la PRENSA-X (tres o más pasajes) los valores de actividad enzimática que evaluamos en el extracto representan un incremento del $28 \%$ con relación a las condiciones inicialmente establecidas para la operación del equipo. Más aún para tener un valor más exacto del contenido en glucosa oxidasa del hon go debemos debemos considerar el porcentaje de actividad que se pierde durante la centrifugación. En este sentido las diferencias aumentan al $35 \%$ y de acuerdo a los datos obtenidos con respecto al peso seco de células de la suspensión, la actividad del micelio calculada en estas condiciones resultó de $198 \mathrm{U} / \mathrm{g}$. Desde èl punto de vista de la producción volumétrica y de acuerdo a la concentración celular del cultivo obtenida con un frasco testigo $(11.8 \mathrm{~g} / 1)$ los rendimientos del proceso son de $2300 \mathrm{U} / \mathrm{l}$.

Por su parte la actividad del micelio calculada según los valores encontrados en las muestras con un solo pasaje resultó de $125 \mathrm{U} / \mathrm{g}$ lo cual es coincidente con los datos obtenidos en los anteriores procesos. De esta manera el estudio realizado nos permitió evaluar con mayor exactitud los rendimientos de la fermentación mediante un correcto manejo del proceso de ruptura celular y con un conocimiento más detallado de la extracción enzimática. Considerando estos resultados y para los estudios de producción en tanques agitados se decidió entonces determinar la actividad de glucosa oxidasa en la suspensión total de micelio, luego de su procesamiento con tres pasajes por el equipo. 


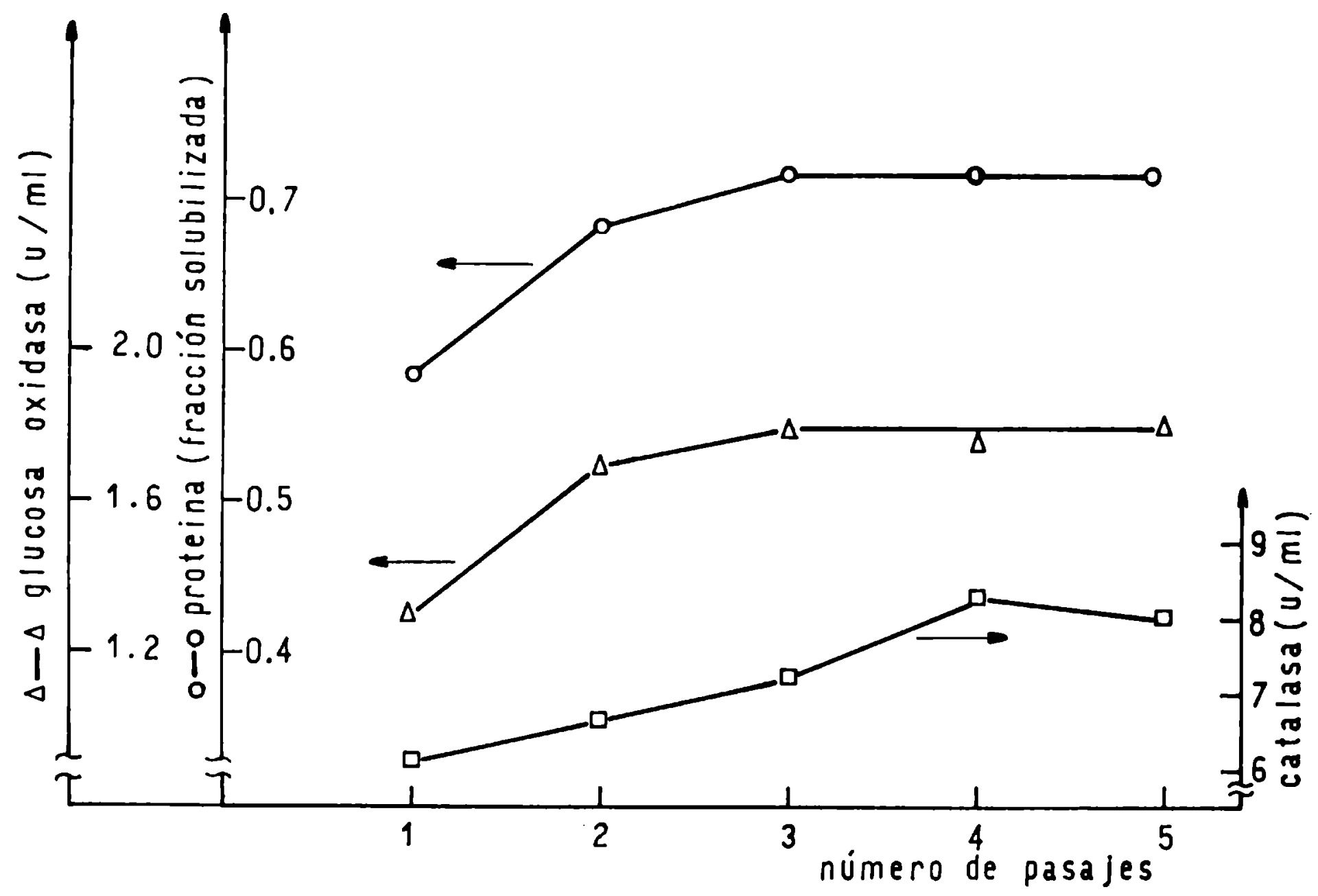

Figura 10: Efecto del número de pasajes con la PRENSA-X en la extracción de glucosa oxidasa, catalasa y en la fracción de proteina solubilizada del micelio de Aspergillus Niger.

Temperatura de la muestra:-28 $\mathrm{C}$. Concentración celular: $1 \mathrm{~g}$ de micelio húmedo ( $26 \%$ de materia seca) en $25 \mathrm{ml}$ de agua destilada. La concentración de proteinas de las muestras es del $4.03 \%$ que representa un $38 \%$ en relación al peso seco de células.

La actividad de las enzimas* y la proteina solubilizada se determinaron en el sobrenadante luego de separar los restos celulares a $20.000 \mathrm{~g}$ durante 20 minutos $(13.000 \mathrm{rpm}$ en Rotor Sorvall SS-34).

* La actividad de catalasa se determinó por el método espectrofotométrico de Sizer and Beers (91). 


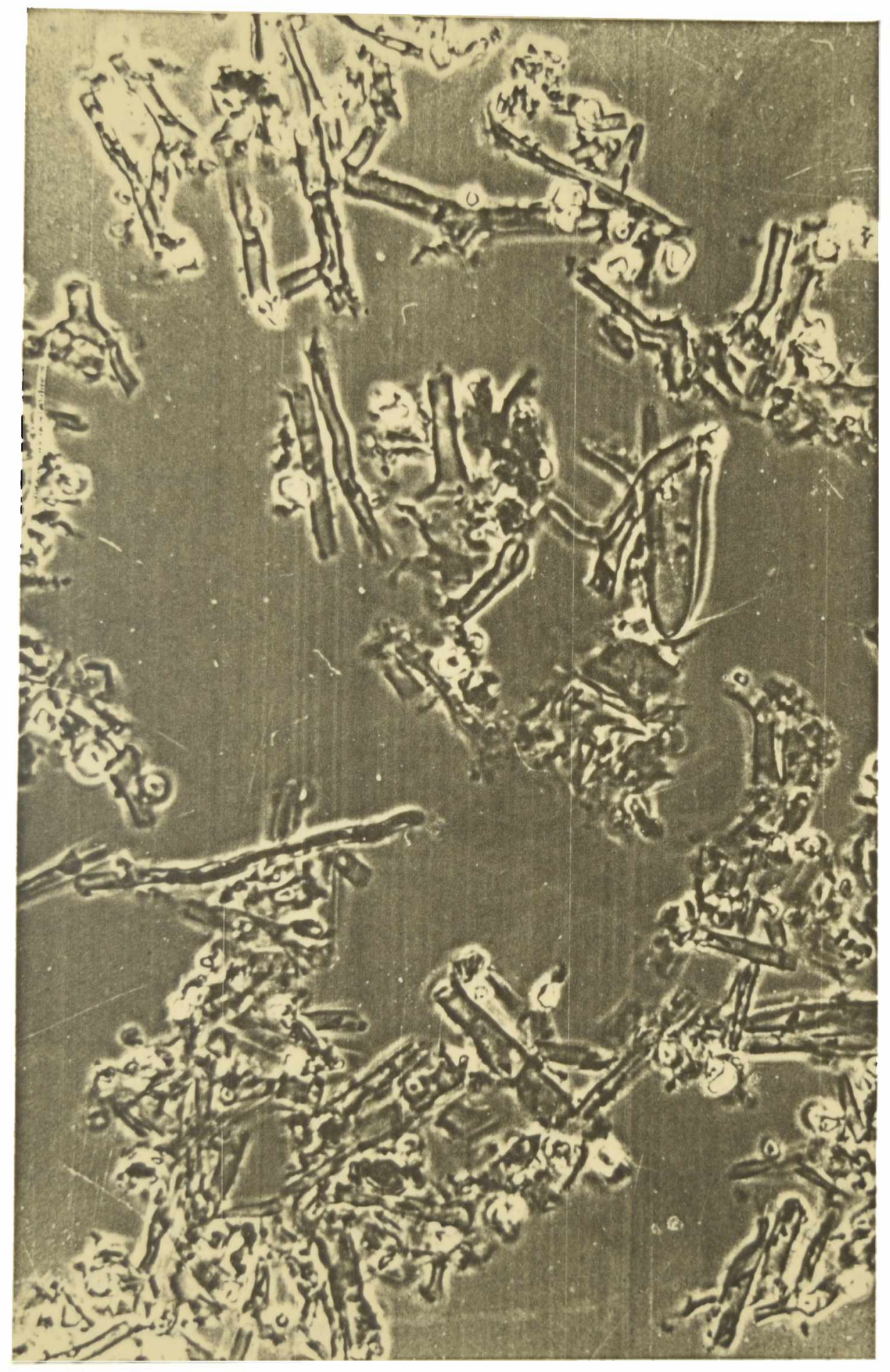

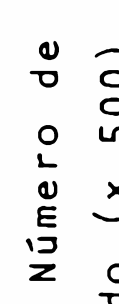

. 0

니로도

. 5

c 0

n

-

미 우

ป

品

(1)

$\therefore$

$\therefore \quad u$

ए)

u

E

- $)$

(1)

م 0

ㄴ

$\times \quad$ ن

$\infty$

in

C 1

$\stackrel{0}{2}$

a

-

- i

ข

- E

$>1$

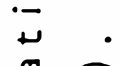

เ

का

$\stackrel{1}{2}$

$\therefore$

n $m$

o.

v

임ำ

u

(1) n

世 


\subsection{ESTUDIOS EN TANQUES AGITADOS}

Utilizando el medio de producción seleccionado de los ensayos en frascos agitados (medio modificado), se realizó la etapa final del trabajo en la cual se emplearon fermentadores con agitación mecánica y donde se investigó el efecto sobre la producción de enzima de determinadas variables de operación y de la concentración de la fuente de carbono. Tal como se describiera en materiales y métodos (item 2.4.2) el volumen de medio empleado en esta escala fue de cuatro litros y el caudal de aire que se mantuvo sin modificación de 1 litro/litro de medio/minuto ( $v \vee m)$. Para iniciar las experiencias se estableció una agitación de $550 \mathrm{rpm}$ correspondiendo bajo estas condiciones una velocidad de absorción de oxígeno (V.A.0.) de $71.3 \mathrm{~m}$ moles $0_{2} \times 1^{-1} \times \mathrm{h}^{-1}$.

\section{$3 \cdot 5 \cdot 1$ Inóculo}

Las primeras fermentaciones realizadas en tanque mostraron a diferencia de lo que ocurría en los frascos, un escaso desarrollo del micelio precedido generalmente por un periodo lag pronunciado y la aparición aunque variable de una intensa pigmentación amarilla. En algunos ensayos el crecimiento del hongo directamente no se producía. Como este hecho impedía realizar las fermentaciones se buscó la forma de subsanar el inconveniente cuya causa nos era desconocida. Luego de ensayar infructuosamente varias alternativas como por ejemplo modificar las condiciones de esterilización o la agitación del cultivo, se decidió estudiar el tipo de inóculo que empleábamos para sembrar el tanque de fermentación. Una de las causas que motivaron dicho estudio fue la observación frecuentemente realizada en las fermentaciones "fallidas" sobre la morfología de los pellets. Luego de transcurridas algunas horas de proceso los mismos presentaban un aspecto muy compacto a diferencia de la naturaleza laxa tipica de los procesos en frascos. Se supuso entonces que alguna relación podía existir entre esta forma de crecimiento $y$ las condiciones de trabajo en tanque que hacian desfavorable el crecimiento del hongo. Se buscó por lo tanto modificar esta forma de crecimiento lo cual fue logrado incrementando la concentración de esporos con que se sembraba el medio base destinado a obtener el inóculo vegetativo. Al aumentar el número de esporos de $10^{4} / \mathrm{ml}$ a $10^{6} / \mathrm{ml}$ 


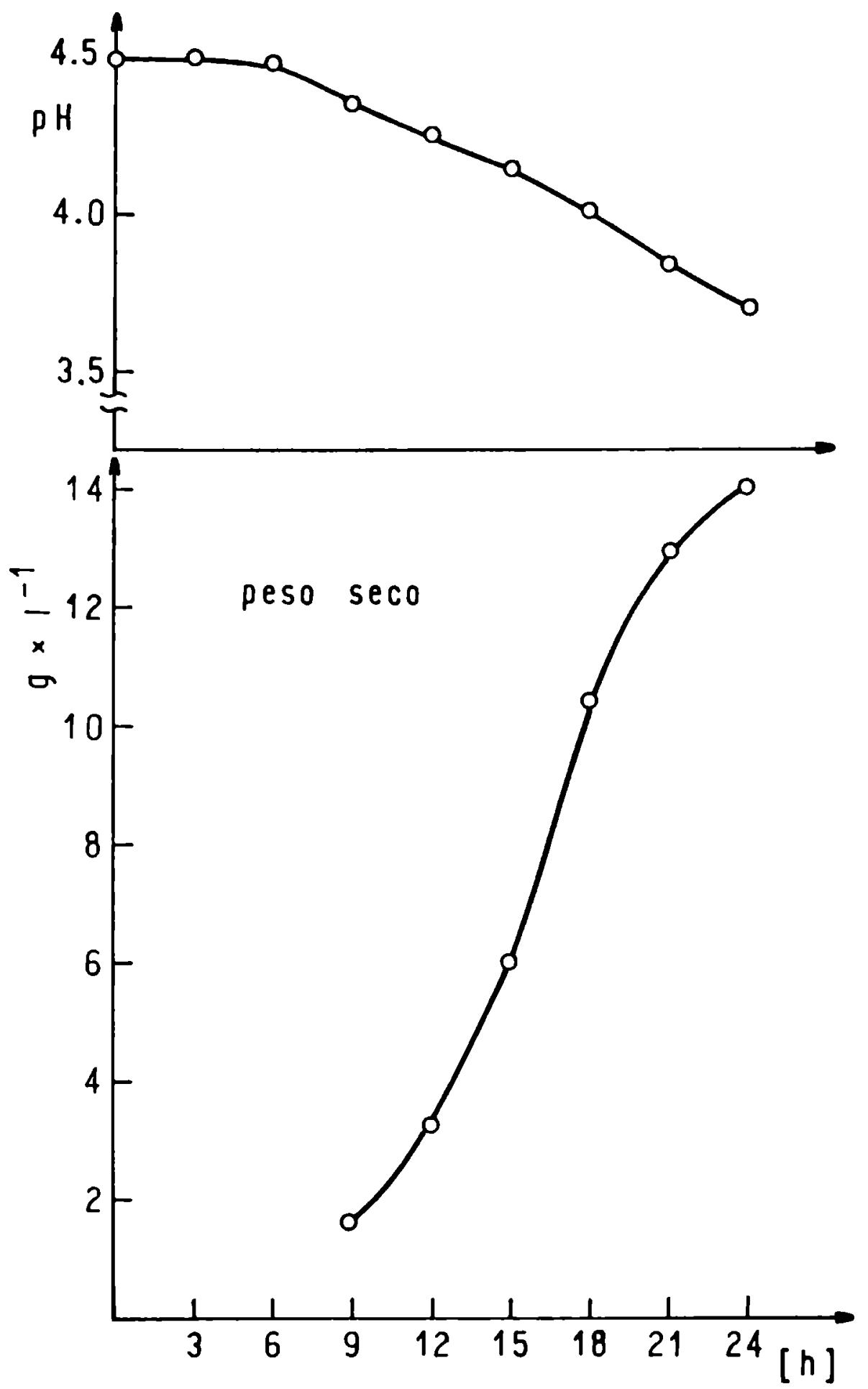

Figura 11 Crecimiento del hongo en la etapa de desarrollo del inóculo vegetativo

Frascos de $1000 \mathrm{ml}$ con $100 \mathrm{ml}$ de medio base (V.A.O: 21 mmoles $\left.0_{2} / 1 / h\right)$

Siembra: $10^{6}$ esporos/ml. 


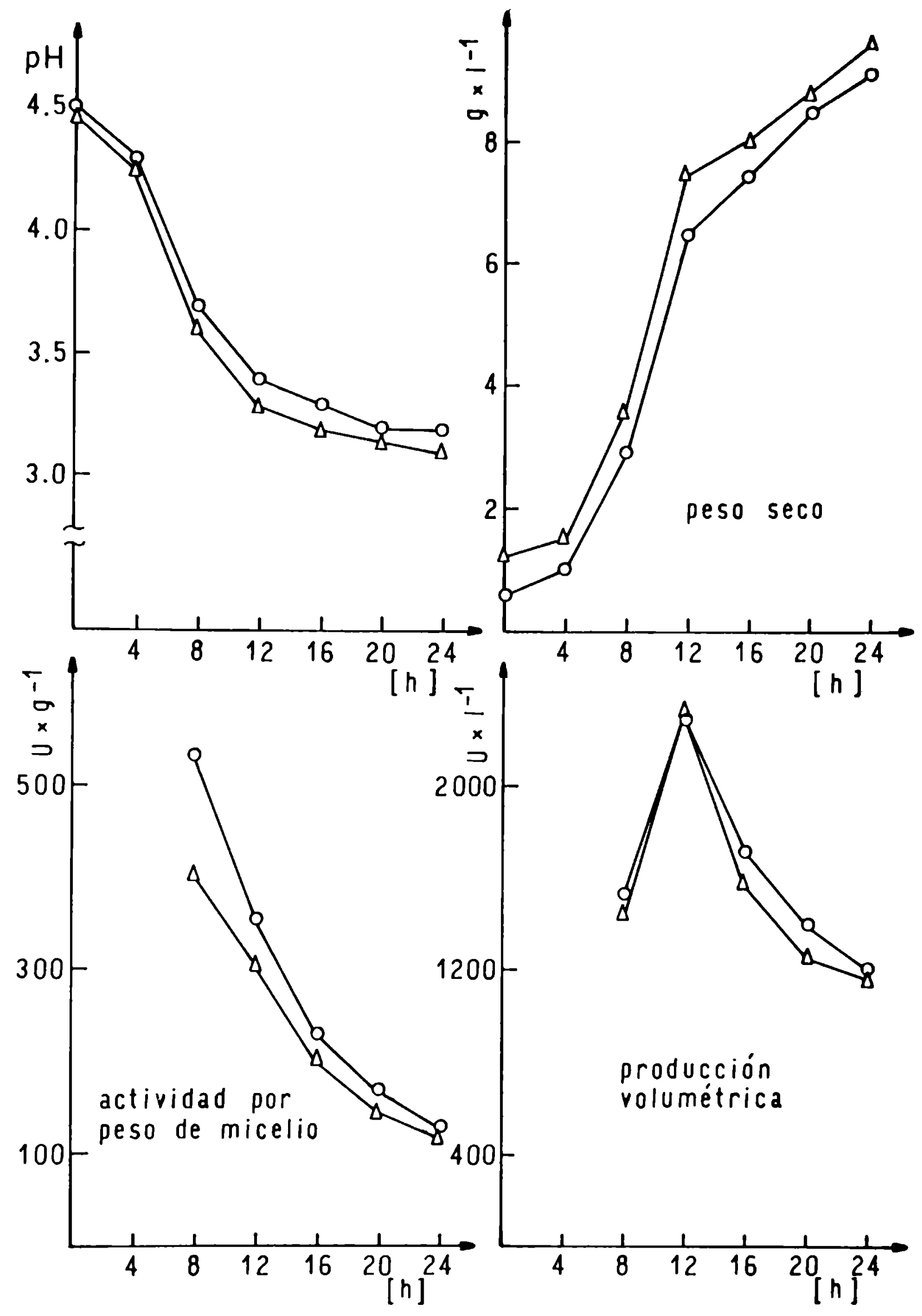

Figura 12 Producción de glucosa oxidasa en tanque agitado Efecto del inóculo

Inóculo de 15 hs o-o, Inóculo de 21 hs $\Delta-\Delta$ Agitación $550 \mathrm{rpm}$. 
el hongo mostraba un crecimiento intermedio entre el pellet y la forma filamentosa. Al trasladar este tipo de inóculo al tan aue los inconvenientes mencionados ro se presentaron $y$ la observación microscópica mostraba nuevamente un micelio laxo, ex tendido sin las aglomeraciones densas y compactas caracterist cas de los procesos "fallidos". Para mostrar los resultados de estas experiencias se representa en la figura 11 el crecimiento del hongo durante su cultivo en el medio base con un inó culo de $10^{6}$ esporos/ml. Luego de un periodo lag de aproximadamente 6 a 8 horas durante el cual los esporos incrementan su tá maño y comienzan a germinar, se produce el desarrollo vegetativo obteniéndose al cabo de 24 horas un peso seco de micelio de $14 \mathrm{~g} / 1$. La velocidad especifica de crecimiento estimada entre las 12 y $18 \mathrm{hs}$ es de $0.2 \mathrm{~h}^{-1}$ (tiempo de generación $3.5 \mathrm{hs}$ ) valor que es caracteristico de este tipo de microorganismo (96). En la figura 12 se muestra la evolución de dos fermentaciones en tanque realizadas con inóculo de 15 y 21 horas de desarrollo en el medio base que corresponde a concentraciones iniciales de micelio seco de 0.6 y $1.3 \mathrm{~g} / 1$ respectivamente. La actividad de glucosa oxidasa en la biomasa es superior durante toda la fermentación en el medio con inóculo de 15 hs., pero el crecimien to celular muestra una tendencia inversa, es mayor con inóculo de $21 \mathrm{hs}$. Al tener en cuenta el balance de ambos factores vemos que la producción total de enzima es semejante con ambos inóculos, obteniéndose un rendimiento de $2300 \mathrm{U} / 1$. Cabe destacar que a pesar de las diferentes condiciones de proceso en el tanque (V.A.0. e inóculo) la producción volumétrica es semejante a la obtenida en los frascos agitados aunque con un efecto favorable respecto a la productividad, ya que el tiempo de fermentación se reduce en este caso de 18 a $12 \mathrm{hs}$., es decir, un $33 \%$. Finalmente y de acuerdo a estos resultados se decidió emplear el inóculo de 15 hs. siendo importante resaltar que bajo estas con diciones los inconvenientes no volvieron a presentarse.

\subsubsection{Influencia del pH}

Durante las experiencias en frascos como las que motivaron el estudio del inóculo en tanque, el pH del medio de cultivo se dejaba evolucionar naturalmente observándose siempre una continua acidificación causada por la acumulación de ácidos orgánicos 
particularmente glucónico. Durante la discusión reallzada sobre la composición del medio de cultivo (item 3.3.7), se habia mencionado que la acidificación del medio tenia generalmente un efecto negativo en la formación de glucosa oxidasa. En forma similar los rendimientos de la fermentación glucónica son Ín crementados cuando la acidez es neutrallzada (24). Teniendo en cuenta estos conceptos se decidió realizar fermentaciones con $\mathrm{pH}$ controlado a fin de observar su efecto en la producción de enzima. El estudio comprendió un proceso testigo (sin control) $y$ otros tres con $\mathrm{pH}$ controlado en 4.5, 5.5. y 6.5 mediante la adición automática de $\mathrm{NaOH}$. Los resultados de estas fermentacio nes se representan en la figura 13. Observando la evolución de los distintos parámetros del cultivo surge como principal carac teristica que el control del pH aumenta considerablemente el consumo de la fuente de carbono, teniendo este efecto una direc ta relación con los niveles de glucosa oxidasa sintetizados por el hongo. Para visualizar mejor esta situación podemos considerar el tiempo de fermentación que transcurre hasta la hora 8 , periodo en el cual la concentración de enzima en el micelio se incrementa y alcanza su valor máximo. Durante dicho lapso en el medio sin control de $\mathrm{pH}$, el consumo de sacarosa representa un $13 \%$ de su concentración inicial $(52-54 \mathrm{~g} / 1)$, en cambio en los medios a pH $4.5,5.5$ y 6.5 el consumo ha sido del 42,53 y $62 \%$ respectivamente. Correlacionándose con este mayor consumo de la sacarosa, la actividad inducida de glucosa oxidasa se incrementó entre 1.9 y 2.2 veces obteniéndose para los distintos niveles de pH una actividad máxima comprendida entre 1100 y $1250 \mathrm{U} / \mathrm{g}$. Posteriormente y en forma similar a lo observado durante los procesos en frascos, la concentración de enzima comienza a declinar en forma progresiva con la edad del cultivo, manteniéndose sin embargo las diferencias relativas de actividad entre los medios con y sin control de pH.

Al considerar los rendimientos obtenidos en los diferentes medios debemos tener en cuenta el efecto del pH sobre el creci miento celular. Como lo muestran las curvas de peso seco, los pH más ácidos son más favorables para el crecimiento del hongo. Tomando como ejemplo los valores de la hora 12 podemos constatar un desarrollo equivalente a $6.1,4.9$ y $4.1 \mathrm{~g} / 1$ de micelio seco en los medios a pH $4.5,5.5$ y 6.5 respectivamente. De esta manera la máxima producción volumétrica y el tiempo en que la 

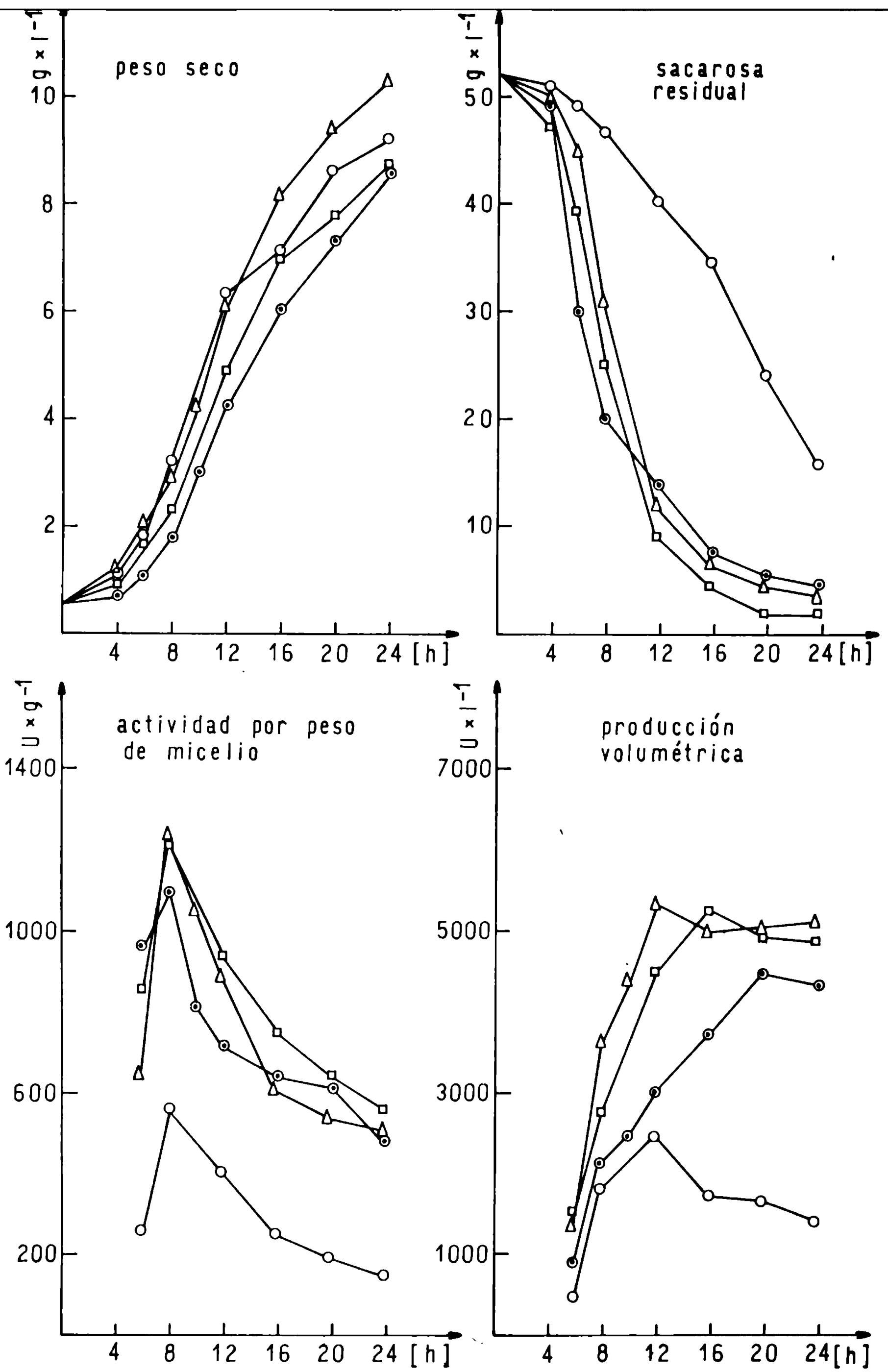

Figura 13 Producción de glucosa oxidasa en tanque agitado Efecto del pH

Medio sin control de $\mathrm{pH} \% \mathrm{O}$. Medios con pH controlado en $4,50 \triangle, 5,50 \square, 6,50 \odot$.

Agitación $550 \mathrm{rpm}$.

* La evolución del pH es semejante al representado en la figura 12. 
Caracteristicas de los cultivos en medios con y sin control de pHen el momento de mayor producción de

glucosa oxidasa

$\begin{array}{cccc}\text { Medio sin } & & & \\ \text { control de } & \text { Medios con } & \text { pH controlado a } \\ \text { pH* } & 4.5 & 5.5 & 6.5\end{array}$

Tiempo de fermentación

12

12

16

20

Peso seco $\left(g \times L^{-1}\right)$

6.3

6.17 .03

$7 \cdot 3$

Actividad por peso

de micelio $\left(U \times g^{-1}\right)$

397

876

750

615

Producción volumétrica

$$
\left(U \times L^{-1}\right)
$$

5343

5272

4489

Productividad

$$
\left(U \times L^{-1} \times h^{-1}\right)
$$

445

329

Sacarosa consumida (\%)

(inicial $52-54 \mathrm{~g} \times \mathrm{L}^{-1}$ )

$24 \cdot 5$

80

91

89

$*$ pH inicial 4.50. En el tiempo indicado el pH del cultivo es 3.3 
misma es alcanzada, es decir, la productividad del proceso se vé afectado por el nivel del pH. Los mayores rendimientos corresponden a los medios con pH 4.5 y 5.5 donde se obtienen $5343 \mathrm{U} / \mathrm{l}$ y $5272 \mathrm{U} / \mathrm{l}$, que son superiores en un $18 \%$ respecto al medio con pH $6.5(4490 \mathrm{U} / \mathrm{I})$ y representan un incremento del $100 \%$ en relación al cultivo sin control de pH. Además y tal co mo se observa en las curvas de producción volumétrica la acumu lación de enzima es más rápida en el medio a pH 4.5. En el Cua dro 10 se detallan para una mejor apreciación las caracteristi cas de los cultivos en el momento de obtenerse los mayores ren dimientos. Además de los aspectos mencionados se puede observar que la sacarosa en los medios con pH controlado ha sido consumida entre un $80 \%$ y $90 \%$. Por lo tanto bajo estas condiciones el momento en que la producción neta de enzima finaliza, coincide con el agotamiento de una gran parte de la fuente de carbono. En cambio en el medio sin control aún queda remanente un $74 \%$ de su concentración inicial. Este resultado es un claro indice del efecto negativo que tiene la disminución del pH sobre la formación de glucosa oxidasa. Es interesante señalar que el pH del cultivo en esteinstante es alrededor de 3.3, valor semejante al observado en el proceso en frasco cuando se alcanza la mayor producción de enzima. Finalmente y como conclusión de este estu dio surge la conveniencia de mantener durante la fermentación el pH controlado en 4.5 .

\subsubsection{Influencia de la aeración}

En forma similar a lo mencionado anteriormente con relación al $\mathrm{pH}$, se ha establecido que los rendimientos de la fermentación glucónica están directamente relaciones con el suministro de oxígeno al cultivo (24). Esto es lógico si pensamos que el ácido glucónico es el producto de una reacción de oxidación donde interviene el oxigeno molecular. Resultó por lo tanto necesario investigar la influencia de la aeración en los rendimientos de glucosa oxidasa.para el lo se hicieron experiencias utilizando una mayor agitación en el fermentador. Se ensayaron 700 y 850 rpm que equivalen a un V.A.0. de 136 y 200 mmoles de $0_{2} \times 1^{-1} \times h^{-1}$, es decir dos y tres veces el valor suministrado a $550 \mathrm{rpm}$ con el cual se venia operando. Los cambios en la agitación se establecieron a partir de las 8 horas de fermentación. 

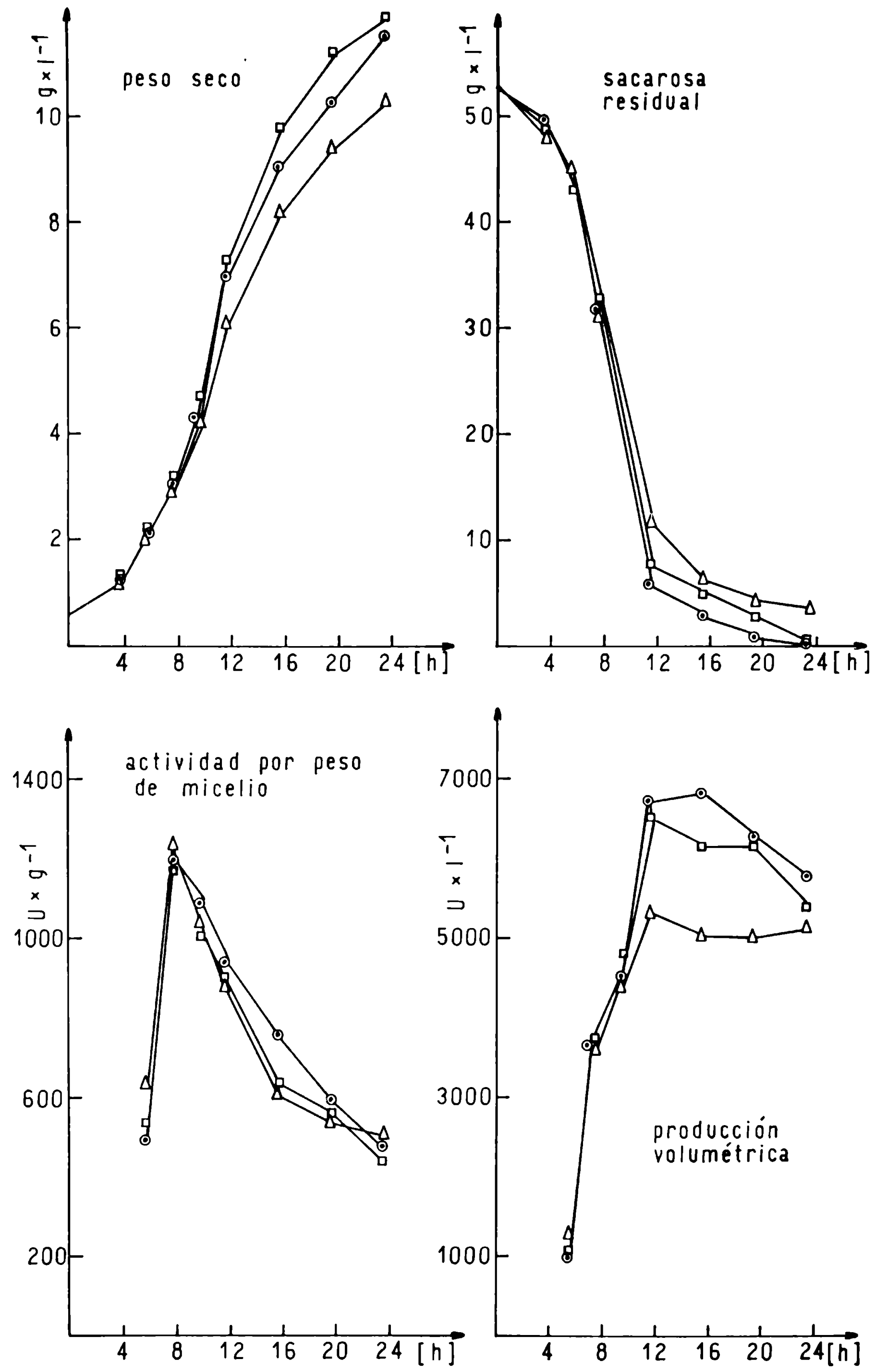

Figura 14 Producción de glucosa oxidasa en tanque agitado Efecto de la aeración.

Agitación constante a $550 \mathrm{rpm} \triangle$. Agitación inicial a $550 \mathrm{rpm}$ y desde la hora 8 se incrementó a $700 \mathrm{rpm} \square$ y $350 \mathrm{rpm} \odot \cdot \mathrm{pH} 4.50$. 
'momento en el cual las células del hongo presentan la mayor actividad enzimática.

Los resultados obtenidos con las distintas condiciones de aeración se representa en la figura 14. Se puede observar que el aumento de la agitación tanto a 700 como a 850 conduce a un mayor crecimiento del hongo pero no permite mantener en el micelio la alta actividad de glucosa oxidasa que es característi ca de la hora 8. En ambos casos la tendencia decreciente que se observa a partir de dicha hora es comparable con la observada en el cultivo a 550. Se puede apreciar además que este incremen to de la aeración no prolonga el tiempo durante el cual las células del hongo producen la enzima. En los medios a 700 y 850 el proceso de acumulación finaliza al igual que en el tanque a 550 , a la hora 12 de la fermentación. Por lo tanto lo que permite la mayor agitación es obtener durante la etapa de producción una ma yor cantidad de biomasa pero con la misma actividad enzimática. Esto conduce evidentemente a mayores rendimientos obteniéndose en los tanques a 700 y 850 una producción de $6550 \mathrm{U} / \mathrm{l}$ y $6750 \mathrm{U} / 1$ respectivamente, que significan un incremento del $23 \%$ y $27 \%$ con relación al tanque a $550(5300 \mathrm{U} / \mathrm{l})$. Esta influencia positiva so bre el crecimiento del hongo se manifiesta también en el mayor consumo de la fuente de carbono. A la hora 12 el consumo de sacarosa en los tanques a 700 y 850 es un $9 \%$ y $13 \%$ superior que en el de 550 lo cual implica el $85 \%$ y $88 \%$ de su concentración inicial $(52-54 \mathrm{~g} / \mathrm{l})$. Tal como se habia mencionado en el ensayo anterior con el pH, la producción de enzima finaliza en forma coincidente con el consumo de un alto porcentaje de la fuente de carbono, es decir, cuando la concentración residual de sacarosa ha disminuido considerablmente $(5-8 \mathrm{~g} / 1)$. En ese momento se aprecia además una marcada disminución de la velocidad de consumo del carbohidrato. Si consideramos que la máxima actividad en el micelio se observa en un momento en el cual la concen tración del azúcar es aún elevada $(30 \mathrm{~g} / \mathrm{l})$, estos hechos sugieren que la producción de glucosa oxidasa está regulada entre otros factores por la concentración de la fuente de carbono en el medio de cultivo.

En la figura 15 se representa la evolución del oxígeno disuelto (\% de saturación), consumo de oxigeno y consumo de alcali. El efecto de la agitación sobre la aeración del cultivo se refleja claramente en los mayores niveles de oxígeno disue 


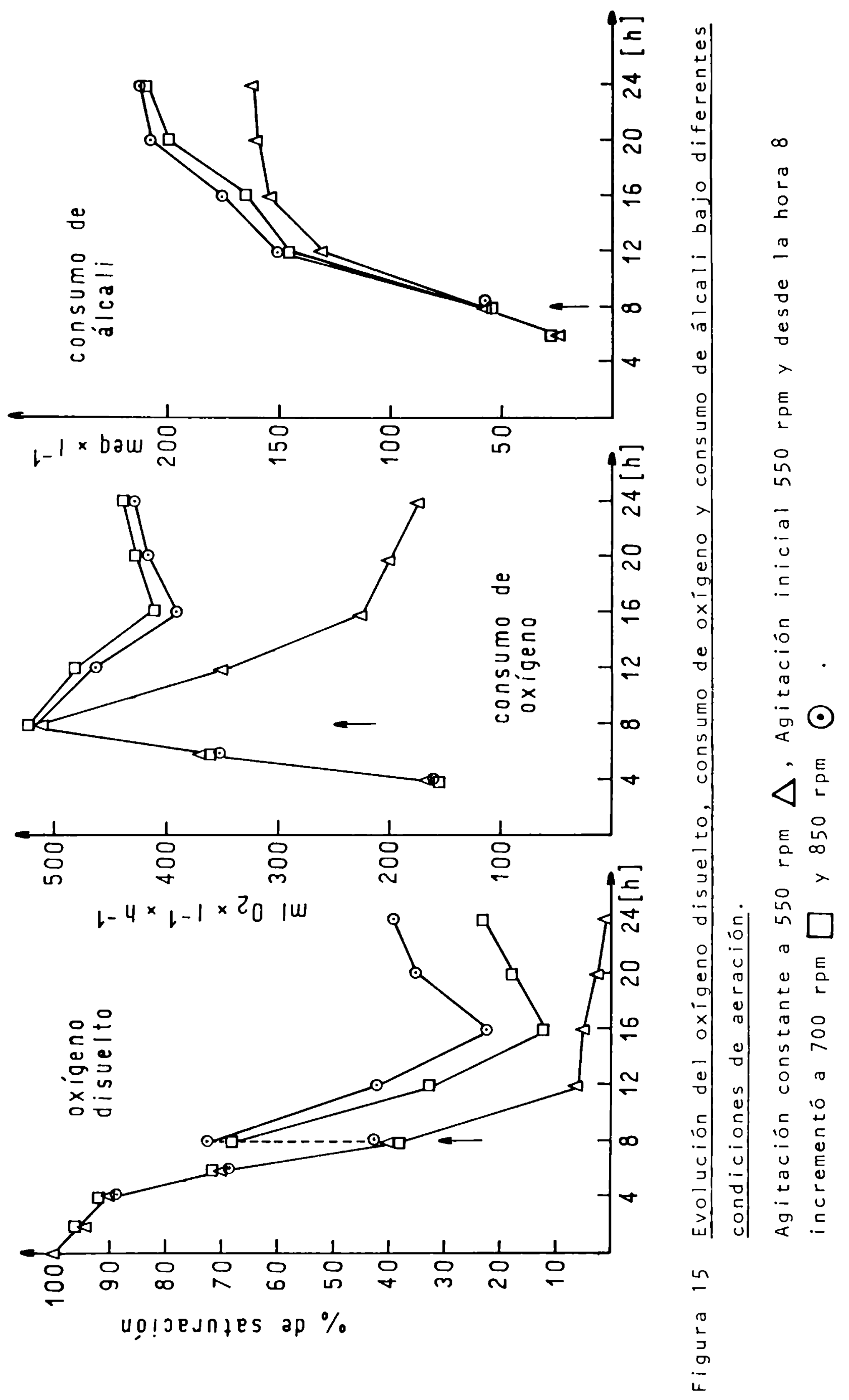


to que presentan a partir de la hora 8 los tanques a 700 y 850 . A dicha hora el nivel de saturación observado es del $40 \%$ (valor medio en los tres tanques) y a 550 se reduce hasta un $6 \%$ cuando se alcanza a la hora 12 la máxima producción. En cambio a 700 y 850 durante el mismo periodo los niveles de saturación se en-cuentran por encima del $30 \%$ y $40 \%$ respectivamente. De igual manera el consumo de oxigeno y de alcali es superior en estos medios lo cual comprueba el efecto beneficioso del mayor suministro de oxígeno en el metabolismo del hongo. Se destaca además que la mayor velocidad de consumo se registra en el momento de máxima actividad del micelio $\left(500-520 \mathrm{ml} 0_{2} / 1 / \mathrm{h}\right)$. La concentración celular del cultivo a esta hora del proceso es de $3 \mathrm{~g} / \mathrm{l}$. Posteriormente cuando se alcanza la mayor producción volumétrica (hora 12) el consumo en:los tanques a 700 y 850 es de $470-$ $480 \mathrm{ml} 0_{2} / 1 / \mathrm{h}$ mientras que el valor registrado en el tanque a 550 es $353 \mathrm{ml} 0_{2} / 1 / \mathrm{h}$ o sea un $25 \%$ inferior. La disminución del consumo de oxígeno que se observa en forma paralela a los niveles de oxigeno disuelto puede ser atribuido a una disminución en la transferencia de oxígeno del sistema (V.A.0.) debido a los cambios en la reología del medio que producen el crecimiento de este tipo de microorganismos (108).

Los valores de consumo de base muestran un comportamiento interesante del sistema. En el momento de mayor producción de enzima la cantidad total de $\mathrm{NaOH}$ adicionada para mantener el pH constante en 4.5 representa un gasto para los diferentes tanques de 132,140 y $150 \mathrm{meq} / 1$. Si tenemos en cuenta el consumo correspondiente de la fuente de carbono que fue de 43,46 y $48 \mathrm{~g} / 1$ de sacarosa y asumiendo que el único ácido formado es el glucónico ( 1 equivalente $=196 \mathrm{~g}$ ), surge entonces una relación en peso entre ácido producido y azúcar consumida de $0.60,0.59$ y 0.61 , lo cual equivale aproximadamente a la producción de un mol de glucónico por mol de sacarosa consumida. Esta relación podria ser interpretada si consideramos que el ácido es formado a expensas de la oxidación total de la glucosa obtenida luego de la hidrólisis de la sacarosa, mientras que la fructosa es en realidad la fuente de carbono a partir de la cual el hongo obtiene su energía y sintetiza su biomasa. En el cultivo a 550 la producción de ácido declina y cesa a partir de la hora 20. En cambio en los tanques a 700 y 850 y fundamentalmente a 
partir de la hora 16 el consumo de base se incrementa en proporción mucho mayor que lo esperado según el oonsumo de sacarosa. Esto podría deberse a que otros ácidos orgánicos son segregados al medio de cultivo como resultado de cambios en el metabolismo del hongo favorecidos de alguna manera por la aeración del cultivo. Es probable también que el ácido glucónico sea utilizado en esta etapa como fuente de carbono (24,53). Es de destacar que en estos medios comienza a percibirse a partir de dicha hora una ligera pigmentación amarillenta que se hace más pronunciada hacia el final del proceso. También se puede apreciar la aparición de numerosos órganos de fructificación en las hifas del micelio. Estos cambios que se mencionan se producen en un período posterior a la etapa de producción de la enzima.

\subsubsection{Influencia de la concentración de la fuente de carbono}

En la experiencia anterior habíamos mencionado que la producción de glucosa oxidasa podría estar regulada, entre otros factores, por la concentración de la fuente de carbono. Las observaciones realizadas sugieren que la producción de enzima se ve favorecida por una alta concentración de sacarosa. Para estudiar este posible efecto se hicieron fermentaciones utilizando una mayor concentración inicial de carbohidrato como ser $7 \%$ y $10 \%$. Considerando además los resultados obtenidos con las diferentes condiciones de agitación, los tanques se operaron a $550 \mathrm{rpm}$ hasta la hora 8 y luego a 700 rpm hasta el final del proceso. En la figura 16 podemos observar los resultados de estas fermentaciones donde se incluye con fines comparativos un proceso con $5 \%$ de sacarosa. Como se puede apreciar los medios con $7 \%$ y $10 \%$ presentan el clásico período inicial de 8 hs. en el cual la concentración de glucosa oxidasa en el micelio se incrementa y alcanza su máximo valor. En el medio con 7\% la actividad es semejante al de 5\% (1200 U/g) aunque luego durante la fase de declinación se mantiene ligeramente superior. En cambio con $10 \%$ la actividad inducida es un $15 \%$ mayor y a diferencia de los otros medios esta máxima actividad se mantiene hasta la hora 10. Observando el correspondiente consumo de la fuente de carbono llama la atención la marcada diferencia que presentan los medios con $5 \%$ y $7 \%$ en relación al de $10 \%$. En el primero 
de los casos y durante este periodo inicial de 8 horas el consumo de sacarosa es semejante y corresponde a 21-22 g/l de carbohidrato. Pero con $10 \%$ el consumo es el doble es decir $40 \mathrm{~g} / 1$. Estos resultados muestran que la concentración de sacarosa favorece por encima de un determinado nivel la velocidad de consumo del carbohidrato y este efecto estimula una mayor formación de enzima. Un efecto similar pudimos apreciar en el estudio con el pH. Es evidente además que durante un breve periodo de 2 horas la velocidad de sintesis de glucosa oxidasa es comparable con la velocidad de crecimiento de la biomasa de manera que su concentración se mantiene constante. Luego decae pero manteniendo niveles superiores a los presentes en los medios con $5 \%$ y $7 \%$. Por otra parte en los medios con mayor nivel de sacarosa la acumulación volumétrica se prolonga hasta la hora 16 donde se obtiene la mayor producción. Como vemos la sacarosa residual a esta hora es de 7 a $9 \mathrm{~g} / \mathrm{l}$, similar a la que presenta a la hora 12 el medio con 5\%. A diferencia de lo que ocurre con la actividad de glucosa oxidasa, la concentración de sacarosa tiene sobre el crecimiento del hongo un efecto contrapuesto. A medida que aumentamos el nivel de azúcar el crecimiento inicial es menor y las curvas de peso seco se desplazan en el tiempo. De esta manera el efecto que logramos con una mayor concentración de azúcar es la producción durante toda la fermentación de una biomasa más activa en glucosa oxidasa pero en menor concentración. Cuando hacemos el balance de ambos parámetros encontramos que la máxima producción en el medio con $7 \%$ es semejante al de $5 \%$ pero el mayor tiempo de proceso que necesita para alcanzarlo disminuye la productividad. Con $10 \%$ los rendimientos de la hora 12 alcanzan un valor similar al medio con $5 \%$ y en el momento de mayor producción es un $13 \%$ superior $(7333 \mathrm{U} / 1)$. En este medio la productividad es también menor. En el cuadro 11 se consignan los datos que caracterizan a cada medio en el momento de mayor producción enzimática. La eficiencia del proceso considerando los rendimientos obtenidos y el gasto de carbohidrato es muy superior en el medio con 5\%. Con $10 \%$ se consume el doble de azúcar $(94 \mathrm{~g} / \mathrm{l})$ y el incremento del rendimiento es solamente del 13\%. Se puede observar además que la relación molar entre el gasto de alcali y consumo de carbohidrato se incrementa con el nivel inicial de sacarosa. 

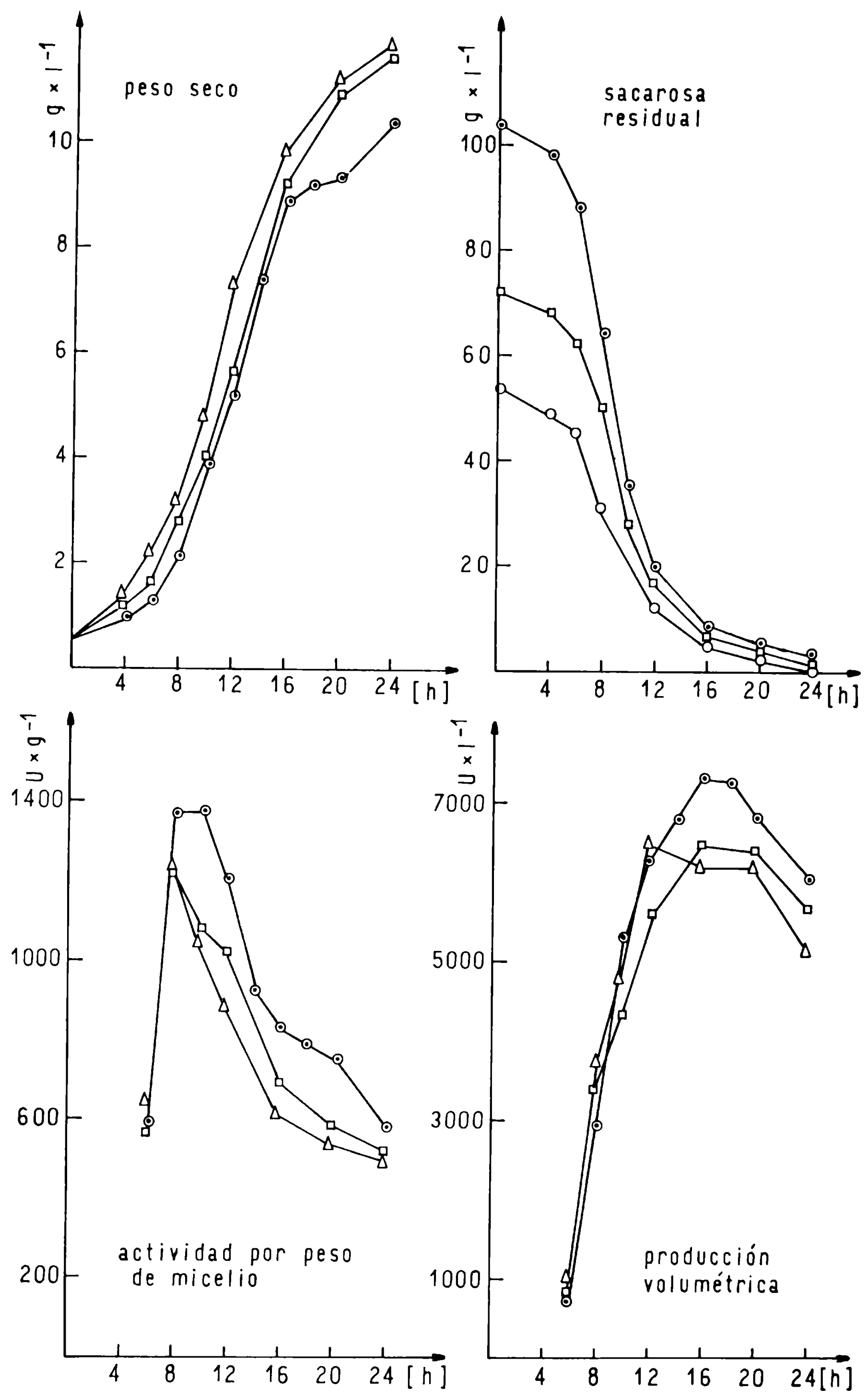

Figura 15. Producción de glucosa oxidasa en tanque agitado: Efecto de la concentración inicial de sacarosa. $5 \% \triangle, 7 \% \square, 10 \% \odot$. Agitación inicial. $550 \mathrm{rpm}$ y a partir de la hora 8, $700 \mathrm{rpm}$. pH 4.50. 
Caracteristicas de los cultivos con diferentes concentraciones iniciales de fuente carbono en el mo mento de mayor producción de glucosa oxidasa

\begin{tabular}{|c|c|c|c|}
\hline & \multicolumn{2}{|c|}{$\begin{aligned} \text { Concentración } d \\
$\[ \left(g \times L^{-1}\right. \]$\end{aligned}$} & sacarosa \\
\hline & 53 & 72 & 104 \\
\hline Tiempo de fermentación (hs) & 12 & 16 & 16 \\
\hline $\begin{array}{l}\text { Actividad por peso de } \\
\text { micelio (Uxg }\end{array}$ & 897 & 700 & 834 \\
\hline Peso seco $\left(g \times L^{-1}\right)$ & 7.3 & 9.2 & 8.9 \\
\hline Producción volumétrica $\left(U \times L^{-1}\right)$ & 6548 & 6440 & 7333 \\
\hline Productividad $\left(U \times L^{-1} \times h^{-1}\right)$ & 545 & 402 & 458 \\
\hline Sacarosa consumida $(\%)$ & 87 & 89 & 91 \\
\hline$\frac{\text { Producción volumétrica }}{\text { sacarosa consumida }}$ sug $^{-1}$ de & 142 & 100 & 80 \\
\hline$\frac{\text { Moles de alcali adicionado }}{\text { moles de sacarosa consumido }}$ & 0.98 & 1.07 & 1.15 \\
\hline
\end{tabular}


En la figura 16 se representa un proceso típico con $10 \%$ de sacarosa. Como vemos la producción de glucosa oxidasa acompaña al crecimiento de la biomasa pero la velocidad con que dicha biomasa sintetiza la enzima varía continuamente durante toda la fermentación. De este modo la concentración en el micelio no es constante y muestra siempre su perfil caracteristico de acumulación y posterior declinación. La máxima actividad que se obtiene entre la hora 8 y 10 es de $1370 \mathrm{U} / \mathrm{g}$. Desde el punto de vista de una posterior purificación la calidad de micelio más apropiada es la que corresponde a este momento del proceso. Pero la baja concentración celular $(3,9 \mathrm{~g} / 1$ a la hora 10) hace que los rendimientos sean todavia inferiores en un $37 \%$ en relación a la máxima producción de la hora 16.

A dicha hora tenemos $8.9 \mathrm{~g} / 1$ de micelio seco con una actividad de $834 \mathrm{U} / \mathrm{g}$, es decir la concentración enzimática se ha reducido ya en un $40 \%$. Como ha sido caracteristico de todos los procesos realizados, la mayor producción de enzima y la máxima actividad del micelio se encuentran desfasados en la fermentación. La velocidad especifica de crecimiento es máxima entre las 6 y 10 horas $\left(0.27 \mathrm{~h}^{-1}\right)$ y en forma paralela tenemos también la máxima velocidad volumétrica de consumo de sacarosa $(13.2$ $\mathrm{g} / \mathrm{l} / \mathrm{h})$ y de producción de ácido. En cambio la velocidad especifica de consumo de sacarosa es mayor entre las 6 y 8 horas $y$ coincide con el periodo de acumulación de la enzima en el micelio. La velocidad de consumo de oxígeno sigue una tendencia similar a la curva de actividad enzimática. El pico se alcanza a la hora $8\left(630 \mathrm{ml} 0_{2} / 1 / \mathrm{h}\right)$, momento en el cual la velocidad específica de crecimiento está dentro de su valor máximo. Estos valores reflejan el oxígeno consumido en el metabolismo energético del hongo y el empleado por la glucosa oxidasa para la producción de glucónico. El tiempo que transcurre entre la hora 8 y 10 es de alguna manera el estado de mayor actividad metabólica del hongo. A partir de dicha hora se puede percibir un decaimiento de la velocidad de la fermentación (crecimiento, consumo de sacarosa, etc.) que indica probablemente el comienzo de un cambio en el metabolismo del hongo. Por su parte el consumo de $\mathrm{NO}_{3}^{-}$(expresado en ppm de N) muestra que en el momento de mayor producción volumétrica su concentración ha disminuido en un $59 \%$ es decir el aprovechamiento de esta fuente no es total. Finalmente cabe men- 


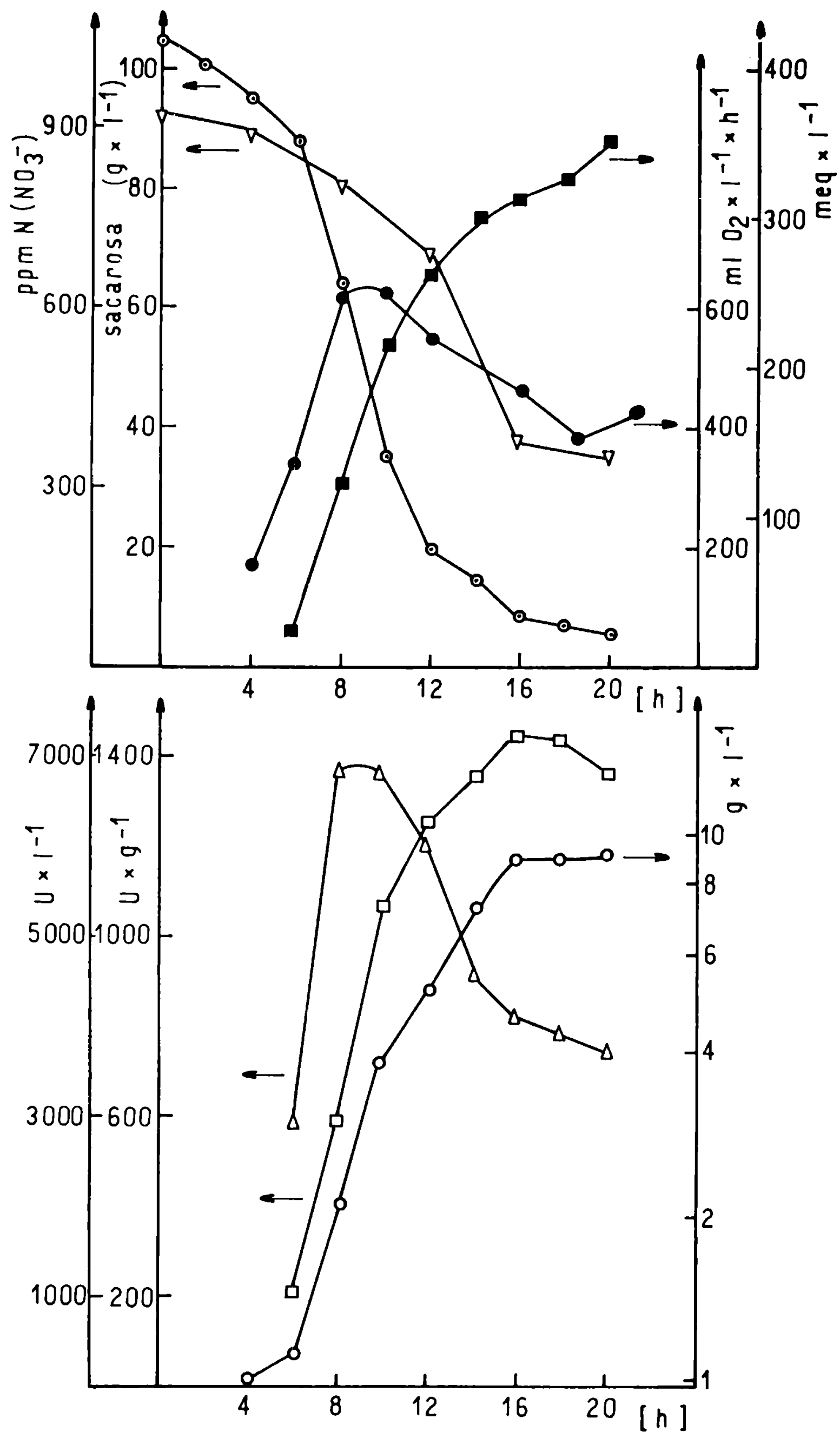

Figura 16 Producción de glucosa oxidasa en tanque agitado con $10 \%$ de sacarosa.

Actividad por peso de micelio $\triangle$. Crecimiento celular (escala logarítmica) $\bigcirc$. Producción volumétrica $\square$. Sacarosa residual $\odot$. Consumo de álcali $\square$. Consumo de $0_{2} \bigcirc$. Nitrógeno residual $\left(\mathrm{NO}_{3}^{-}\right) \nabla$. Agitación inicial $550 \mathrm{rpm}$ y desde la hora 8 se incrementó a $700 \mathrm{rpm}$. pH 4.50 . 
cionar que a partir de la hora 16 se comienza a observar en el medio una leve pigmentación amarillenta (similar a lo que ocurre en los otros medios) que se hace más intensa hacia el final del proceso. También se puede apreciar la aparición de órganos de fiructificación y en forma más tardía un incremento del consumo de oxigeno y de alcali. Este comportamiento del cultivo refleja que el estado fisiológico del hongo en esta etapa de la fermentación ha variado en forma muy pronunciada.

\subsubsection{Discusión de los resultados en tanque}

Las primeras fermentaciones realizadas en tanque mostraron que el crecimiento de los pellets era dificultoso y en algunos casos el desarrollo del hongo no se producia. A diferencia del proceso en frasco donde el pellet era muy homogéneo y presentaba un aspecto laxo, su morfología en tanque era muy diferente y el mismo adquiría luego de un cierto tiempo de cultivo una textura bien compacta. Este comportamiento del sistema no puede ser definitivamente intrepretado pero es sabido que son numerosos los factores que afectan la formación, el crecimiento y la morfología de los pellets (58). Entre estos factores se encuentra la agitación. De acuerdo a la bibliografía la obtención de pellets de naturaleza laxa o suelta se ve favorecida por condiciones moderadas de agitación, como puede ser en nuestro caso las del agitador rotatorio o bien con fermentadores aerados sin agitación mecánica $(24,58)$. Dependiendo del tipo de reactor y la cepa empleada, la agitación mecánica puede promover el desarrollo de pellets pequeños y compactos y en un caso extremo cuando es muy enérgica, destruir el pellet y favorecer el crecimiento filamentoso (58). Con nuestra cepa y las condiciones de trabajo impuestas en el tanque el efecto observado corresponde al primero de los casos mencionados. Podemos suponer que el retardo considerable que se aprecia en el crecimiento microbiano está de algu na manera relacionado con esta modificación de la estructura del pellet yaque en estas condiciones la transferencia de nutrientes al interior del mismo se ve seriamente limitada $(58,96)$. Por lo tanto el tipo de crecimiento filamentoso aparece como más adecuado para trabajar en el tanque agitado. Por otra parte se pudo establecer que el desarrol lo del inóculo vegetativo en forma de pellet está determinado por las condiciones de cultivo en el medio base. Entre ellas podemos mencionar la concentración de esporos. Cuando se aumentó la concentración de esporos de $10^{4}$ a $10^{6} / \mathrm{ml}$ se pudo obtener una forma intermedia entre el pellet y el crecimiento filamentoso. Este re- 
sultado es coincidente con lo descripto en la bibliografía ya que en general cuando mayor es la concentración de esporos en el inóculo más se favorece el desarrollo filamentoso (24).Es interesante destacar que la presencia de los sólidos del macerado de maíz favorece la coagulacion de los esporos alrededor de los mismos y tiende a promover la formacion del pellet. Esta observación está de acuerdo con el rol que cumplen los sólidos en la formación del pellet ya que al actuar como centros de nucleamiento estimulan la aglomeración de los esporos y el desarrollo de este tipo de crecimiento (58). Por lo tanto regulando la concentración de esporos en el inóculo se pudo conseguir el objetivo buscado que fue modificar aunque sea parcialmente esta forma de crecimiento. Si bien con este tipo de inóculo los inconvenientes no volvieron a presentarse, no podemos establecer definitivamente en base a la información parcial obtenida que la causa de los mismos sea motivada exclusivamente por la forma de crecimiento del hongo. Es interesante destacar que una vez seleccionado un tiempo de cultivo del inóculo,la producción enzimática alcanzada en tanque fue similar a la obtenida en frasco, es decir $2300 \mathrm{U} / \mathrm{l}$, pero con un aumento en la productividad ya que tiempo de proceso se reduce en este caso de 18 a 12 horas.

Los estudios con el pH demostraron en forma concluyente que la producción de glucosa oxidasa es afectada cuando la acidez del cultivo disminuye a un nivel crítico y además que el adecuado control de esta variable permite aumentar en forma muy significativa los rendimientos de la fermentación. Con el control del pH la formación de glucosa oxidasa en el hongo se incrementa considerablemente y este efecto se podría relacionar con el consumo de la fuente de carbono. En condiciones de pH oontrolado (4.5, 5.506 .5$)$ la velocidad de consumo de la sacarosa por el micelio aumenta en forma pronunciada, estimulando la formación de enzima. Este comportamiento es consistente con el concepto del metabolismo por sobreflujo de los carbohidratos mencionado en la introducción del trabajo. A su vez en estos medios la producción de enzima continúa hasta que la concentración del carbohidrato disminuye a un determinado valor que generalmente oscila entre 5 y $12 \mathrm{~g} / 1$. En el medio sin control de pH la velocidad de consumo de la fuente de carbono es menor y la concentración de enzima en la biomasa también. Sin embargo la continua acidificación del medio tiene en determinado momento un efeoto represivo sobre la sintesis de glucosa oxidasa ya que a la hora 12 la producción de enzima cesa (no se observa más acumulación 
volumétrica) quedando aún remanente un $74 \%$ de la fuente de carbono inicial, o sea en este caso la sintesis neta de glucosa oxidasa no continúa hasta el agotamiento de la casi totalidad de la sacarosa. Esta acción represiva es un claro ejemplo del complejo efecto que el pH tiene en el metabolismo de los hongos y se considera que el mismo está relacionado con cambios en la asimilación de los nutrientes del medio debido a modificaciones en la permeabilidad de la membrana y en la actividad de ciertas enzimas localizadas en la superficie del micelio (96). Estas alteraciones del metabolismo de los hongos, promovidas por las variaciones de $\mathrm{pH}$, ha sido frecuentemente observada en fermenta ciónes de otros ácidos orgánicos como cítrico u oxálico (24). Es interesante destacar los resultados de Malanowska quien pudo constatar (en un medio con sacarosa) que la producción de la enzima era casi nula en un cultivo donde el pH se mantuvo controlado en 3.0 (55). Este valor coincide con el nivel critico observado en nuestras fermentaciones que osciló entre 3.2 y 3.3. Este autor obtuvo además sus máximos rendimientos a pH 4.5 que coincide con nuestros resultados. Sin embargo en este trabajo no se dan datos de consumo de azúcares y por lo tanto no podemos establecer una mayor comparación de los procesos. Estos resultados explican además el comportamiento de las sales de amonio durante los ensayos realizados en frascos. Estas fuentes acidifican en forma pronunciada el medio de cultivo $\left(\mathrm{pH}_{2}-2.5\right)$ y por ello la formación de enzima se reprime. Cabe mencionar que la influencia del pH en el consumo de otros azúcares como la glucosa ha sido también establecida particularmente en estudios sobre la fermentación glucónica $(16,24)$. El efecto del pH sobre el consumo de sacarosa se podria relacionar con la actividad de la invertasa. En levaduras esta enzima disminuye marcadamente su actividad a valores de pH por debajo de 4.0 (33). Un comportamiento análogo de la enzima fúngica sería consistente con los resultados obtenidos. Finalmente cuando consideramos los rendimientos del proceso (producción volumétrica) se debe tener en cuenta además de la actividad del micelio el simultáneo crecimiento de la biomasa. El pH afecta también el crecimiento del hongo que 
es más favorable a pH más ácidos. En relación a los rendimientos y productividad la condición más favorable resultó a pH 4.5. El trabajar a este valor de pH tiene ventajas desde el punto de vista de la esterilidad del cultivo, ya que los riesgos de contaminación bacteriana se reducen.

Los estudios de aeración mostraron que la producción de enzima se vio favorecida fundamentalmente por un mayor cre cimiento de la biomasa ya que el incremento en la actividad del micelio fue poco significativo. Esto indica que en las condiciones ensayadas la síntesis de glucosa oxidasa no está limitada por el suministro de oxígeno al cultivo. Zetelaki observó un comportamiento similar operando en fermentadores con agitación mecánica a un V.A.0. de 100 y $130 \mathrm{~m}-$ moles de $0_{2} / 1 / h(108)$. En cambio cuando suministró oxígeno puro (V.A.0. 260) si bien la actividad absoluta de enzima no se incrementó. Ia misma se mantuvo en un nivel constante durante un período más prolongado de tiempo. En nuestro caso particular no se ensayó con oxígeno puro y si bien el fermentador permite operar con una mayor agitación (hasta 1500 rpm), el principal inconveniente que surge es el efecto mecánico de la paleta del agitador sobre la hifa del micelio. Trabajando a $850 \mathrm{rpm}$ se puede apreciar un daño en las células del hongo que se manifiesta en la ruptura de las hifas y la aparición de trozos esparcidos por el medio. Incluso al operar con esta agitación desde la hora inicial del proceso, el efecto se vuelve más notorio por la menor concentra ción celular. Es por ello que se decidió realizar el cambio de agitación a partir de la hora 8 para reducir el tiempo durante el cual se sometió al hongo a estas condiciones adversas. Por lo tanto debemos mencionar que si bien los tanques muestran una alta capacidad de transferencia de oxígeno, el efecto mencionado impide trabajar por encima de una cierta agitación y de esta manera los estudios con un mayor V.A.0. no se pueden realizar. Una alternativa sería operar con sobre presión como en la fermentación glucónica (24) pero los tanques no se encuentran diseñados para ello. De igual manera el incremento de $550 \mathrm{rpm}(\mathrm{V} . \mathrm{A} .0 .71 .3)$ a $700 \mathrm{rpm}$ (V.A.0. 136) aumentó la producción de enzima en un $26 \%$. Los mayores niveles de oxígeno disuelto (\% de saturación), consumo de oxigeno y consumo de alcali en los medios con mayor agitación de- 
muestran el efecto estimulante del oxigeno en el metabolismo general del hongo. En relación a los valores de alcali es interesante destacar la relación molar observada con el consumo de sacarosa. Habíamos mencionado como hipótesis que esta relación podría indicar que el ácido glucónico se forma a expensas de la glucosa y que en realidad la fructosa se utiliza. como fuente de carbono y energía para el desarro llo del microorganismo.

Las fermentaciones realizadas incrementando la concentración de sacarosa en el medio de cultivo muestran cierta concordancia con el comportamiento observado en el estudio del pH. Con un valor inicial de $10 \%$ se estimuló el consumo del carbohidrato y concomitantemente se produjo una mayor formación de glucosa oxidasa. Este efecto de la concentración del azúcar se puede relacionar con un aumento en el contenido de invertasa de las células del hongo como respuesta a la elevada concentración del carbohidrato (29). Por otra parte y a diferencia de lo observado habitualmente en todos los procesos, el estado de máxima actividad del mi celio se mantuvo durante un breve periodo de dos horas reflejando de esta manera que la velocidad de síntesis de la enzima es comparable al crecimiento global de la biomasa. En este medio y al igual que con niveles del $5 \%$ o $7 \%$ la acumulación de enzima en el cultivo finaliza cuando la concentración del azúcar en el medio se ha reducido considerablemente $(5-8 \mathrm{~g} / \mathrm{l})$. La concentración de sacarosa muestra en cambio un efecto opuesto sobre el crecimiento del hongo, particularmente en las primeras horas de la fermentación. De esta manera con $7 \%$ y $10 \%$ los valores de peso seco se desplazan en el tiempo y son siempre inferiores (a una misma ho ra del proceso) que las correspondientes al medio con 5\%. El resultado final que se obtiene en los medios con mayor concentración inicial de azúcar, es una biomasa más rica en en zima pero en menor concentración. De esta manera los rendimientos en el medio con $10 \%$ no alcanzan los valores esperados y sólo se supera la producción enzimática con respecto al de $5 \%$ en un $13 \%$. Mas aún el tiempo de fermentación para alcanzar la mayor producción es superior y con ello la productividad del proceso se reduce. Se deduce entonces que la posibilidad de mantener una alta actividad enzimática simul- 
táneamente a un crecimiento abundante del micelio no puede ser logrado con el simple incremento de la concentración inicial del carbohidrato (suponiendo que ambos parámetros pueden regularse con dicha variable) y debe buscarse la posibilidad de utilizar un diseño diferente del proceso fermentativo como por ejemplo una alimentación periódica del carbohidrato. Algunos resultados obtenidos en esta experien cia son también interesantes de destacar. A juzgar por el consumo de sacarosa en el medio con $10 \%$ y teniendo en cuenta la hipótesis de la producción de glucónico a partir de la glucosa y del empleo de la fructosa como fuente de carbono y energía, los rendimientos de micelio son muy inferiores a los que cabia esperar. Sin embargo los valores de consumo de alcali se alejan de la relación molar esperada y hace suponer que una fracción de la fructosa puede ser empleada en la formación del a lgún ácido orgánico (noglucónico) por ejemplo en citrico. Se ha establecido que la fructosa puede conducir incluso a mayor rendimiento de citrico que la propia glucosa (24). Es evidente que esta situación requiere un cierto "sobre flujo" de fructosa como los que puede promover una concentración equivalente a $50 \mathrm{~g} / 1$ del carbohidrato. (50\% de la sacarosa). El proceso tipico con $10 \%$ de sacarosa nos refleja los cambios del metabolismo que transcurren durante toda la fermentación. En relación a la producción de glucosa oxidasa la situación se puede resumir de la siguiente manera: la sintesis de glucosa oxidasa en relación al crecimiento del hongo es superior en la etapa inicial de 8 horas y por ello su concentración en el micelio aumenta. Durante un breve intervalo se mantiene igual y luego la velocidad de formación de la enzima disminuye. La producción neta de enzima finaliza a la hora 16 que representa el momento de máxima acumulación volumétrica. El rendimiento en dicho instante está determinado por el balance que se pueda lograr entre el crecimiento celular y la concentración de glucosa oxidasa en dichas células. El periodo de acumulación y máxima actividad coincide con el momento de mayor velocidad especifica de crecimiento y consumo de sacarosa. Este estado de máxima actividad metabólica se refleja también en el consumo de oxígeno y producción de glucónico. Estos cambios parecen estar regulados por el consumo de la fuente de carbono, que rápidamente se va ago- 
tando en el medio de cultivo. Debemos tener en cuenta un aspecto que no se ha considerado hasta el momento como es la homogeneidad del micelio. Es dificil suponer que toda la biomasa se comporta de manera semejante y que no existe envejecimiento y diferenciación celular. Como se sabe las zonas mas activas del micelio son las apicales donde hay un permanente proceso de lisis y biosintesis de la pared celular (82). Se ha establecido además que en el micelio se produce una continua diferenciación histológica con una creciente vacuolización de las partes más viejas de la hifa (96). Como la localización intracelular de la enzima no ha sido definitivamente establecida tampoco es posible inferir si algunas zonas del micelio son más ricas en enzima que otras. La única información bibliográfica se refiere a ciertos estudios citoquímicos que mostrarían que la distribución de la glucosa oxidasa en el micelio no es homogénea incluso durante el período de cultivo de máxima actividad enzimática (53). Por lo tanto los cambios que se describen reflejan indudablemente un estado fisiológico promedio de la biomasa del hongo. En este sentido si se desea establecer un modelo que interprete en su conjunto el comportamiento del sistema, será necesario considerar esta falta de homogeneidad que puede presentar el cultivo. 
La puesta a punto del método colorimétrico permitió establecer condiciones definidas para realizar la determinación enzimática y disponer de esta manera de un procedimiento rápido, sencillo y reproducible para evaluar la glucosa oxidasa. El método permite medir un rango de actividad comprendido entre $8 \times 10^{-3}$ y $0.056 \mathrm{U} / \mathrm{ml}$ de mezcla de reacción con un tiempo de ensayo de un minuto. Medidas comparativas con la técnica manométrica muestran diferencias del $2.6 \%$ y $5.4 \%$ para un preparado comercial de glucosa oxidasa y muestras de extractos celulares respectivamente.

La enzima es extraida del micelio en forma eficiente mediante tratamiento con abrasivos (arena) o con el empleo de la Prensa-X. La Prensa-X presenta la ventaja de ser un método limpio y permite estandarizar las condiciones de la opera ción. La máxima extracción se alcanza con 3 pasajes por el equipo (temperatura-2 $8^{\circ} \mathrm{C}$ ). El porcentaje de enzima remanente en solución luego de separar los restos celulares por centrifugación es del $90 \%$.

Los ensayos en frascos agitados donde se estudió la composición delmedio de cultivo en la producción de enzima, demuestran el carácter inducible de la misma y la marcada influencia sobrelos rendimientos de la fermentación. Con las fuentes de nitrógeno y carbono los mayores niveles de glucosa oxidasa en el micelio y la máxima producción volumétrica se alcanzan en presencia de nitrato de calcio y de sacarosa o glucosa respectivamente. La presencia de amonio inhibe la formación de enzima. La adición de bajas concentraciones de productos que aportan factores de crecimiento como $0.1 \%$ de extracto de carne o de levadura, estimulan la formación de enzima y el crecimiento del hongo. Con mayores concentraciones se aprecia un efecto represivo en la producción enzimática. La concentración de nitrato de calcio también afecta la producción de glucosa oxidasa. Los mayores rendimientos se obtienen en medios que contienen concentraciones de 0.8 a $1.25 \%$. Con la correcta selección de los componentes del medio es posible obtener a escala de frascos una producción 
de $2300 \mathrm{U} / 1$ en 18 horas de proceso. En las condiciones de cultivo empleadas el microorganismo desarrolla en forma de pellets que alcanzan en el momento de máxima producción un diámetro aproximado de $1 \mathrm{~mm}$.

Las experiencias conducidas en fermentadores con agitación mecánica muestran que con este sistema de cultivo, el crecimiento tipo filamentoso es más adecuado que el desarrollo en pellet. Los resultados del estudio con el pH indican que el control de la acidez del medio permite incrementar considerablemente la producción de enzima. En un medio sin control de pH, la formación de glucosa oxidasa se inhibe cuando el mismo alcanza un valor cercano a 3.0. En dicho instante ( 12 horas de fermentación) se alcanza un rendimien to de $2300 \mathrm{U} / \mathrm{I}$ con un consumo del $25 \%$ de la fuente de carbo no. Controlando el pH en 4.5 y en el mismo tiempo de proce so se alcanza una producción de $5343 \mathrm{U} / \mathrm{l}$ y un consumo del $80 \%$ de la sacarosa. A pH 5.5 el rendimiento es similar pero la productividad menor. Los ensayos sobre el pH se realizaron trabajando con una agitación constante de 550 rpm (V.A.0. 71.3 m moles de $\left.0_{2} / 1 / h\right)$. Incrementando a partir de la hora 8 la agitación a $700 \mathrm{rpm}$ (V.A.0. 136) se estimula el crecimiento del micelio pero no se induce una mayor formación de glucosa oxidasa. El aumento en la biomasa conduce a una mayor producción enzimática obteniéndose con el mismo tiempo de cultivo $(12 \mathrm{~h})$ un rendimiento de $6548 \mathrm{U} / \mathrm{l}$. Con una mayor ag $\mathbf{i}$ tación por ejemplo $850 \mathrm{rpm}$ los resultados son comparables a los de 700. Con esta condición se puede apreciar además un cierto efecto mecánico sobre el hongo que se manifiesta en la ruptura de las hifas del micelio. El aumento de la concentración de sacarosa de un $5 \%$ al $7 \%$ no introduce ninguna mejora en la producción enzimática. Con $10 \%$ se induce una mayor formación de glucosa oxidasa pero en forma contrapuesta el crecimiento del hongo es menor. De esta manera la máxima producción de enzima es de $7333 \mathrm{U} / \mathrm{l}$ que representa un incremento del $13 \%$ con relación al medio con $5 \%$. Como el tiem po de fermentación en que se alcanza diche producción es mayor $(16 \mathrm{~h})$, la productividad del proceso con esta concentra ción de carbohidrato es finalmente inferior a la obtenida en el medio con 5\%. La actividad enzimática del micelio varía continuamente durante el curso de la fermentación. Se observa 
una fase inicial de acumulación que en tanque es de 8 horas en la cual la concentración de glucosa oxidasa en la biomasa aumenta y alcanza su máximo valor. La actividad que en este instante es de 1200 a $1400 \mathrm{U} / \mathrm{g}$. Luego comienza a disminuir en forma progresiva y en general cuando se alcanza la máxima producción de enzima la actividad del micelio se ha reducido en un 20 a $30 \%$. Este comportamiento indica que la velocidad a la cual las células del hongo sintetizan la enzima en relación al crecimiento global de la biomasa varia en forma constante y de acuerdo a ciertos resultados la misma estaría regulada por la velocidad de consumo de la fuente de car bono. Los rendimientos enzimáticos que se pueden obtener en un determinado tiempo de la fermentación dependen del balance entre la actividad del micelio y la concentración del mis mo en el medio de cultivo. Los resultados obtenidos con diferentes concentraciones de la fuente de carbono sugieren la posibilidad de estudiar un sistema de cultivo en el cual el carbohidrato se suministre al medio en forma periódica. 
1. Abbott B.J. Inmobilized cells. En: Perlman D. (ed). Annual Reports on fermentation processes (vol 2), $0.91-124$ Academic Press. New York. San Francisco. London. 1978 .

2. Adams E.C, Mast R.L, Free A.H. Specificity of glucose oxidase. Arch. Biochem,91:230-234, 1960.

3. Alexander P.W, Seegopaul P. Automated potentiometric determination of glucose oxidase activity with a gas-sensing sulfur dioxide probe. Anal. Chim.acta, 121:61-70, 1980.

4. Applied Biochemistry and Bioengineering. Inmobilized enzyme principles (vol. 1). Wingard L.B, Goldstein L, Katchalski-Katzir E. (eds). Academic Press New York. San Francisco. London, 1976.

5. Applied Biochemistry and Bioengineering. Enzyme Technology (vol.2). Wingard L.B, Goldstein L, Katchalski-Katzir E. (eds). Academic Press. New York. San Francisco. London,1979.

6. Bailey J.E, Cho Y.K. Inmobilization of gluco-amylase and glucose oxidase in activated carbon: Effects of particle size and inmobilization conditions on enzyme activity and efectiveness. Biotechnol. Bioeng. 25: 1923-1935, 1983 .

7. Barker S.A, Shirley J.A. Glucose oxidase. En Rose A.H. (ed) Microbial Enzymes and Bioconversions, p.173-181. Academic Press. London. New York, 1980.

8. Bentley R. Glucose oxydase. En: Boyer P, Lardy H, Myrback K. (eds). The enzymes, vol.7, p.567-586. Academic Press. New York. London, 1963.

9. Bentley R. Glucose aerodehydrogenase (glucose oxidase) En: Colowick S.P, Kaplan 0.N. (eds). Methods in Enzymology (vol l). p.340-345. Academic Press. New York. London, 1955.

10. Boudrant J, Chaftel C. Application of the oxygen mass transfer theory. Determination of the Michaelis constant of glucose oxidase for oxygen. Biochimie. 57(2): 117-122, 1975 . 
1.1. Bouin J.C, Hultin H.0. Stabilization of glucose oxidase by inmobilization-modification as a function of pH. Bio technol. Bioeng. 24 (5): 1225-1231, 1982.

12. Carbohydrate metabolism. En Doelle H.W. (ed). Bacterial Metabolism. 2nd ed. Cap. 5. p.250-267. Academic Press. New York. London. San Francisco, 1975.

13. Chance B, Maehly A.C. Assay of catalases and peroxidases. En Colowick S.P, Kaplan 0.N. (eds). Methods in Enzimology. vol II p.764-775. Academic Press. New York, 1955.

14. Cooper C.M, Fernston G.S, Miller S.A. Performance of ag $i$ tated gas liquid contactors. Ind.Eng.Chem. 36: 504-509, 1944 .

15. Coulthard C.E, Michaelis R, Wallace F. Bactericidal sustances. Brit.patent 552.619. 1943.

16. Daguerre R, Ertola R. Obtención de gluconato de sodio por fermentación continua. Industria y Química. 25:376$379,1967$.

17. Drews B, Small H. Glucose oxidase and gluconic acid fermentation in Aspergillus Niger. Brauntweinwirtschaft $109(2): 21-27.1969$.

18. Duke F, Weibel M. Glucose oxidase mechanism. Enzyme activation by sustrate. J. Amer. Chem. Soc. 91(14): $3904-$ $3909,1969$.

19. Edebo L. A new press for the disruption of microorganism and other cells. J. Biochem. Microb. Technol. Eng. 2:453$479,1960$.

20. Edebo L. Desintegration of cells. En Perlman D. (ed). Fermentation Advances. p.249-272. Academic Press. New York. London, 1969.

21. Elzainy T.A, Hassan M.M, Allam A.M. New pathway for nonphosphorilated degradation of gluconate by Aspergillus Niger. J. Bact. 114 (1): 457-459, 1973.

22. Enzyme Nomenclature: Recommendations (1972) of the Inter national Union of Pure and Applied Chemistry and the International Union of Biochemistry. Amsterdam: Elseview, 1973 . 
23. Eriksson K.E. Swedish developments in biotechnology based on lignocellulosic materials. En Fiechter A. (ed). Advances in Biochemical Engineering. vol 20. p.193-204.

Springer-Verlag. Berlin. Heidelberg. New York, 1981.

24. Foster J.W. Chemical activities of Fungi. Academic Press. Inc. publishers. New York, 1949.

25. Fales F.W. Glucosa (enzimático). En: Aguilar S.A. (ed). Métodos seleccionados de Análisis Clínicos. Vol IV. P. 129-145. Madrid (España), 1966.

26. Franke W, Eichborn G, Mochel L, Bertram I. Physiology and enzymology of gluconic and fermentation by Aspergillus Niger. Archiv. Microb. 46:96-116, 1063.

27. Franke W, Mochel L, Rall C. Conditions for induced glucose oxidase formation by Aspergillus Niger. Archiv. Microb. 49: $64-80,1964$.

28. Franke W, Mochel L, Gummich E. The effect of quantitative variations of a basal medium on the induced formation of glucose oxidase by Aspergillus Niger. Archiv. Microb. $50: 382-400,1965$.

29. Franke $W$, Mochel L, Heyek L. The influence of a variation of $C$ and $N$ source on the induction of the enzyme glucose oxidase in Aspergillus Niger. Archiv.Microb. 51: 323-350, 1965.

30. Gibson Q.H, Swoboda B.E, Massey V. Kinetics and mechanism of action of glucose oxidase. J.Biol. Chem. 239:3927$3934,1964$.

31. Gough D.A, Andrade J.D. Enzymes electrodes. Science 180: $380-384,1973$.

32. Gutcho S.J.Microbial enzyme production. Noyes Data Corporation (ed). New Jersey, 1974.

33. Handbook of Enzyme Biotechnology. Wiseman A. (ed). Ellis Horwood Ltd.

34. Hanus J, Gottwaldova M, Rut M, Kercera J, Fradlecova M, Sedlacek M. Microbial production of glucose oxidase and catalase. Czech. patent $N^{\circ} 143.103,1971$. 
35. Hanus J, Kmimkova M, Gottwaldova M. Fermentation production of glucose oxidase and catalase. Czech patent $N^{0} 144.979$, 1972 .

36. Heckly R.J.Preservation of microorganisms. En Perlman D. (ed). Advances in Applied Microbiology. 24: 1-54. Academic Press. New York. San Francisco. London, 1978.

37. Herbert D, Philipps P.F, Strange R.E. Chemical analysis of microbial cells. En Norris J.R. and Ribbons D.W. (eds). Methods in Microbiology. Vol 5B. p.209-344. Academic Press. London. New York, 1971.

38. Hughes D.E, Wimpeny J.W.T, Lloyd D. The desintegration of microorganisms. En Norris J.R. and Ribbons D.W. (eds). Methods in Microbiology vol 5B p.1-54. Academic Press. London. New York, 1971.

39. Hayvarinen A, Nikkila E.A. Specific determination of blood glucose with o-toluidina. Clin. Chem. Acta. 7: 140-147,1962.

40. I chikawa Y, Imancika H. Gluconic acid fermentation I. Decomposition of gluconic acid by Aspergillus Niger. Nippon Nogei Kagaku Kaishi. 34:961-965, 1980.

41. Itzhaki R, Gill D.M. A microbiuret method for estimating proteins. Anal. Biochem. 9: 401-410, 1964.

42. Johnson J.C. Industrial Enzymes. Recent advances. Noyes Data Corporation (ed). Park Ridge New Jersey, U.S.A., 1977.

43. Keilin D, Hartree E.F. Properties of catalase. Catalysis of coupled oxidations of alcoholis. The Biochem.J. 4: 293$298,1945$.

44. Karube I, Hidrano K, Suzuki S. Glucose oxidase pellets. Biotechnol. Bioeng. 19: 1233-1238, 1977.

45. Keilin D, Hartree E.F. Properties of glucose oxidase (Notatin). The Biochem. J. 42: 221-229, 1948.

46. Keilin D. Hartree E.F. The use of glucose oxidase (Notatin) for the determinacion of glucose in biological material and for the study of glucose producing systems by manometric methods. The Biochem. J. 42: 230-238, 1948. 
47. Keston A.S. Specific colorimetric enzymatic analytical reagents for glucose. Abst. American Chem. Soc. 129 th meeting Dallas 31 C, 1956.

48. Kittrell J.R, Laurence R.L, Hultin H.0. Studies of a catalytic reactor using an inmobilized multi-enzyme system. Enzyme Tecnol. Grantees-Uses. Conf, PB 2650. 548: 34-41, 1975 .

49. Kusai K, Sekuzu 1, Hagihara B, Okumani K, Yamanchi S, Nakai M. Cristallization of glucose oxidase from Penicillum amagasakiense. Biochim. Biophys. Acta (Amst.) 40: 555-557, 1960 .

50. Laksminarayanan K. Fermentative production of glucose oxi dase. U.S. patent $N^{\circ} 3.704 .715$. Dawes Laboratories, 1972.

51. Lawny $F$. Solution for the oxygen mass transfer problem in inmobilized enzyme system. Aiche J. 21(4): 822-824, 1975.

52. Linex $V$, Benes $P$, Sinbule J, Holecek 0 , Maly V. Oxidation of D-glucose in the presence of glucose oxidase and catalase. Biotechnol. Bioeng. 22(12): 2515-2527, 1980.

53. Machek F,Fencl $Z$. Differentiation of filamentous microorganisms as a basis for understanding of product formation. Biotechnol. Bioeng. Symp. N4, p.129-142, 1973.

54. Majkic N, Spasic S, Berkes I. Kinetic assay of glucose oxidase using ABTS:diamonium salt of 2,2 '-azinobis (3ethyl benzthiazolines) sulfonic acid. Acta Pharm. Jugosl. 25(4): $301-306,1975$.

55. Malanowska J. Studies on the production of glucose oxidase preparation. Prace.Inst. Lab. Bad. Przem Spoz 26:275$320,1976$.

56. Maehly A.C, Chance B. The assay of catalases and peroxidases. En Glick D. (ed). Methods of Biochemical analysis. vol 1. p.357-424. Interscience publishers. New York, 1957.

57. Methods of Enzymatic Analysis. Bergmeyer H.U. (ed). Vol 3 p.1205-1222. 2nd Eng. edition. Academic Press. New York. San Francisco. London, 1974. 
58. Metz B, Kossen W.F. The growth of molds in the form of pellets. A Literature Review. Biotechnol. Bioeng. vol 19, $N^{\circ} 6$ p. $781-799,1977$.

59. Miyawaki 0, Wingard L. B. Electrochemical and enzymatic activity of flavine adenine dinucleotide and glucose oxidase inmobilized by adsortion on carbon. Biotechnol. Bioeng. $26: 1364-1371,1984$.

60. Muller H.M. Gluconic acid forming enzymes in Aspergillus Niger. Zbl. Bakt.Abt.। 1 132: 14-24, 1977 .

61. Munk V, Paskova J, Hanus J. Factors influencing glucose oxidase activity in submerged cultivation of Aspergillus Niger on synthetic medium. Folia Microb. 4: 203-215, 1963.

62. Munk V, Paskova J, Hanus J, Vorak Z. Mixed preparation of glucose oxidase and catalase Czech patent $N^{\circ} 112.866$, 1964 .

63. Nakamura S, Hayashi S, Hasuni H. Structure and stability of glucose oxidase: effect of periodate oxidation. En Singer T.P. (ed). Flavin Flavoproteins. Proc. Int.symp. 5th. p.691-702, 1975. Elsevier. Amsterdam (Netherlands). 1976 .

64. Nakamura S, Ogura Y. Kinetics studies on the reaction of glucose. oxidase. En Yagi K. (ed). Flavins Flavoproteins. Proc. Conf. 2nd. p.164-177, 1968 .

65. Nakamatsu T, Akamatsu T, Miyajima R, Shho I. Microbial production of glucose oxidase. Agric. Biol. Chem. 39 (9): $1803-1811,1975$.

66. Novak M. Fencl Z. Kinetic analysis of the relationship between batch and continuous cultivation of Aspergillus Niger. Biotechnol. Bioeng. Symp. $N^{\circ} 4$. p.43-52, 1973.

67. Ostaszewicz D, Rzedowski W. Production of glucose oxidase. Prace Inst. Lab. Badaw Przem Spozyw. 14 (4): 21-30, 1964.

68. Onions H.S. Preservation of Fungi. En Booth C. (ed). Methods in Microbiology. vol 4 p.113-151. Academic Press. London. New York, 1971. 
69. Ostaszewick D, Rzedowski W. Influence of composition of medium on producing glucose oxidase by Aspergillus Niger Prace Inst. Lab. Badaw Przem Spozyw. 20 (1): 19-30, 1970.

70. Pardue H, Simon R. Automatic amperometric assay of glucose oxidase. Anal. Biochem. 9: 204-210, 1964.

71. Paskova J, Munk V, Hanus J. I solation and purification of glucose oxidase. Veda Vyzhum Potvavinarskhem. Primysslu. 12: 415-428, 1963.

72. Pazur H.J, Klepp K. 0xidation of glucose and related compounds by glucose oxidase from Aspergillus Niger. Biochemistry 3: 578-583, 1964.

73. Pazur H.J, Kleppe K, Cepure A. A glycoprotein structure for glucose oxidase from Aspergillus Niger. Archiv.of Biochem. Biophys. 111: 351-357, 1965.

74. Pazur H.J. Glucose oxidase from Aspergillus Niger. En: Word A.W. (ed). Methods in Enzymology, vol 9, p.82-87. Academic Press. New York, London, 1966.

75. Porkroskaya N.V, Kislyakova 0.V. Glucose 0xidase preparation. U.S.S.R. patent $N^{\circ} 212.945,1968$.

76. Puget K, Michelson A.M. Microestimation of glucose and glucose oxidase. Biochimie 58 (6) 757-758, 1976.

77. Rand A.G, Hourigan J.A. Direct enzymic conversion of lactose in milk to acid. J. Diary Sci. 58 (8): $1144-$ $1150,1975$.

78. Reiss J. Cytochemical demonstration of glucose oxidase in Aspergillus Niger. Histochemie 7 (3): 202-210, 1966.

79. Rhodes A, Fletcher D.L. Principios de Microbiología Industrial, cap. 14, p.221-222. Editorial Acribia. Zaragoza (España), 1969.

80. Romano T.A. Automated glucose methods: evaluation of a glucose oxidase-peroxydase system. Clin. Chem. 19: 1152$1157,1973$.

81. Roth M. Fluorimetric assay of enzymes. En Glick D. (ed). Methods in Biochemical Analysis, vol 17. p.221-222. Interscience publishers, 1969. 
82. Rosenberg R.F. The Cell Wall. En Smith J.C. and Berry D.R. (eds). The filamentous fungi, vol 2 p.328-344 Edward Arnold (Publishers), 1976.

83. Scott D, Hammer F. Determination of catalase. Enzymology $22: 194-197,1961$.

84. Scott D. Applications of glucose oxidase. En Reed G. (ed) Enzymes in food processing p.517-547. Academic Press. New York. San Francisco. London 1975.

85. Scott D. Glucose oxidase. En Reed G. (ed). Enzymes in food processing, p.219-254. Academic Press. New York. San Francisco. London, 1975.

86. Schmidt R.D. Oxidoreductases. Present and potential applications in technology. Process Biochemistry.5: 2-8, 1979.

87. Sada E, Katoli S, Shiozawa M, Matsui l. Rates of glucose oxidation with a column reactor utilizing a magnetic field. Biotechnol. Bioeng. 25: 2285-2292, 1983 .

88. Seiter C.W, Hill D.H, Summer K.G. Automated fluorometric micromethod for blood glucose. Clin. Chem. 19: 1296-1299, 1973 .

89. Sizer J.W. Medical applications of microbial Enzymes. Adv. Appl. Microbiol. 15: 1-11, 1972 .

90. Sizer J.W. Enzymes and their applications. Adv. Appl.Microbiol. 6: 207-226, 1964 .

91. Sizer I.W, Beers R.F. A spectrophotometric method for measuring of breakdown of hidrogen peroxide by catalase. J. Biol. Chem. 195: 133-140, 1952 .

92. Smith F, Spriestersback M. Paper cromatography of organic acids. Nature 174: 466-467, 1954.

93. Skrimshire G.H, Antibacterial sustance from molds. Brit. Patent $N^{\circ} 561.175$. British Drug Houses Ltd. 1944.

94. Solomons G.L. Biotechnological applications of proteins and enzymes. Bohak Z. and Sharon N. (eds) P.51-62. Academic Press. New York. 1977. 
95. Swoboda B.E, Massey V. Purification and properties of the glucose oxidase from Aspergillus Niger. J.Biol. Chem. 240: 2209-2215, 1965.

96. The filamentous Fungi. Vol I. Industrial Mycology. Smith J.E. and Berry D.R. (eds). Edward Arnold (publishers), 1975.

97. Taylor M.J, Rchardson T. Applications of microbial enzymes in food systems and in Biotechnology. En Perlman D. (ed). Advances in Applied Microbiology. Vol 25 p.7-36. Academic Press. New York. London. Toronto. Sydney. San Francisco, 1979 .

98. Tholey G, Wurtz B. Relations entre activité glucose oxydasique et croissance en presence de diverses sources carbonées et azottées. C.R. Soc. Biol. 159: 2512-2517, 1965.

99. Trevan M.D. Inmobilized Enzymes. An introduction and applications in Biotechnology. John Wiley and Sons (ed). Chichester. New York, Brisbane, Toronto, 1980.

100. Tsao G. Oxygen transfer rate measured by gluconic acid production. Biotechnol. Bioeng. 11 (6): 1289-1290, 1969.

101. Tsuge H. Natsuaki 0, Ohashi K. Purification, properties and molecular features of glucose oxidase from Aspergillus Niger. J.Biochem. 78: 835-843, 1975.

102. Underkofler L.A. Properties and applications of the fungal enzyme glucose oxidase. Proc. Internat. Symp. of Enzyme Chemistry. Tokyo-kyoto. p.486-490, 1958.

103. Valentova V, Marek M, Svec F, Stamberg J, Vodrazka Z. Comparison of different methods of glucose oxidase inmobilization. Briotechnol. Bioeng. 23:2093-2104, 1981.

104. Wingard L.B, Katchalski-Katzir, Goldstein L. Analytical applications of inmobilized enzymes and cells. Academic Press, New York 1981.

105. Yao T. Amperometric determination of glucose in blood serum with a chemically modified enzyme membrane electrode in a continuous flow system. Anal. Chim. Acta 153: $175-180,1983$. 
106. Zetelaki K. A study of factors influencing the production of glucose oxidase in submerged culture. Elelmiszeripari Kutatointez Kozlem 3: 9-13, 1965.

107. Zetelaki K. A study into the comminution of mycelium with view to the extraction of glucose-oxidase.

Elelmiszertudomány $1: 49-52,1967$.

108. Zetelaki $K$, Vas $k$. The role of aeration and agitation in the production of glucose oxidase in submerged culture. Biotechnol. Bioeng. 10: 45-59, 1968.

109. Zetelaki K. Disruption of mycelia for enzymes. Proc. Biochemistry 4: 27-29, 1969.

110. Zetelaki K, Karoly V. Factors affecting measurement of glucose oxidase activity of commercial enzyme preparations. Acta Alim. Acad. Sci. Hung. 4(1): 37-61, 1975 .

\section{FE DE ERRATAS}

Pág. 4. Donde dice: "bacteriostáticas" debe decir "bactericidas" En el texto donde dice "Aspergillus Niger"' debe decir "Aspergillus niger"' En el texto donde dice "Penicillum" debe decir "Penicillium" 